ANIMAL CELL TECHNOLOGY:

FROM TARGET TO MARKET 


\title{
Animal Cell Technology: From Target to Market
}

\section{Proceedings of the 17th ESACT Meeting Tylösand, Sweden, June 10-14, 2001}

Edited by

\author{
E. Lindner-Olsson \\ N. Chatzissavidou \\ E. Lüllau
}

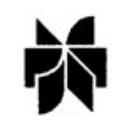

SPRINGER-SCIENCE+BUSINESS MEDIA, B.V. 
A C.I.P. Catalogue record for this book is available from the Library of Congress

ISBN 978-94-010-3897-3 ISBN 978-94-010-0369-8 (eBook)

DOI $10.1007 / 978-94-010-0369-8$

Printed on acid-free paper

All Rights Reserved

(C) 2001 Springer Science+Business Media Dordrecht

Originally published by Kluwer Academic Publishers in 2001

Softcover reprint of the hardcover 1st edition 2001

No part of the material protected by this copyright notice may be reproduced or utilized in any form or by any means, electronic or mechanical, including photocopying, recording or by any information storage and

retrieval system, without written permission from the copyright owner. 


\section{Table of Contents}

17th ESACT Meeting Committees xix

ESACT Executive Committee $\quad$ xx

Sponsors $\quad$ xxi

Companies Participating in the Trade Exhibition xxii

List of Participants xxiii

Introduction - From Target to Market Ixxiii

$\begin{array}{lll}\text { Acknowledgements } & \text { lxxv }\end{array}$

\section{CHAPTER I: IDENTIFICATION OF DRUGS AND DRUG TARGETS}

In Vitro Testing of a New Substance with Anti-Tumor Activity on Mammalian Cells Using Flow Cytometry

Burzlaff, A., Kasper, C., Christmann, M., Bhatt, U., Kalesse, M. and Scheper, T.

Destabilization of Green Fluorescent Protein by Substitution of Its AminoTerminal Residue

Lesmana, J. and Friedl, P.

Anti-Tumor Activity of Noguchi Catalyser 21 ${ }^{\mathrm{TM}}$, a Mineral Water Containing Natural Leaf Soil

Kawahara, T., Teruya, K., Katakura, Y., Takada, H. and Shirahata, S.

Fermented Milk, Kefram-Kefir Enhances Glucose Uptake into Insulin-

Responsive Muscle Cells

Teruya, K., Yamashita, M., Tominaga, R., Katakura, Y., Tokumaru, S.,

Barnes, D. and Shirahata, S.

Optimization of Medium for M2 (Anti-Flag) Hybridoma Using Factorial

Matrix Designs

Peppers, S., Allison, D., Talley, D., Loke, H., Johnson, T. and Caple, M.

Neurite Outgrowth Promoting Substance from a Marine Alga, Sargassum

Macrocarpum

Tsang, C.K., Sagara, A. and Kamei, Y.

Neutralization of the Biological Activity of Glycosylated and Non-Glycosylated hGM-CSF by Monoclonal Antibodies

Oggero, M., Frank, R., Kratje, R. and Etcheverrigaray, M. 
High Cell Density Cultivation of Mast Cells in Fluidized-Bed and Fixed-Bed Bioreactors

Noll, T.

\section{CHAPTER II: EXPRESSION SYSTEMS FOR TARGET AND} DRUG PRODUCTION

Over-Expression of Protein Kinase B $\alpha$ Enhances Recombinant Protein Expression in Transient Systems

Ettehadieh, E., Wong-Madden, S., Aldrich, T., Lane, K. and Morris, A.E.

100 Liter Transient Transfection

Girard, P., Derouazi, M., Baumgartner, G., Bourgeois, M., Jordan, M. and

Wurm, F.M.

Application of Alphavirus Vectors in Drug Discovery

Lundstrom, $\mathrm{K}$.

The Use of UCOE Vectors in Combination with a Preadapted Serum Free, Suspension Cell Line Allows for Rapid Production of Large Quantities of Protein

Benton, T., Chen, T., McEntee, M., Fox, B., King, D., Crombie, R., Thomas, T. and Bebbington, $\mathrm{C}$.

Overexpression of a Transcription Factor to Maximize Glycoprotein Production in an Inducible Expression System

Murthy, M.V.R., Lipscomb, M.L. and Kompala, D.S.

Glucose Dehydrogenase as Detector Protein of Recombinant Fusion-Proteins Directly in SDS Gels

Burger, C., Linxweiler, W., Pöschke, O., Wolf, A., Hofmann, U. and Rieke, E.

Successful Transfection of Partially Purified DNA in the HEK293EBNA Cell Line for Transient Expression

Wright, J.L., Jordan, M. and Wurm, F.M.

Capillary-Aided Cell Cloning: A Technique for One Step Cloning with High

Probability of Monoclonality

Onadipe, A.O., Metcalfe, H.K., Freeman, P.R. and James, C.

The Comparative Study of Culture and Productive Characteristics of Different Recombinant Cell Lines Producing Human Erythropoietin

Kolokoltsova, O., Schumakova, O., Belova, N., Nechaeva, E. and Kolokoltsova, T.

The Use of C-FOS-GFP Reporter System for Monitoring Apoptosis of Animal Cells Inducec by Exotoxins of Pseudomonas Aeruginosa

Bi, J.-X., Wirth, M., Beer, C., Sabra, W. and Zeng, A.-P.

High Performance Transient Expression in Mammalian Cells

Goffe, R.A., Goffe, A.S., Martin, T.J., Rosler, R.J., Mersberg, M.A., Haugen, J.A., 
Gurgel, J.L., Yeung, A.C., Brooks, L.B. and Berninger, R.W.

In 30 Days from Plasmid to Product: Expression of a Secreted Fusion Protein Using Hek293-EBNA Cells

Heine, H., Frozzard Solazzo, M.-J., Pena Rossi, C., Papoian, R., Bernard, A.R. and Blasey, H.D.

SF9 Cells Infection and Fuc-TIII Quality in Serum-Free and Serum-

Containing Media

Deparis, V., Cerutti, M., Goergen, J.L. and Marc, A.

Rapid Expression of Recombinant Proteins in Modified CHO Cells Using the Baculovirus System

Payne, L.A., Fornwald, J.A., Kane, J.F., McNulty, D.E., Trill, J.J. and Ramos, L.

Recombinant Glycoprotein Production by CHO Cells in Low Protein Serum Free Medium. Fed-Batch Conditions and Butyrate Additions Effects and Their Modelization

Hendrick, V., Marique, T., Winnepenninckx, P., Van de Velde, N., Cherlet, M. and Werenne, J.

Arginine Is a Limiting Essential Amino Acid in Batch Cultures of Recombinant Chinese Hamster Ovary Cells Producing Thrombopoietin Chung, J.Y., Kim, T.K., Sung, Y.H., Jun, S.C. and Lee, G.M.

Production of Recombinant Allergen Proder P1 by CHO Cells Adapted to Grow in Serum-Free Suspension

Coulon, L., Bel Haj Touzani, O., Magi, M., Bollen, A., Hanus, R. and Jacquet, A.

Pilot Scale Production and Purification of a Soluble E-Selectin IgG

Chimeric Protein

Werner, A., Lütkemeyer, D., Poggendorf, I., Haßelmann, H., Müthing, J.,

Vestweber, D. and Lehmann, J.

\section{CHAPTER III: CELL PHYSIOLOGY AND METABOLISM}

Environmental Effects on Cell Physiology and Metabolism: Response to Elevated $\mathrm{pCO}_{2}$

Schmelzer, A.E., Miller, W.M., Dezengotita, V.M. and Abston, L.R.

Improved Dual-Regulated Expression Systems for Independent Control of Two Different Transgenes

Fux, D. and Fussenegger, M.

Metabolic Flux Analysis in Mammalian Cells - Network Modelling as an Example for Metabolic Design in Recombinant BHK Cells

Paul, W., De Graaf, A., Marx, A., Wagner, R. and Noll, Th.

Assessment of Keratin Expression and Xenobiotic Metabolism in Cultured Normal and Transformed Human Oral Keratinocytes 
Vondracek, M., Hansson, A. and Grafström, R.

Regulation of Cell Cycle and Productivity in NS0 Cells by the

Over-Expression of $\mathbf{p 2 1}^{\mathrm{CIP1}}$

Watanabe, S., Shuttleworth, J. and Al-Rubeai, M.

Loss of Productivity of a Transfectoma in Long-Term Culture: Recovery of Expression

Boggiano, T.

Adaptation and Selection of NSO Myeloma Cell Lines Producing Recombinant Monoclonal Antibodies in Protein-Free Medium

Castillo, A.J., Víctores, S., Rojas, L., Faife, E., Rabasa, Y., Pence, B.L.,

Anderson, M., Barnett, B.B. and Weiss, S.

Specific Effects of Synthetic Oligopeptides in Animal Cell Culture

Franěk, F. and Katinger, $\mathrm{H}$.

Differential Enhancement of Monoclonal Antibody Production by Retinoids in Human Hybridomas

Inoue, Y. and Shirahata, S.

Regulation Mechanisms of Antibody Production from Human PBMC

Immunized in vitro

Yamashita, M., Katakura, Y., Ichikawa, A., Teruya, K. and Shirahata, S.

Influences of Glutamine Concentration on Cellular Metabolism in Continuous Culture of Hybridoma

Matsuoka, H., Andoh, S., Matsuda, Y., Kaneko, H. and Takeda, T.

Study of NS0 Cell Line Metabolism in Lipid Supplemented Protein

Free Media

Ojito, E., Labrada, G., Garcia, Z., Garcia, N. and Chico, E.

Metabolic Shifts in Hybridoma Cells Utilising Wheat Peptides

Simpson, N.H., Wegkamp, H.B.A., Bulthuis, B.A., Siemensma, A.D.

and Martens, D.E.

Bi-Phasic Culture Strategies Based on Medium Formulation: Substitution of Glucose by Galactose in CHO Culture

Altamirano, C., Cairó, J.J. and Gódia, F.

New Advanced Protein-Free, Animal Component-Free Medium for

Recombinant Protein Expression in Adherent CHO Cell Cultures

Kao, K., Ross, J., Albee, A., Fuhr, B. and Caple, M.

$\mathrm{Na}^{+}$Is Responsible for Intra-Run Variations of Specific Productivity of CHO

Cell Lines Producing Human Anti Rh D IgG in Bioreactors

De Jesus, M.J., Hunt, L., Bourgeois, M., Baldi, L., Jordan, M., Baumgartner, G.,

Tromba, P., Amstutz, H. and Wurm, F.M.

The Influence of pH on Cell Growth and Specific Productivity of Two CHO 


\section{Cell Lines Producing Human Anti Rh D IgG}

De Jesus, M.J., Bourgeois, M., Baumgartner, G., Tromba, P., Jordan, M.,

Amstutz, H. and Wurm, F.M.

The Modification of a Serum-Free Media Formulation for the Production of Reovirus and the Growth of Vero, MRC-5, MDCK and BHK Cell Lines Burgener, A., Patrick, M., Coombs, K., Moffatt, D., Huzel, N. and Butler, M.

The Role of Vitamins in Cell Culture Media

Büntemeyer, $\mathrm{H}$. and Lehmann, J.

Effect of Sodium Butyrate on Glycosylation of Recombinant Erythropoietin Chung, B., Jeong, Y., Choi, O. and Kim, J.

Identification of Betacellulin as a Major Growth Factor in Foetal Bovine Serum and Development of a Recombinant Betacellulin Analogue for Use in Serum-Free Cell Culture

Bastian, S., Dunbar, A., Simula, T. and Goddard, C.

Monitoring Growth and Death of Vero Cells Cultivated in Bioreactor with Serum-Containing and Serum-Free Media

Quesney, S., Marvel, J., Marc, A., Gerdil, C. and Meignier, B.

Effects of a Rice Protein Hydrolysate on Growth of CHO Cells and Production of Human Interferon- $\boldsymbol{y}$ in a Serum-Free Medium

Baré, G., Charlier, H., De Nijs, L., Verhoeye, F., Schneider, Y.-J., Agathos, S. and Thonart, $\mathrm{P}$.

Suppressive Effect of Electrolyzed-Reduced Water on the Growth of Cancer Cells and Microorganisms

Komatsu, T., Kabayama, S., Hayashida, A., Nogami, H., Teruya, K., Katakura, Y., Otsubo, K., Morisawa, S. and Shirahata, S.

Transient Bcl- $x_{L}$ Overexpression Has Different Effects on Protein Production in Various CHO-Derived Cell Lines

Meents, H., Enenkel, B., Bailey, J.E., Noe, W., Werner, R.G. and Fussenegger, M.

Proteolytic Potential during Batch Cultivation in Serum Free Media of an IFN- $\boldsymbol{\gamma}$ Producing CHO Cell Line

Mols, J., Burteau, C., Verhoeye, F., Peeters-Joris, C., Bastin, G., Agathos, S.N. and Schneider, Y.-J.

Genetic Strategies for Apoptosis Protection of Hybridoma Cells Based on Overexpression of Cellular and Viral Proteins

Vives, J., Juanola, S., Gabernet, C., Prats, E., Cairó, J.J., Cornudella, L. and Gódia, F.

Modulation of Cell Proliferation by Metabolic Engineering

Ifandi, V. and Al-Rubeai, M.

S-Phase Synchronized CHO Cells Show Elevated Transfection Efficiency and 
Expression Using $\mathrm{CA} / \mathrm{PO}_{4}$

Grosjean, F., Batard, P., Jordan, M. and Wurm, F.M.

Expression of Yeast Pyruvate Carboxylate in hGM-CSF-Producing CHO Cells

Bollati Fogolín, M., Schulz, Ch., Wagner, R., Etcheverrigaray, M. and Kratje, R.

The Influence of Culture Conditions on the Development of Trans-Epithelial Electrical Resistance (TEER) and the Junctional Complex of MDCK Cells. Trans-epithelial Electrical Resistance and Junctions of MDCK Cells Kessler, N. and Roche, G.

Bioreactor for Pharmaceutical Screening Generally Applicable for Primary Cells

Langsch, A., Schmidt-Richter, I. and Bader, A.

Increasing Population of Amniotic Epithelial Cells

Ogawa, A., Terada, S., Miki, M. and Sakuragawa, N.

Evaluation of the Biological Activity of Some Hormones, Growth Factors and Drugs on Cultured Cells, Isolated from Animal and Human Reproductive Organs

Sirotkin, A.V., Makarevich, A.V., Grossmann, R., Kotwica, J., Marnet, P.-G., Kwon, H.B., Franek, J., Sanislo, P., Florkovicová, I., Pivko, J., Schaeffer, H.-J., Mlyncek, M., Bulla, J. and Hetényi, L.

Cultivation of Human Articular Chondrocytes for Autologous Transplantation. Possible Solutions to Problems Arising from Insufficient or Delayed Supply of Autologous Serum

Malicev, E., Kregar-Velikonja, N., Krašna, M., Bonaca, O., Wozniak, G., Radosavljevic, D., Jeras, M. and Kneževic, M.

A Cell Culture System from the Eye Stalk of Penaeus Indicus

Kumar, G.S., Singh, I.S.B. and Philip, R.

Cytotoxicity of Pyrethroid Insecticides in Rat Hepatoma-Derived Fa32 Cells

Dierickx, P.J., Smit, C. and Scheers, E.M.

New Technologies for Automated Cell Counting Based on Optical Image Analysis "The Cellscreen"

Brinkmann, M., Lütkemeyer, D., Gudermann, F. and Lehmann, J.

Application of an Acceleration-Stat to Study Insect Cell Metabolism

Marteijn, R., Oude-Elferink, M., Bron, R., Martens, D. and Tramper, H.

\section{CHAPTER IV: PROCESS TECHNOLOGY}

Factorial Design and Analysis for Rapid Development of an Antibody

Production Process in CHO Cells

Delacruz, N., Crupi, G., Etcheverry, T. 
Development of a Large Scale Process for the Production of Recombinant Truncated Factor VIII in CHO Cells under Cell Growth Arrest Conditions Chotteau, V., Björling, T., Boork, S., Brink-Nilsson, H., Chatzissavidou, N., Fenge, C., Lindner-Olsson, E., Olofsson, M., Rosenquist, J., Sandberg, H., Smeds, A.-L. and Drapeau, D.

Continuous Perfusion versus Discontinuous Fed-Batch. Production of a 'Cytotoxic' Glycoprotein in Protein-Free CHO Suspension Cultures Müller, D., Simic, G., Steinfellner, W., Keijzer, T., Kunert, R., Benes, E., Gröschl, M., Trampler, F., Doblhoff-Dier, O. and Katinger, H.

The Use of Hydrocyclones for Mammalian Cell Retention in Perfusion Bioreactors

Jockwer, A., Medronho, R.A., Wagner, R., Anspach, F.B. and Deckwer, W.-D.

High Throughput Cultivation of Animal Cells Using Shaken Microplate Techniques

Strobel, R., Bowden, D., Bracey, M., Sullivan, G., Hatfield, C., Jenkins, N. and Vinci, V.

Continuous Isolation of rFVIII from Mammalian Cell Culture

Vogel, J.H., Pritschet, M., Wolfgang, J., Wu, P. and Konstantinov, K.

Sodium Butyrate Treatment: A Study of Critical Parameters Using CHO Cell Lines Expressing the Green Fluorescent Protein

Hunt, L., Jordan, M. and Wurm, F.M.

Development of a Robust Protocol for the Production of Recombinant

Proteins up to 20-L Scale Using BEVS

Danielsson, A., Kanttinen, A., Fenge, C. and Lüllau, E.

Optimising the Production of a Nuclear Receptor in SF9 Cells Using Response Surface Analysis

Sävenhed, J., Alarcon, M. and Calles, K.

Growth of High-Five ${ }^{\text {TM }}$ Cells on Cultispher-S Microbarriers

Drugmand, J.-C., Ikonomou, L., Schneider, Y.-J. and Agathos, S.N.

Catching the Wave: The BEVS and the Biowave. Optimisation of Protein Expression in the Baculovirus System and Establishment of the Wave Bioreactor for Sf-9 Insect Cell Culture

Weber, W., Weber, E., Geisse, S. and Memmert, K.

Physiology of Insect Cells Cultured in a New Serum-Free Medium

Ikonomou, L., Drugmand, J.-C., Bastin, G., Schneider, Y.-J. and Agathos, S.N.

Characterisation and Evaluation of a New Screening System for Animal Cell Culture

Selander, M., Hassel, J., Dartsch, C., Fenge, C. and Lüllau, E.

Development of Bioprocess Concepts on Vaccine Production: Influenza Virus 
as an Example

Genzel, Y., Voges, L. and Reichl, U.

Assay of Serum and Animal Protein Free Media for the Production of a Veterinary Rabies Vaccine by BHK-21 Cells

Jouini, A., Majoul, S., Rourour, S. and Kallel, H.

Cell Cultivation System on the Basis of Porous Ceramic for the Production of Virus-Like Particles

Lemke, K., Frense, M., Wedig, H. and Metze, J.

Influence of Cell Culture Media on Adhesion of Animal Cells on

Microcarriers

Landauer, K., Blüml, G., Dürrschmid, M., Wiederkum, S., Klug, H., Simic, G., Doblhoff-Dier, O. and Katinger, $\mathrm{H}$.

Comparison of Three Different Serum Free Media: Scale up of a Semi-Continuous CHO Cell Process in an Industrial Application Chatzissavidou, N., Björling, T., Hauptig, P., Pettersson, H., Chotteau, V. and Ljung, C.

Use of Plant Peptone-Containing Serum-Free Media for the Cultivation of CHO Cells in Suspension and on Microcarriers

Verhoeye, F., Burteau, C., Mols, J., Ballez, J.-S., Bare, G., Thonart, P., Bastin, G., Agathos, S.N. and Schneider, Y.-J.

Application of Protein-Free Cell Culture Media for the Manufacturing of Biopharmaceuticals

Hesse, F., Wagner, R., Katinger, H., Lübben, H., Vorlop, J. and Chatzisavido, N.

Fluid Bed Granulation as an Alternative to Milled Powders to Improve Performance of Dry-Form, Serum-Free Nutrient Media

Jayme, D., Fike, R., Hassett, R., Dadey, B., Radominski, R. and Cady, D.

NanoColloids: A New Method for Solubilization of Lipophilic Substances

Used in Cell Culture

Pfitzner, I., Engelhart, K., Dressler, D., Mayer, D. and Knebel, G.

Development and Validation of a Novel Process for the Production of Powdered Cell Culture Media

Ray, K. and Caple, M.

Separation of Mammalian Cells Using a Specially Designed Rotating Disc Filter. Applications to Simultaneous Perfusion Cultivation and Product Purification

Castilho, L.R., Anspach, F.B. and Deckwer, W.-D.

Comparison of Fluidised Bed and Ultrasonic Cell-Retention Systems for High Cell Density Mammalian Cell Culture

Dürrschmid, M., Landauer, K., Simic, G., Klug, H., Müller, D., Keijzer, T.,

Trampler, F., Oudshoorn, A., Gröschl, M. and Doblhof-Dier, O. 
Ultrasonic Cell Separation - Production of Monoclonal Antibodies in Continuous Perfusion Cultures

Heine, H., Arod, C.Y., Bernard, A.R. and Blasey, H.D.

Increased Production Yields of Native Interferon- $\boldsymbol{\gamma}$ in Membrane

Bioreactors by Continuous Harvest

Yalcin, E., Kloth, C., Buchholz, R., Emmrich, F., Harnisch, J., Lemke, U.,

Gerlach, J. and Marx, U.

Production of rhEPO in Hollow Fibers' Bioreactor

Garbuio, A., Rodrigues, M.T.A., Oliveira, J.M., Raw, I. and Moro, A.M.

Production of rhEPO under Variants of Cultivation Media

Targino, R.C., Rodrigues, M.T.A., Garbuio, A., Bertolino, D.C. and Moro, A.M.

Solution to the High Dissolved $\mathrm{CO}_{2}$ Problem in High-Density

Perfusion Culture of Mammalian Cells

Matanguihan, R., Sanaj, E., Zachariou, M., Olson, C., Michaels, J., Thrift, J. and Konstantinov, $\mathrm{K}$.

Perfusion Cell Culture in Disposable Bioreactors

Ohashi, R., Singh, V. and Hamel, J.-F.P.

Process Development in a Packed Bed Bioreactor

Ducommun, P., Ruffieux, P.-A. and Kadouri, A.

The Art \& Science of Micro-Sparging in High-Density Perfusion Cultures of Animal Cells

Qi, H., Jovanoic, G., Michaels, J. and Konstantinov, K.

Culture of the CB.Hep-1 Hybridoma Using Different in vitro

Systems

Gómez, H., González, M., González, Y., García, J., Ibarra, N. and Valdés, R.

Selection of Suitable Anti-rHBsAg Mabs for in vitro Production

González, Y., Gómez, H., González, M., Ibarra, N., Montero, J.A., Alvarez, T., Cruz, L.J., Acevedo, B., Fernández de Cossio, M.E. and Valdés, R.

Reorganizing of Monoclonals Antibodies Process in the Era of Human Genome Cloning

Maio, A., De Bernardi, N., De Mattei, C. and Nolli, M.L.

Production of a Highly Pure Mab from Cell-Pharm System CP-2500

Valdés, R., González, Y., Ibarra, N., González, M., Gómez, H., Dorta, L.,

García, J., Reyes, B. and Gómez, L.

How Does Protein Free Medium Turbodoma ${ }^{\text {TM }}$ HP-I Perform in Mouse Hybridoma Cultures in Different Culture Systems?

Valdés, R., Ibarra, N. and Fischer, R.

Effects of Seed Cell Density on Specific Growth Rate Using CHO Cells as Model 
Rodriguez, E.N., Perez, M., Casanova, P. and Martinez, L.

Adaptation and Growth Kinetics of the Universal Host CHO Cell Lines in Serum-Free Medium

Verhoeye, F., Burteau, C., Chenu, S., Goergen, J.-L., Marc, A., Bastin, G., Agathos, S.N. and Schneider, Y.-J.

Process Development for Functional Membrane Receptor Production in Mammalian Cells

Fenge, C., Jansson, I., Fröberg, T., Danielsson, A., Jönsson, M., Sygowski, L., Moore, C., Snyder, D., Lüllau, E. and Wood, M.

Development of an Automated, Adaptive Model-Based Control for the Effective Cultivation of Hybridoma Cells

Frahm, B., Atzert, H., Lane, P., Hoffmann, M., Hass, V.C., Munack, A. and Pörtner, R.

The One Step Inoculation Concept: A New Seed-Train Expansion for Recombinant Mammalian Cell Lines

Heidemann, R., Mered, M., Wang, D.Q., Gardner, B., Zhang, C., Michaels, J., Henzler, H.-J. and Konstantinov, K.

In-Situ Microscopy for On-Line and In-Line Monitoring of Cell Populations in Bioreactors

Frerichs, J.-G., Joeris, K., Scheper, T. and Konstantinov, K.

Measurement of the Viable Cell Density: Validation and Integration of On-Line and Off-Line Capacitance Biomass Monitors for Cell Culture Processes

Olomolaiye, D., Guan, Y.H., Carvell, J.P. and Kemp, R.B.

Robot Automation of Sampling and Sample Management during Cultivation of Mammalian Cells in Pilot Scale

Lütkemeyer, D., Poggendorf, I., Scherer, T., Zhang, J., Knoll, A. and

Lehmann, J.

Rapid Estimation of Human Monoclonal Antibody (IgG4) Concentration in Cell Culture Supernatants

Osborne, M., Bracewell, D., Dempsey, J., Field, R., Fish, B. and Ritchie, C.

Use of Ion-Exchange Membrane Adsorbers for Production of Biopharmaceuticals

Pora, H. and Hall, C.

\section{CHAPTER V: CHANGES IN THE REGULATORY ENVIRONMENT}

Pharmaceuticals Produced by Biotechnology: Quality and Safety Issues

Dayan-Kenigsberg, J.

Factory IQ/OQ, A New Approach for Streamlining Validation of Cell 
Culture Equipment

Fraune, E. and Kappel, W.

Critical Issues for the Use of Tangential Flow Filtration Systems for Cell Harvesting Applications

Hall, C. and Gyepi-Garbrah, I.

A General Method for the On-Line RT-PCR Detection of Retrovirus Contamination in Cell Lines Used for Protein and Viral Vector Production Müller, K. and Wirth, M.

Novel Assay for Protein Impurities in Biopharmaceuticals Based on Fluorescence Intensity Distribution Analysis (FIDA)

Richter, A., Wolter, T., Matika, A., Christoph, S. and Meyer-Almes, F.-J.

Development of Mammalian Cell Bioreactor Processes.

Increasing Productivity and Process Robustness

Wayne, J.R.T.

\section{CHAPTER VI: NEW TECHNOLOGIES FOR ADMINISTRATION OF CELL DERIVED PROTEINS}

Development of Microgranulated Form of the Live Measles Vaccine Nechaeva, E.A., Varaksin, N.A., Ryabicheva, T.G., Getmanova, T.N., Zaitsev, R.N., Smolina, M.P., Kolokoltsova, T.D., Zhilina, N.V., Sen'kina, T.Yu., Vilesov, A.D. and Aksenova, N.A.

CHAPTER VII: NOVEL PROPHYLACTIC AND THERAPEUTIC APPROACHES BASED ON ANIMAL CELLS OR NUCLEIC ACIDS

Bioprocess Development for the Cultivation of Human T-Lymphocytes Hilbert, U., Bohnenkamp, H. and Noll, T.

Adenovirally Modified Dendritic Cells for Immunotherapy: From Basic Development to Clinical Application

Pägelow, U., Wirth, M., Buhr, P., Macke, L., Hannig, H., Dittmar, K.E.J.,

Berlin, J., Wörmann, B. and Lindenmaier, W.

GMP Compliant Expansion of Hematopoietic Stem Cells (CD34+) Selected from Cord Blood for a Phase I Cell Therapy Trial

Schröder, B., Fahr, C., Bug, G., Roßmanith, T. and Merget-Millitzer, H.

Multi-Plasmid Vaccines for HIV-1: Issues and Advancements

Kim, J.J. and Weiner, D.B.

Continuous Retroviral Vector Production in a Perfusion Bioreactor System

Knoess, H., Merget-Millitzer, H. and Schroeder, B.

Monolayer and Suspension Cultures of HEK293 Cells for Recombinant 
Adenovirus Production for Gene Therapy: Effect of "Cell Passage Number" Lee, M.S., Park, M.T., Kim, S.H., Jo, E.C. and Lee, G.M.

Possible Strategies for the Production of Viral Vector: The Role of Engineering Design

Sendresen, C., Fassnacht, D., Benati, C. and Pörtner, R.

Establishing Novel Hepatoma Cell Line for Bioarticifial Liver

Terada, S., Kumagai, T., Ogawa, A., Yamamoto, N., Miki, M., Fujita, T. and Suzuki, E.

An Improved Oxygenation Hollow Fiber Bioreactor for the Cultivation of Liver Cells

Jasmund, I., Simmoteit, R. and Bader, A.

Medium for Gene Therapy: Improved Protein-Free Media for Growth and Production of Viral Vectors for Use in Gene Therapy

Hanff, C., Fuhr, B., Johnson, T. and Caple, M.

Induction of a T Helper Cell Response against the Tumor Associated Antigen Her-2 Using Monocyte-Derived Dendritic Cells

Metzger, J., Nicklisch, N., Schmidt, B., Kufer, P., Peschel, C. and Bernhard, H.

Cultivation of Human HCMV Specific Lymphocytes - An Example for Adoptive Immunotherapy

Hilbert, U., Biselli, M. and Noll, T.

Application of hTERT Promoter to Cancer Therapy

Fujiki, T., Katakura, Y., Miura, T. and Shirahata, S.

Establishment of a Genetic System to Coordinate Feeder Cell Growth in Cocultures with Primary Cells

Schroeder, K., Koschmieder, S., Ottmann, O.G., Hoelzer, D. Hauser, H. and Mueller, P.P.

Construction and Operation of a Bioreactor for Three-Dimensional Cartilage-Implants

Nagel-Heyer, S., Feyerabend, F., Goepfert, C., Adamietz, P., Meenen, N.M., Jeschke, B. and Pörtner, R.

Tissue Engineering of Meniscal Cartilage

Neves, A.A., Medcalf, N. and Brindle, K.M.

Anti-Oxidative Water Improves Diabetes

Shirahata, S., Nishimura, T., Kabayama, S., Aki, D., Teruya, K., Otsubo, K., Morisawa, S., Ishii, Y., Gadek, Z. and Katakura, Y.

Effect of Transfection-Induced Changes in Expression of Insulin-Like Growth Factor Binding Proteins on Secretory Activity and Responses of Ovarian Cell Cultures

Sirotkin, A.V., Makarevich, A.V., Corkins, M.R., Kotwica, J., Kwon, H.B., 
Bulla, J. and Hetenyi, L.

Cultivation of Primary Osteogenic Cells in Serum-Reduced or Serum-Free Culture Media: Attachment, Proliferation and Differentiation

Barthold, M., Mayer, H. and Jäger, V.

Author Index

Subject Index 


\section{7th ESACT Meeting Committees}

Organizing Committee

Elisabeth Lindner-Olsson (Chair)

Metcon Medicin

Björn Lundgren (Sponsorship)

Amersham Pharmacia Biotech

Elke Lüllau (Poster Awards)

Astra Zeneca

Nathalie Chatzissavidou

Biovitrum AB

Alain Bernard

Serono

Eva Ljungkvist (Conference Coordinator)

SKD Konferensservice

Ewa Engström (Trade Exhibition)

Christophe Losberger (Webmaster)

SKD Konferensservice

Serono

Scientific Committee

Elisabeth Lindner-Olsson (Chair)

Alain Bernard

Hansjörg Hauser

Lena Häggström

Leif Kongerslev

Peter Liljeström

Elke Lüllau

Karin Mellström

Sarbari Roy

Metcon Medicin

Serono

GBF

Royal Institute of Technology

NatImmune

Karolinska Institute

Astra Zeneca

KaroBio

BioInvent

Poster Award Committee

Elke Lüllau (Chair)

Astra Zeneca

Stephanos Grammatikos

BI Pharma

Nathalie Chatzissavidou

Biovitrum $\mathrm{AB}$ 


\section{ESACT Executive Committee}

Manuel CARRONDO, Chairman

Otto-Wilhelm MERTEN, Secretary

Bryan GRIFFITHS, Treasurer

Elisabeth LINDNER-OLSSON, Meeting Chair

Florian WURM

Alain BERNARD

Caroline MACDONALD

Francesc GODIA
IBET, Portugal

Généthon, France

Porton, UK

Metcon Medicin, Sweden

EPFL, Switzerland

Serono, Switzerland

University of Paisley, UK

Universitat Autonoma de

Barcelona, Spain 


\section{Sponsors}

ESACT and the Organising Committee wish to thank the following companies for their generous support

$\begin{array}{ll}\text { Abgenix } & \text { Intervet International } \\ \text { Agilent Technologies } & \text { Invitrogen } \\ \text { Amersham Pharmacia Biotech } & \text { KaroBio } \\ \text { Astra Zeneca R\&D } & \text { Merck } \\ \text { Aventis Pasteur } & \text { Metcon Medicin } \\ \text { B. Braun Biotech International } & \text { NatImmune } \\ \text { BioInvent Production } & \text { Nature Biotechnology } \\ \text { BioReliance } & \text { Novo Nordisk } \\ \text { BioSource Recruitment } & \text { Nunc } \\ \text { Biovitrum AB } & \text { Pall } \\ \text { Bio Whittaker } & \text { PCS Process Control } \\ \text { Boehringer Ingelheim Pharma } & \text { Perbio Science } \\ \text { Chiron Bering } & \text { Q-One Biotech } \\ \text { Covance Laboratories } & \text { Schärfe System } \\ \text { Genentech } & \text { Schering Berlin } \\ \text { Genespan Corporation } & \text { Serono } \\ \text { Genetics Institute } & \text { Siegfried } \\ \text { Gesellschaft Biotechnische Forschung } & \text { Sigma-Aldrich } \\ \text { Glaxo SmithKline } & \text { Smithkline Beecham Biologicals } \\ \text { Glaxo Wellcome } & \text { Sorebio } \\ \text { Innovative Cell Technologies } & \text { Trends in Biotechnology } \\ \text { Int. De Recherhe Pierre Fabre } & \end{array}$




\section{Companies in Trade Exhibition}

Aber Instruments
Agilent Technologies
Amersham Pharmacia Biotech
Applikon
Ashby Scientific
B. Braun Biotech International
Bioengineering
BioInvent Production
BioReliance
Biotech-IgG
Biovitrum AB
BioWhittaker
Boehringer Ingelheim Pharma
Cell Culture Technologies
Cellon
Chemometec
Corning Life Science
Covance
DASGIP
Genespan Corporation
Genetic Engineering News
Greiner Bio-One
Guava Technologies
Infors HT/Bergman and Beving Instrument
Innovatis
Institut Pasteur
Inveresk Research
Invitrogen

JM Separations

JRH Biosciences

Kendro Lab

Lonza Biologics

Medi-Cult

MicroSafe/Amsterdam Molecular

Therapeutics

Moregate

New Lab BioQuality

NUNC

Pall

Papaspyrou Biotechnology

PCS Process Control Systems

Perbio Science

PRIOR Separations Biotechnology

Q-One Biotech

Quest International

Schärfe System

Selborne Biological Services

Seriological Proteins

Sigma Aldrich Sweden

SSS Rütten Engineering

Stedim

Terracell International

The Automation Partnership

Wave Biotech

Y.S.I. 


\section{List of Participants}

RANYA ABBAS, USA, Phone: 17187602 743, E-mail: nayali@ hotmail.com

Dr KEVIN ADAMS, Huntingdon Life Science, Wolley Road, Alconbury PE28 4HS, UNITED KINGDOM, Phone: 441480893 024, E-mail: adamsk@ukorg.hutingdon.com

Mr LARS ADAMSON, Pharmacia Strandbergsgatan 47, 11287 Stockholm, SWEDEN, Phone: +46 8 705-840629 E-mail: lars.adamson@eu.pnu.com

Prof SPIROS AGATHOS, Universite Catholique de Louvain, Place Croix du Sud 2/19, Louvain-la-Neuve B-1348, BELGIUM, Phone: +32 104736 644, E-mail: agathos@gebi.ucl.ac.be

Dr TEIT AGGER, NatImmune A/S, Fruebjergvej 3, Box 3, DK 2100 Copenhagen, DENMARK, Phone: 4539169 439, E-mail: ta@ natimmune.dk

Dr REZA AGHANOURI, University of Tehran, Faculty of Veterinary Medicine, Azadi Avenue, Tehran 14155-6453, IRAN, Phone: 9821921 436, E-mail: raghanouri@yahoo.com

Mr FRANCOIS AGUILON, Sanofi - Synthelabo, BP 137, 31676 Labege-Innopole, FRANCE, Phone: +33561004159

Dr BERT AL, CLB dept. Biotechnology, P.O. Box 9190, AD 10061 Amsterdam, THE NETHERLANDS, Phone: 205123 658, E-mail: b_al@clb.nl

SIVERT ALEXANDERSSON, Novaferm AB, Företagsvägen 30, 22761 Lund, SWEDEN, Phone: 4646157 755, E-mail: sivert.alexandersson@novaferm.se

Mr ISAC ALKSTRAND, Bergman \& Beving Instruments, Box 732, 19427 Upplands Väsby, SWEDEN, Phone: +46 83170684 62, E-mail: isac.alkstrand@bbi.pld.se

Dr BJØRN ALLAN, Huntingdon Life Sciences, Klampenborgvej 102, 2800 Kongens Lyngby, DENMARK, Phone: 4545934 213, E-mail: huntingdon.scandinavia.pc.dk

Dr BILLY ALLEN, Lilly Research Laboratories, Lilly Corporate Center, 46285 Indianapolis, IN, USA, Phone: 13172764 810, E-mail: allen_billy_r@lilly.com

Mr SVANTE ALMKVIST, Pharmacia, Strandbergsgatan 47, 11287 Stockholm, SWEDEN, Phone: +46 869726 30, E-mail: svante.almkvist@eu.pnu.com

Mr KOEN ALOSSERY, Innogenetics N.V., Industriepark, Box 4, B-9052 Ghent/ Zwijnaarde, BELGIUM, Phone: +3292410918

Dr MOHAMMAD AL-RUBEAI, University of Birmingham, B15 2TT Birmingham, UNITED KINGDOM, Phone: 441214143 888, E-mail: m.al-rubeai@bham.ac.uk

Dr CLAUDIA ALTAMIRANO, Universidad Católica de Valparaiso, Av. Brasil 2147, Valparaiso, CHILE, Phone: +56 322737 55, E-mail: claudia.altamirano@ucv.cl 
Dr MASSIMO AMADORI, Instituto Zooprofilattico, 25124 Brescia, ITALY, Phone: 9 390302290 277, E-mail: mamapori@bs.izs.it

Mr HANSPETER AMSTUTZ, ZLB Bioplasma AG, Wankdorfstrasse 10, 3000 Bern, SWITZERLAND, Phone: 41313445 554, E-mail: hanspeter.amstutz@zlb.com

Mr DANA ANDERSEN, Genentech, Inc., 1 DNA Way, 94080 South San Francisco, CA, USA, Phone: 16502551 555, E-mail: GP@gene.com

Mr HANS JUUL ANDERSEN, Statens Serum Institut, Artillerivej 5, 2300 Copenhagen S, DENMARK, Phone: +45 326836 45, E-mail: hju@ssi.dk

Dr JØRN ANDERSEN, Novo Nordisk A/S, Hagedornsvej 1, DK-2820 Gentofte, DENMARK, Phone: +45 444386 47, E-mail: jsoa@novonordisk.com

Mr DAN ANDERSSON, BioInvent Production, 22370 Lund, SWEDEN, Phone: 4646 28685 61, E-mail: pkp@bioinvent.se

Mr RICKARD ANDERSSON, SWEDEN, Phone: +46 403067 00, E-mail: rickard@1konsult.se

Dr CARLO ANDRETTE, Biospectra AG, Zuercherstrasse 137, CH-8952 ZuerichSchlieren, SWITZERLAND, Phone: +41 1 7302120, E-mail: andretta@ biospectra.ch

Mr RICK ANDREWS, Bio Whittaker Inc., 8830 Bigap Ford Road, 21793 Walkersville MO, USA, Phone: 13018987 025, E-mail: rick.andrews@biowhittaker.com

Dr AXEL ANGERMANN, Merkle GmbH, D-89079 Ulm, GERMANY, Phone: +49 731 4027393

\section{Mr LUIGI ANNONI, ITALY}

FUTOSHI ARANISHI, Biotechn Research Inst NRC, 6100 Royalmount Avenue, H4P 2R2 Montreal, CANADA, Phone: 15144962 662, E-mail: aranishi@ hotmail.com

ELEANOR S ASHTON, SmithKline Beecham, Harlow Essex, CM19 5AW Harlow, UNITED KINGDOM, E-mail: eleanor_s_ashton@sbphrd.com

Dr FRED ASSELBERGS, Novartis Pharma, CH-4002 SWITZERLAND, Phone: 4161 32449 89, E-mail: fred_am.asselbergs@ novartis.pharma.com

Dr JOHN AUNINS, Merck Research Laboratories, P.O. Box 4, Sumnaytown Pike, 19486-0004 West Point, PA, USA, Phone: 12156525 577, E-mail: aunins@merck.com

Ms ANNA-MAIJA AUTERE, National Agency for Medicines, P.O. Box 55, 00301 Helsinki, FINLAND, Phone: 3589473 341, E-mail: anna-maja.autere@nam.fi

Dr GREGOR AWANG, Cangene Corp., 26 Henlow Bay, R3Y I64 Winnipeg, CANADA, Phone: 2042754 336, E-mail: gawang@ cangene.com

Mr NICK AYERS, Covance, Box 11045, 31041 Gullbrandstorp, SWEDEN, Phone: +46 3550699

Mr DENIS AZRA, Medi-Cult A/S, Moellehaven 12, 4040 Jyllinge, DENMARK, Phone: 
+4546790200

Dr TORBEN BACHMANN, Novo Nordisk A/S, Novo Allé Building 3BM1.03, 2880 Bagsvaerd, DENMARK, Phone: +45 444266 52, E-mail: tolb@novonordisk.com

Mr ALLAN BAEKGAARD, Medi-Cult A/S, Moellehaven 12, 4040 Jyllinge, DENMARK, Phone: +45 467902 00, E-mail: ajb@medi-cult.dk

Dr KYM BAKER, School of Biosciences, CT2 7NJ Canterbury, Kent, UNITED KINGDOM, Phone: 441227764 000, E-mail: k.n.baker@ukc.ac.uk

Mr YVES BARBIER, Institut Pasteur-Texell, 25-28 Rue du Docteur Roux, 75724 Paris Cedex 15, FRANCE, Phone: +33 145688435

Dr GHISLAIN BARE, University of Liege CWBI, Boulevard de Rectorat 20 B40, 4000 Sart Tilman, BELGIUM, Phone: +32 436628 61, E-mail: g.bare@ulg.ac.be

Dr DOMENICO BARONE, LCG-RBM, Via Ribes 1, I-10010-Colleretto Giacosa (TO), ITALY, Phone: 390125222 176, E-mail: lcg.rbm@ flashnet.it

Dr SIMON J. BARTELING, ID-Lelystad, P.O. Box 65, NL-8200 AB Lelystad, THE NETHERLANDS, Phone: 31320238 607, E-mail: s.j.barteling@id.waz_ur.nl

Mr MARE BARTHOLD, GBF, Mascherode weg 1, 38124 Braunschweig, GERMANY, Phone: 495316181 181, E-mail: mba@gbf.de

Mr THIERRY BATTLE, Serono Pharmaceutical Research Inst, Chemin des Aulx 14, 1228 Plan Les Ouates Geneva, SWITZERLAND, Phone: +41 22706 9666, E-mail: thierry.battle@serono.com

Prof LEO A. BEHIE, The University of Calgary, 2500 University Dr. N.W., Calgary, Alberta T2N 1N4, CANADA, Phone: 14032206 692, E-mail: behie@ucalgary.ca

Mr BENSON, Quest International, P.O. Box 2, 1400 CA Bussum, The Netherlands

Ms TRISH BENTON, Corixa Corporation, 600 Gateway Blvd, 94080 South San Francisco, USA, Phone: 16505532 070,E-mail: trish_benton@corixa.com

Mr GUY BERG, NewLab BioQuality AG, Max Planck-strasse 15A, D-406 99 Erkrath, GERMANY

Ms MARGARET BERGERIOUX, Institut Pasteur-Texell, 25-28 Rue du Docteur Roux, 75724 Paris Cedex 15, FRANCE, Phone: +33 145688435

Dr ALAIN BERNARD, Serono, Zone Industrielle, CH 1267 Coinsins, SWITZERLAND, Phone: +41 2235454 06, E-mail: alain.bernard@serono.com

JOHN BERNTSEN, Bie \& Berntsen AS, Sandbaekvej 7, DK-2610 Rödovre, DENMARK, Phone: 45449488 22, E-mail: jk@bie-berntsen-as.dk

Mrs CHARLOTTE BERTELSEN, NatImmune A/S, Fruebjergvej 3, Box 3, DK 2100 Copenhagen, DENMARK, Phone: +45 391694 34, E-mail: cber@natimunne.dk

Ms EVA BERTRAM, Royal Inst. of Technology, Teknikringen 34, 10044 Stockholm, 
SWEDEN, Phone: 08-790 75 00, E-mail: eva@biotech.kth.se

Dr WALTER BEYELER, PCS Process Control Systems AG, Werkstrasse 8, 8623 Wetzikon, SWITZERLAND, Phone: +41 193121 44, E-mail: office@pcs.ag.com

Dr JING-XIU BI, GBF, Mascherode weg 1, 38124 Braunschweig, GERMANY, Phone: 495316181 432, E-mail: bji@gbf.de

Mr HEINRICH BIEHL, Medi-Cult A/S, Moellehaven 12, 4040 Jyllinge, DENMARK

Dr RICHARD BIEUER, Bayer AG, Bldg. E41, D-51368 Leuerhusen, GERMANY, Phone: 4921430 71850, E-mail: richard.bieuer.rb@bayer-ag.de

Dr ROGER A. BINOT, European Space Agency, P.O. Box 299, 2200 AG Noordwijk, THE NETHERLANDS, Phone: 317156548 15, E-mail: rbinot@estec.esa.nl

Prof JOHN BIRCH, Lonza Biologics Plc, 228 Bath Road, SLI 4DY Slough, UNITED KINGDOM, Phone: 9441753716 576, E-mail: jbirch@lonza.co.uk

Mr ROBERT BIRD, Ashby Scientific Ltd, Unit 2 Brunel Way, LE67 3HF Coalville, UNITED KINGDOM, Phone: 441530832 590, E-mail: robert.bird@ashbyscientific.co.uk

Ms ISABELLE BISSON, CHUV, Pédiatrique, Labo 73, 1011 Lausanne, SWITZERLAND, Phone: +41 2131431 12, E-mail: isabelle.bisson@ chov.hospvd.ch

Mr LARS BJÖRK, Biovitrum, Lindhagensgatan 133, 11287 Stockholm, SWEDEN

Dr ROBERT BJÖRNESTEDT, Astra Zeneca, 15185 Södertälje, SWEDEN, Phone: 0855 2538 80, E-mail: robert.bjornestedt@astrazeneca.com

Mr STIG BJÖRNLAND, New Brunswick, NORWAY

Prof HENRI BLACHERE, Bioprocess, 4 rue Mareschal, 34000 Montpellier, FRANCE, Phone: +33 4679256 14, E-mail: hbl314@aol.com

Mr DAVID BLACK, Excell Biotech Ltd, Pentlands Sciene Parl, Edinburgh EH26 0PZ, UNITED KINGDOM, Phone: 4413144456 231, E-mail: david@excellbiotech.com

Dr GERALD BLUEML, Amersham Pharmacia Biotech, Muthgasse 18, A-1190 Vienna, AUSTRIA, Phone: +43 13600 6620, E-mail: blueml@edv1.boku.ac.at

Dr MARINA BOGRIANTSEVA, State Research Centre, Vector, RUS-633159 Koltsovo, Novosibirsk, RUSSIA, Phone: 73832366 215, E-mail: troskova@online.nsk.su

Ms ELISABETH BÖHLEN, Bioengineering AG, Sagenrainstrasse 7, 8636 Wald, SWITZERLAND, Phone: + 41552538 111, E-mail: n.watanabe@bioengineering.ch

Dr JOHN BOIRCH, Lonza Biologics Plc, 228 Bath Road, SLI 4DY Slough, UNITED KINGDOM, Phone: 440175377 000, E-mail: jbirch@lomza.co.uk

Mr MAXIMILLIAN M BOLDT, Innovatis GmbH, Meissenstrasse 96, 33607 Bielefeld, GERMANY, Phone: 4915212997 287, E-mail: info@innovatis.com

Ms MARIELA BOLLATI FOGOLIN, ZKT (GBF), Mascheroder weg 1, 38124 
Braunschweig, GERMANY, Phone: 495316181 181, E-mail: mrb@gbf.de

Dr BRYAN BOLTON, ECACC/CAMR, Porton Down, Salisbury Wilts SP4 OJG, UNITED KINGDOM, Phone: 441980612 512, E-mail: bryan.bolton@camr.org.uk

Mr JOHN BONHAM-CARTER, Biotech-IgG A/S， Østerbrogade 95, DK-2100 Copenhagen, DENMARK

Mr MARCO BOORSMA, Cytos Biotechnol. AG, Wagistrasse 21, CH-8952 ZürichSchlieren, SWITZERLAND, Phone: +41 173340 25, E-mail: boorsma@cytos.com

Mr MATS BORÉN, Sigma-Aldrich Sweden AB, Solkraftsvägen 14C, 13570 Stockholm, SWEDEN, Phone: +46 874242 00, E-mail: mboren@eurnotes.sial.com

Dr CLAUS BORNAES, Maxygen, Agern Alle 1, DK-2970 Hørsholm, DENMARK, E-mail: cb@maxygen.dk

Ms MARIANA BOSTAN, State University of Moldova, Str. Armeneasca 27B, MD-2012 Moldova, MOLDOVA, Phone: +373 2248 490, E-mail: tudor@mail.md

Dr ETIENNE BOUTRY, Aventis Pasteur, 1541 Av. Marcel Mérieux, 69280 Marcy l'Etoile, FRANCE, Phone: +33 43733 3498, E-mail: etienne.boutry@aventis.com

Mr THIERRY BOVY, Bio Whittaker Europe, Parc Industriel de Petit Rech., B-4800 Vervuis, BELGIUM, Phone: +32 87321 611, E-mail: thierry.bovy@ cambrex.com

Mr LEO BOWSKI, Hoffman Laroche, 340 Kingsland Street, Nutley N.J. 07110, USA, Phone: 919732353 579, E-mail: leo.bowski@roche.com

BROOKS BOYD, Aradigm, 3929 Point Eden Way, Hayward, CA 94545, USA, Phone: 15 102658 808, E-mail: boydb@aradigm.com

Mr RICHARD BRADLEY, Kendro Laboratory Products GmbH, Heraustrasse 12-14, 63450 Hanau, GERMANY, Phone: +49 618135 3834, E-mail: yknof@kendro.de

Dr MICHAEL BRAILSFORD, Immeble Paris Sene, 3 aller de la Sene F-94854 Ivry-SurSene, FRANCE, Phone: 009334959 2000, E-mail: nbrail@lordchef.fr

Dr MICHAEL BRAILSFORD, Immeble Paris Sene, 3 aller de la Sene, F-94854 Ivry-SurSene, FRANCE, Phone: 0093314959 2000, E-mail: mbrailsfrod.lordnet.fr

Dr RUUD BRANDS, Solvay Pharmaceuticals, 13010 DA Weesp, THE NETHERLANDS, Phone: 31294479 372, E-mail: ruud.brands@ solvay.com

Mrs MONTSERRAT BRASO, Biokit, Can Xicota s/n, ESP-Llica d'Amunt (Barcelona), SPAIN, Phone: +34 9384148 50, E-mail: mbraso@biokit.com

Mr MALCOLM BRATTLE, Q-One Biotech Ltd, West of ScotlanScience Park, Glasgow G20 OXA, UNITED KINGDOM, Phone: 9441419469 999, E-mail: mbrattle@g_one.co.uk

Dr YOLANDA BRAVO DE ALBA, Aventis Pasteur, 1541 Av. Marcel Mérieux, 69280 Marcy l'Etoile, FRANCE, Phone: 33043737 9385, E-mail: yolanda.bravodealba@aventis.com 
Mr STEVEN BRENNAN, Genetic Institute, 1 Burtt Road, Andover MA 01810, USA, E-mail: sbrennan@genetics.com

Ms SUSAN BRIDGES, JRH Biosciences, 13804 West 107 th Street, 66215 Lenexa, Kansas, USA, Phone: 19134695580

Ms CATHERINE BROWN, University of Queensland, St. Lucia, 4072 Brisbane, AUSTRALIA, Phone: 733653 812, E-mail: cathyb@cheque.uq.edu.au

Dr MICHAEL BROWN, MBROWN Lonza Biologics, ESACT member, 224 Bath Road Berks, SLI 4DY Slough, UNITED KINGDOM, Phone: 441753716 584, E-mail: mbrown@lonza.co.uk

Dr GUSTAF BRUNIUS, Gentekniknämnden, 17184 Solna, SWEDEN, Phone: +46 8730 9228

Prof BARRY BUCKLAND, Merck \& Co. Inc., P O Box 2000, Rahway NJ 07090, USA, Phone: 17325945 908, E-mail: barry_buckland@merck.com

Dr BENJAMIN BUEHRER, Karo Bio USA, 4222 Emperor Blvd. Ste S60, 27703 Durham, NC, USA, Phone: 19194748 888, E-mail: dana.fowlkes@karobio.com

Mr MARC BUEVINK, New Brunswick Scientific, Kerkenbos 1101, 6546 BC Nijmegen, THE NETHERLANDS, Phone: +31 243717 608, E-mail: a.v.beekhuizen@nbsbv.nl

Dr SANDY BULLOCH, Sigma Aldrich Scotland, Second Avenue, Irvine KA12 8NB, UNITED KINGDOM, Phone: 441294312 222, E-mail: sbulloch@euronotes.sial.com

Dr BEN BULTHUIS, Centocor, Einstein weg 101, 2333 CB Leiden, THE NETHERLANDS, Phone: +31 715242 803, E-mail: bulthuis@ centocor.com

Dr HEINO BÜNTEMEYER, University of Bielefeld, P.O. Box 100131, 33501 Bielefeld, GERMANY, Phone: 495211066317

Dr CHRISTA BURGER, Merck KGaA, Frankfurter strasse 250, 64271 Darmstadt, GERMANY, Phone: +496151 72 6032, E-mail: chburger@ merck.de

Ms CAROLINE BURTEAU, University of Louvain, 1, Place Louis Pasteur, 1348 Louvain la Neuve, BELGIUM, Phone: +32 104730 39, E-mail: c.burteau@ bioc.ac.be

Dr MICHAEL BUTLER, Oxford University, South Parks Road, OX1 3QU Oxford, UNITED KINGDOM, Phone: 441865275 764, E-mail: butler@cc.umanitoba.ca

Ms LOUISA CAAMANO, Biogen Inc., 14 Cambridge Center, Cambridge MS 02142, USA, Phone: 16176793 128, E-mail: louisa_camano@biogen.com

Ms KARIN CALLES, KaroBio AB, 14157 Huddinge, SWEDEN, Phone: +46 860861 02, E-mail: karin.calles@karobio.se

Mr JOSEPH CAMIRE, HyClone Laboratories, Inc., 1725 S. HyClone Rd., 84321 Logan, Utah, USA, Phone: 4357920 169, E-mail: joseph.camire@perbio.com

Mr TODD CAMPUS, Q-One Biotech Ltd, West of ScotlanScience Park, Glasgow G20 OXA, UNITED KINGDOM, Phone: 9441419469999 
Dr MATTHEW CAPLE, Sigma Aldrich Corp, 3050 Sprice Street, MO 63103 ST Louis, USA, Phone: 13147715 765, E-mail: mcaple@ siel.com

Mr HUBERT CARLANDER, Getinge Seget, Box 69, 31044 Getinge, SWEDEN, Phone: 0351555 00, E-mail: hubert.carlander@ seget.getinge.com

Mr C-E CARLSSON, AKA Filter AB, Box 160, 42122 Västra Frölunda, SWEDEN, Phone: 031-496250

Ms NATALIE CARRICK, The Automation Partnership, York Way, SG8 5WY Royston, UNITED KINGDOM, Phone: 441763227216

Prof MANUEL CARRONDO, IBET, Apartado 12, 2781-901 Oeiras, PORTUGAL, Phone: +351 2144277 87, E-mail: mjtc@itqb.unl.pt

JERRY CARSON, BASF Bioresearch Corporation, 100 Research Drive, Worcester MA 01605, USA, Phone: 15088492 652, E-mail: carsong @basf.com

Ms ANA VERÓNICA CARVALHAL, IBET, Apartado 12, 2781-901 Oeiras, PORTUGAL, Phone: +351 21446 9424, E-mail: uva@itgb.unl.pt

Dr JOHN CARVELL, Aber Instruments Ltd, Science Park, SJ23 3AH Aberystwyth, UNITED KINGDOM, Phone: 441670636 300, E-mail: sales@ aber-instruents.co.uk

Dr SUSAN CASNOCHA, Pharmacia Corporation, 800 N Lindbergh Blvd, St Louis MO 63167, USA, Phone: 13146941 509, E-mail: susan.a.casnocha@pharmacia.com

Ms LEDA CASTILHO, GBF, Mascheroder Weg 1, D-38 124 Braunschweig, GERMANY, Phone: 495316181 178, E-mail: leda@gbf.de

Mr ADOLFO CASTILLO, Center of Molecular Immunology, Calle 216 y 15 Atabey Playa, Havana 11600, CUBA, Phone: +53 7217 211, E-mail: adolfo@ict.cim.sld.cu

Prof MARINA CAVAZZANA-CALVO, Hopital Necker Enfants Malades, 149 rue de Sévres, 75743 Paris Cedex 15, FRANCE, Phone: +33 1444950 68, E-mail: cavazzan@necker.fr

Dr AZIZ CAYLI, Boehringer Ingelheim Pharma KG, Birkendorfer Strasse 65, 88397 Biberach, GERMANY, Phone: +49 735154 476, E-mail: aziz.cayli@bc.boehringeringelheim.com

Dr STEVEN CHAMOW, Abgenix, 7601 Dumbarton Circle, Freemont CA 94555, USA, Phone: 15106084 680,E-mail: chamow_s@abgenix.com

Dr TIMOTHY CHARLEBOIS, Genetic Institute, 1 Burtt Road, Andover MA 01810, USA, Phone: 19782472 024, E-mail: tcharlebois@genetics.com

Dr LARRY CHASIN, Columbia University, Dept of Biological Sciences, 10027 New York, USA, Phone: 12128544 645, E-mail: lac2@columbia.edu

Ms NATHALIE CHATZISSAVIDOU, Biovitrum AB, Lindhagensgatan 133, 11276 Stockholm, SWEDEN, Phone: +46 86973038 E-mail:

nathalie.chatzisavido@biovitrum.com 
SHAN-CHUN CHEN, Department of Health, 100 Ei-Kuo E. Rd, Taipei, R.O.C., CHINA, Phone: +1 88622321 0151, E-mail: scchen@dohr6.doh.gov.tw

Prof ZHAOLIE CHEN, Institute of Biotechnology, Fengtai, 100071 Beijing, CHINA, Phone: +86 10638 41526, E-mail: chenzl@nic.bmi.ac.cn

XIAO CHENGZU, Institute of Biotechnology, Fengtai, 100071 Beijing, CHINA, Phone: 861638415 26, E-mail: xiaoCZ@ nic.bmi.ac.cn

Mr DMITRY CHERNYSHOV, Department of Cell Biology, 2 Tereschenkovskaya St., 01004 Kiev, UKRAINE, Phone: 380442123 236, E-mail: dmitry_chernyshov@yahoo.com

Mr ADRIAN CHEW, Lonza Biologics, 224 Bath Road, SLI 4DY Slough, UNITED KINGDOM, Phone: 441753777 000, E-mail: anagle@lonza.co.uk

Dr WEI-KUANG CHI, TAIWAN, Phone: 886229325123 ext. 2103, E-mail: weikchi@mail.dcb.org.tw

ERNESTO CHICO, Centro de Inmunologia Molecular, P.O. Box 16040, Habana 11600, CUBA, Phone: 5372133 57, E-mail: chico@ict.cim.sld.cu

Dr MYUNG-SAM CHO, Bayer Corporation, 800 Dwight way/P.O. Box 1986, 94710 Berkeley, California, USA, Phone: 15107055 424, E-mail: myung-sam.chu.b@bayer.com Mr ONE CHOI, Kaist, 373-1 Kusong-Dong Yusong-gu, 305-701 Taejon, KOREA, Phone: +82 42869 2654, E-mail: choione@ cais.kaist.ac.kr

Ms VERONIQUE CHOTTEAU, Pharmacia \& Upjohn AB, 11287 Stockholm, SWEDEN, Phone: +4686958507, E-mail: veronique.chotteau@eu.pnu.com

Dr BOKHWAN CHUN, KOREA, Phone: 008253581 7700, E-mail: chunbh@hotmail.com

Mr JOO YOUNG CHUNG, Daewoong Pharmaceuticals Co Ltd, 223-23 SangdaewonDong, JungwonGu, 462-120 Sungnam, KOREA, Phone: +82 31741 7700, E-mail: jychung@daewoong.co.kr

Dr SONYA A CLARK, BioMarin Pharmaceutical, 46 C Alli Dr, 94949 Novato, USA, Phone: 14158846 752, E-mail: sclark@biomarinpharm.com

Mr TOM CLARK, Esact Newsletter, La Tuilerie, 81630 Montdurausse, FRANCE, Phone: +3356333 5519, E-mail: tclark5604@aol.com

Mr MARTIN CLARKSON, Novartis Animal Vaccines, Springwood Ind. Estate, Braintree C09 2BT, UNITED KINGDOM, Phone: 441376551 222, E-mail: martin.clarkson@ah.novartis.com

Mr MARTIN CLARKSON, Maxygen, Agern Alle 1, DK-2970 Hørsholm, DENMARK, Phone: 4570205 550, E-mail: mpc@maxygen.dk

Mr UFFE CLAUSEN, Novo Nordisk A/S, Hallas Allé, DK-4400 Kalundborg, DENMARK, Phone: 4544448 888, E-mail: uc@novonordisk.com 
Dr ALDA CLEMENTE, Universität Stuttgart, Pfaffenwaldring 57, D-705 50 Stuttgart, GERMANY, Phone: +351 2171651 41, E-mail: alda.fedalgo@waili.j.net.p

Dr CATHERINE CLEUZIAT, Merial, 25 rue Marcel Merieux, 69007 Lyon, FRANCE, Phone: +33472 7230 00, E-mail: catherine.cleuziat@merial.com

Dr JOSE COCO MARTIN, DSM Biologics, P.O. Box 454, NL-9700 AL Groningen, THE NETHERLANDS, Phone: +31 50522223 08, E-mail: jose.coco-martin@dsm-group.com

Mr DAVID COLLINS, Inveresk Research, Tranent, E Lothian EH33 2NE, UNITED KINGDOM, Phone: 441875618 561, E-mail: daiv.collins@inveresk.com

Mr ERIC CORNAVACA, Invitrogen Corporation, 3175 Staley Road, 14072 Grand Island, USA, Phone: 17167746 660, E-mail: eric.cornavaca@invitrogen.com

Ms ANA COROADINHA, IBET, Apartado 12, 2781-901 Oeiras, PORTUGAL, Phone: +351214469422, E-mail: avalente@ltqb.unl.pt

Dr RUTA CORVINDT, AZ-VUB, Laarbeeklaan 101, B-1090 Brussel, BELGIUM, Phone: 009322477477 46, E-mail: Criactr@az.vub.ac.be

Dr JULIA COSTA, PORTUGAL, Phone: 351144694 37, E-mail: jcosta2itgb.unl.pt

Ms LUDIVINE COULON, Université Libre de Bruxelles, Rue des professeurs Jeener et Brachet, 12, 6041 Gosselies, BELGIUM, Phone: +32 265099 10, Email: lcoulon@sga.ulb.ac.be

Mr THOMAS COUTTS, Life Technologies, Inchinnan Business Park, Paisle, Paisley PA4 9RF, UNITED KINGDOM, Phone: 441418146 298, E-mail: coutts@beach.com

Prof Dr DAAN CROMMELIN, Faculty of Pharmacy, Sorbonnelaan 16, 3584 CA Utrecht, THE NETHERLANDS, Phone: +31 30253 6973, E-mail: d.j.a.crommelin@pharm.uv.nl

Ms JOANNE CROSSLEY, Bayer Plc, Stoke Poges, Slough SL2 4LY Buckinghamshire, UNITED KINGDOM, Phone: 441635566 740, E-mail: joanne.crossley.jc@ bayer.co.uk

Dr EUGENIA CRUZ, Ineti, Est. Paco Lumiar 22, 1699 Lisboa, PORTUGAL

Dr PEDRO CRUZ, IBET, Apartado 12, 2781-901 Oeiras, PORTUGAL, Phone: + 35121 446 9417, E-mail: pcruz@ibet.unl.pt

Mr ARCHIE CULLEN, Life Technologies, Inchinnan Business Park, Paisle, Paisley PA4 9RF, UNITED KINGDOM, Phone: 4401418146129

Dr SAMUEL CYMBALISTA, SWITZERLAND, Phone: +41 21800 5617, E-mail: cymbalistasamuel@urbanet.ch

Ms ANETTE DANIELSSON, Astra Zeneca, 15185 Södertälje, SWEDEN, Phone: 855 252 917, E-mail: anette.danielsson@astrazeneca.com

Dr CHRISTINE DARTSCH, Astra Zeneca, 15185 Södertälje, SWEDEN, Phone: +46 8 55251 309, E-mail: johanna.wahlberg@astrazeneca.com

Dr CAROL DAVID, Interpharm Laboratories, Kiryat Weizman, IL-75110 Ness Ziona, 
ISRAEL, Phone: +97289382576

Dr JOHN DAVIS, Bio-Products Laboratory, Dagger Lane, WD6 3BX Elstree, UNITED KINGDOM, Phone: 442082582 323, E-mail: jd20470@bpl.co.uk

JACQUELINE DAYAN-KENIGSBERG, Head Biotech Medicinal Products/MPA, MPA, FRANCE, Phone: +33155874115

Dr BRUNO DE BORTOLI, Bio Whittaker Europe, Parc Industriel de Petit Rech., B-4800 Vervuis, BELGIUM, Phone: +32 8732 16 11, E-mail: elvira.mersi@cambrex.com

Mr RAYMOND DE BURLET, SmithKline Beecham Biologicals, Rue de I-Institut 89, B-1330 Rixensart, BELGIUM, Phone: 0032265683 45, E-mail: Raymond.deBurlet@sbbio.be

Dr MARIA DE JESUS, Ecole Polytechnique Fédérale, CH-1015 Lausanne, SWITZERLAND, Phone: 412169361 36, E-mail: maria.dejesus@epfl.ch

Dr GREG DEAN, Cambridge Antibody Technology, The Science Park, SG8 6JJ Melbourn, South Cambs, UNITED KINGDOM, Phone: 441763269 378, E-mail: emma.dixon@cambridgeantibody.com

Mr FRANK DEER, Millennium Pharmaceuticals, 640 Memorial Drive, 02139 Cambridge, Massachusetts, USA, Phone: 16173747 629, E-mail: deer@mpi.com

Mrs NESLIHAN DELACRUZ, Genentech, Inc., 1 DNA Way, 94080 South San Francisco, CA, USA, Phone: +1 65022520 29, E-mail: delacruz.neslihan@gene.com

JEAN PIERRE DELAGE, NOVA BIOMEDICAL FRANCE, 15 av du Quebec, 91965 Les Ulis, FRANCE, E-mail: novabio@infonie.fr

Mr CÉDRIC DELSEMME, Henogen SA, Rue de Professeurs Jeener et Bracket 12, 6041 Charleroi, BELGIUM, Phone: +32 265099 85, E-mail: cedric.delsemme@ henogen.com

Dr JÜRGEN DELZER, Knoll AG, Knollstrasse, D-67061 Ludwigshafen, GERMANY, E-mail: juergen.delzerk@knoll-ag.de

Dr CLAUDIO DENOYA, Pfizer Inc., Eastern Point Road, Groton 06339, USA, Phone: 18 604414 791, E-mail: claudio_d_denoya@groton.pfizer.com

Ms VÉRONIQUE DEPARIS, LSGC - CNRS, 2 Avenue de la Foret De Haye, 54500 Vandoeuvre, FRANCE, Phone: +33 835957 80, E-mail: deparis@ensqiq.impl.mancy.fr

Mr GEERT DESCHAMPS, Innogenetics N.V., Industriepark, Box 4, B 9052 Ghent/Zwijnaarde, BELGIUM, Phone: +32 924107 11, E-mail:

geertdes@innogenetics.be

COSETTE DEYIRMENDJIAN, Directeur, NOVA BIOMEDICAL FRANCE, 15 av du Quebec, 91965 Les Ulis, FRANCE

Dr FRÉDÉRIC DHAINAUT, LFB, 3 Avenue des Tropiques BP 305, Les Ulis 91958 Courtab Euf Cedex, FRANCE, Phone: +33 16982 70 28, E-mail: dhainaut@lfb.fr

Dr FRITZ DIENER, SSS Rütten Engineering AG, Industriestrasse 9, CH-8712 Stäfa, 
SWITZERLAND, Phone: 4119282930

Mr PAUL DIERICKX, Institute Public Health, Wytsmanstraat 14, B-1050 Brussels, BELGIUM, Phone: 322642 5107, E-mail: p.dierickx@iph.fgov.be

Mr OHTMAR J DILL, Target GmbH, Waldhofer Strasse 102, 69123 Heidelberg, GERMANY, Phone: 496221705 644, E-mail: othmardill@cs.com

Prof OTTO DOBLEHOFF DIER, Institute of Applied Microbiology, Muthgasse 18, 1190 Vienna, AUSTRIA, Phone: +43 136006 6204, E-mail: dobelhoff@edv2.bokv.ac.at

Dr DENIS DRAPEAU, Genetic Institute, 1 Burtt Road, Andover MA 01810, USA, E-mail: ddrapeau@gentics.com

Mr DIRK DRESSLER, University of Hohenheim, Zeppelinstrasse 85, 70193 Stuttgart, GERMANY, E-mail: dressler@uni-hohenheim.de

Mr YUVAL DROR, Interpharm Laboratories, Kiryat Weizman, IL-75110 Ness Ziona, ISRAEL, Phone: +972 8938 2491, E-mail: dror_yuval_tlv01/serono@serono.com

Mr JEAN-CHRISTOPHE DRUGMAND, Université Catholique de Louvain (UCL), Place croix du sud zi 19, 1348 Louvain-la-Neuve, BELGIUM, Phone: +32 10473039

Mr PAUL DUCOMMUN, Serono, Zone Industrielle B, Fenil-sur-Corsier 1809, SWITZERLAND, Phone: +41 2192320 00, E-mail: paul.ducommun@epfl.ch

Dr DENIS DUFRANE, University Tissue Bank, 53, Av Mounier 5388 Tour Pasteur, 1200 Brussels, BELGIUM, Phone: +32 276453 88, E-mail: denis.dufrane@clin.ucl.ac.be

Mr PATRICK DUMAS, GlaxoSmithKline Biologicals s.a, rue de l'Institut 89, 1330 Rixensart, BELGIUM, Phone: +32 2656 7227, E-mail: patrick.dumas@gskbio.com

Dr REINHARD DUNKER, Merck KGaA, Frankfurter Strasse 250, 64271 Darmstadt, GERMANY, Phone: +49 615172 7449, E-mail: rdunker@merck.de

Mr JAMES DUNSTER, Moregate Biotech, AUSTRALIA, Phone: 441296714555

Mr MARKUS DÜRRSCHMID, Institute of Applied Microbiology, Muthgasse 18, 1190 Vienna, AUSTRIA, Phone: 431360066 587, E-mail: h9040929@edv1.boku.ac.at

SEVIM DUVAR, GBF, Mascherode weg 1, 38124 Braunschweig, GERMANY, Phone: 495316181 679, E-mail: sdr@gbf.de

Dr CHARLOTTE DYRING, M\&E Biotech, Kongle Allé 6, 2970 Hörsholm, DENMARK, Phone: +45 451625 25, E-mail: cd@me.dk

Dr LÉNA EDELMAN, GBF, Mascheroder Weg 1, D-38 124 Braunschweig, FRANCE, Phone: +3314568 82 11, E-mail: ledelman@pasteur.fr

Mrs JOKE EDERVEEN, Microsafe BV, Niels Bohrweg 11-13, 2333CA Leiden, THE NETHERLANDS, Phone: +31 71523 1886, E-mail: info@microsafe.nl

Mrs VIVEKA EHRNSTÉN, FINLAND, Phone: 0093589 547680, E-mail: viveka.ehrnsten@medix.biochema.lu 
Ms CHRISTINA EKSTRÖM, Active Biotech Research AB, Scheelevägen 22, 22363 Lund, SWEDEN, Phone: 046-19 12 38, E-mail: christina.ekstrom@activebiotech.com

VIVIANNE EKSTRÖM, Phone: 046-289 3957

Mr TRYGVE ELIASSEN, Alpharma AS, P.O. Box 158, SKoyen, N-0212 Oslo, NORWAY, Phone: +4722529091

Dr BARBARA ENENKEL, Boehringer Ingelheim Pharma KG, Birkendorfer Strasse 65, 88397 Biberach, GERMANY, Phone: +49 7651544801

Mr CHRISTIAN ENGAARD, Nunc A/S, Kamstrupvej 90, DK-4000 Roskilde, DENMARK, Phone: +45 463121 86, E-mail: che@nunc.dk

Dr PAUL ENGBERG, Amersham Pharmacia Biotech AB, Björkgatan 30, 75184 Uppsala, SWEDEN, Phone: +46 1861204 39, E-mail: paul.engberg@eu.apbiotech.com

EWA ENGSTRÖM, SKD Konferensservice

Ms MARIANNE ERIKSSON, Pharmacia Diagnostics AB, Rapsgatan 7, 75182 Uppsala, SWEDEN, Phone: +46 181642 01, E-mail: marianne.eriksson@eu.pnu.se

Dr ULRICH ESSIG, Roche Diagnostics GmbH, Nonnewald 2, 82372 Penzberg, GERMANY, Phone: +49 885660 3336, E-mail: ulrich.essig@ roche.com

Dr SANDINO ESTRADA-MONDACA, Institute of Biotechnology UNAM, Av Universidad 2001 Chamilpa, 62210 Cuernavaca, MEXICO, Phone: 5273291617 , E-mail: sanidno@ibt.unam.mx

Dr KAREN ETCHBERGER, JRH Biosciences, 13804 West 107 th Street, 66215 Lenexa, Kansas, USA, Phone: 19134695580

Dr MARINA ETCHEVERRIGARAY, Universidad Nacional del Litoral, Santa Fe 3000, Provincia de Santa Fe, ARGENTINA, Phone: +54 3424575 214, E-mail: marina@fbcb.unl.edu.ar

Dr MARKUS EWERT, GERMANY, Phone: +49 89740 1650, E-mail: ewert@biogene.de Dr OUZIEL EZRA, Interpharm Laboratories Ltd, Science-Based Industrial Park, IL76110 Ness-Ziona, ISRAEL, Phone: 009728 9382657, E-mail: ezra.ouziel.il-throse.com

Dr DIRK FACIUS, PRIOR Separations Technology GmbH, VWP, A-6840 Götzis, AUSTRIA, Phone: 433523521 060, E-mail: marketing@ @ priorsep.com

Mr JASON FATINI, Biovest International, 22A Roehampton Drive, Merseyside L23 7XD, UNITED KINGDOM, Phone: +44 1519245351

RODOLFO FEDELHO, Lotemento Agrotuela, Loteb Subcave esquerda, 5300 Braganca, PORTUGAL

Mr CHARLES FELIX, FRANCE, Phone: +33 4727230 00, E-mail:

charles.felix@merial.com

Dr CHRISTEL FENGE, Astra Zeneca, Building 841, 15185 Södertälje, SWEDEN, 
Phone: +46 8552549 93, E-mail: christel.fenge@astrazeneca.com

Mr RICHARD FESTEN, JRH Biosciences, 13804 West 107 th Street, 66215 Lenexa, Kansas, USA, Phone: 19134695 580, E-mail: cwempe@jrhbio.com

Dr HOLGER FEURER, SSS Rütten Engineering AG, Industriestrasse 9, CH-8712 Stäfa, SWITZERLAND, Phone: 4119282930

Ms WENDY FILSELL, Unilever Research, Colworth House Sharnbrook, MK44 ILQ Bedford, UNITED KINGDOM, E-mail: wendy.filsell@unilever.com

Mr DAVID FIORENTINI, Biological Industries Ltd, Kibbutz Beil, 25115 Haemek, ISRAEL, Phone: +972 4996 0595, E-mail: bioind@inter.net.il

Ms IVANA FISMOLOVA, Institute of Experimental Botany, Videnska 1083, CZ-142 20 Prague 4, CZECH REPUBLIC, Phone: +420 24752 636, E-mail: ivana@ biomed.cas.cz

Mr INGO FOCKEN, Aventis Pharma Deutschland GmbH, Building H 825, 65926 Frankfurt am Main, GERMANY, Phone: +49 69305 42602, E-mail: ingo.focken@aventis.com

Prof RAISSA FODEHERNYAEVA, Inovsky Institute of Virology, Gamaleya Str. m, RUS-123 098 Moscow, RUSSIA, Phone: +7 951902870

Mr ANDREW FORD, Corning Life Sciences, Gordon Road, High Wycombe HP13 6EQ Blick, UNITED KINGDOM, Phone: 441494684 703, E-mail: allenj@london.corning.com

Dr SEAN FORESTELL, Genetic Therapy, 9 W. Watkins Mill Road, 20878 Gaithersburg, USA, Phone: 13012584630

Mr BJOERN FRAHM, Technical University Hamburg-Harburg, Denickestrasse 15, 21071 Hamburg, GERMANY, Phone: +49 404287 84061, E-mail: b.frahm@tu-harburg.de

JOHANN FRAIN, Marketing Communication Manager, Life Technologies, 3 Fountain Drive, Inchinnan Business Park, UNITED KINGDOM, Phone: 441418146 108, E-mail: frainj@1418146287

Dr FRANTISEK FRANEK, Institute of Experimental Botany, Radiova 1, CZ-10227 Praha 10, CZECH REPUBLIC, Phone: +420 2475 2121, E-mail: franek@biomed.cas.cz

Mrs HEIKE FRANKL, B. Braun Biotech International GmbH, Schwarzenberger Weg 73-79, 34212 Melsungen, GERMANY, Phone: +49 566171 3400, E-mail: heike.frankl@bioscipro.com

Dr ELISABETH FRAUNE, B. Braun Biotech International GmbH, Schwarzenberger Weg 73-79, 34212 Melsungen, GERMANY, Phone: +49 5661713400

Mr JAN-GERD FRERICHS, University of Hannover, Callinstrasse 3, 30167 Hannover, GERMANY, Phone: 495117622 381,E-mail: frerichs@iftc.uni-hannover.de

Dr STEPHEN FROUD, Lonza Biologics, 224 Bath Road, SLI 4DY Slough, UNITED KINGDOM, Phone: 9441753716 643, E-mail: sfroud@lonza.co.uk

Mr RICHARD FRY, Cellon SA, 2021 Ronie Argon, L8010 Strassen, LUXEMBURG, 
Phone: 352312 313,E-mail: cellon@gms.lu

Mr TSUKASA FUJIKI, Kyushu University, 6-10-1 Hakozaki Higashi-ku, 812-8581 Fukuoka, JAPAN, Phone: 926423 050, E-mail: tfujiki@grt.kyushu-u.ac.jp

Mr JIM FUREY, Biotech-IgG A/S, Østerbrogade 95, DK-2100 Copenhagen, DENMARK

Dr MARTIN FUSSENEGGER, Institute of Biotechnology, ETH Hoenggerberg, HTP, CH-8093 Zurich, SWITZERLAND, Phone: +41 1633 34 48, E-mail:

fussenegger@biotech.biol.ethz.ch

Mrs TRACEY GAGER, Glaxo SmithKline, New Frontiers Science Park North, 3rd Av, CM19 5AW Harlow, UNITED KINGDOM, Phone: 441279622 000, E-mail: Tracey_Gager-1@sbphrd.com

Dr GILAD GALLILI, Biological Laboratories Teva, (ABICVET), P.O. Box 27047, 97800 Jerusalem, ISRAEL, Phone: +972 258485 20, E-mail: gilad.gallili@ teva.co.il

Mrs CATHERINE GARDNER, Moregate TCS Ltd, Botolph Clamdon, NK18 2LR Buckingham, UNITED KINGDOM, Phone: 441296714 555, E-mail:

catherineg@tcsgroup.co.uk

Ms CAROLINE GARRISON, JRH Biosciences, 13804 West 107 th Street, 66215 Lenexa, Kansas, USA, Phone: 19134695 580, E-mail: cwempe@jrhbio.com

Ms CHRISTINE GAUCHER, LFB, 3 Avenue des Tropiques BP 305, Les Ulis 91958 Courtab Euf Cedex, FRANCE, Phone: +33 320494583

Dr MARTIN GAWLITZEK, Genentech, Inc., 1 DNA Way, 94080 South San Francisco, CA, USA, Phone: 16502258 869, E-mail: gawlitzek.martin@gene.com

Dr ROBERT GAY, University of New South Wales, 34 Chiswick Court, Moss Lane, HA5 3AP Pinger, Middlesex, UNITED KINGDOM, Phone: +44 20886646 28, E-mail: robert_gay@yahoo.com

Mr ROBERT D GAY, AUSTRALIA, Phone: +61 29385 3869, E-mail: r.gay @unsw.edu.au

Dr FRANCOIS GEERAERTS, Amersham Pharmacia Biotech, Plankstraat 28, B-2800 Mechelen, BELGIUM, Phone: +32 4754833 04, E-mail:

francois.geeraerts@eu.apbiotech.com

Dr SABINE GEISSE, Novartis Pharma Research, CH-4002 Basel, SWITZERLAND, Phone: +41 61324 8274, E-mail: sabine.geisse@pharma.novartis.com

Dr DETLEF GELEICK, Ludwig Institute for Cancer Research, Austin \& Repariation Medical Centre, 3084 Heidelberg, AUSTRALIA, Phone: +61 39496 5463, E-mail: detlef.geleick@ludwig.edu.au

Dr YVONNE GENZEL, Max-Planck-Institute Magdeburg, Leipziger Str. 44, 39120 Magdeburg, GERMANY, Phone: +49 6117-571, E-mail: genzel@mpi-magdeburg.mpg.de

Dr DONALD GERSON, Acambis Inc., 38 Sidney Street, Cambridge 02139, USA, Phone: 16174941 339, E-mail: don.gerson@acambis.com 
Dr STEVE GIBSON, Q-One Biotech Ltd, West of ScotlanScience Park, Glasgow G20 0XA, UNITED KINGDOM, Phone: 441419469 999, E-mail: sgibson@q-one.co.uk

CYRILLE GIMENEZ, Aventis Pasteur, 1541 Av. Marcel Mérieux, 69280 Marcy l'Etoile, FRANCE, Phone: +33 437379112 E-mail: cyrille.gimenez@aventis.com

Mr PHILIPPE GIRARD, Ecole Polytechnique Fédérale, CH-1015 Lausanne, SWITZERLAND, Phone: +41 2169361 45, E-mail: philippe.girard@epfl.ch

Ms CHRISTINE GJERDRUM, UniTargetingResearch AS, NORWAY, Phone: +47 5558 64 37, E-mail: christine@gjerdrum.com

Dr CRISTINA GLAD, BioInvent Production, 22370 Lund, SWEDEN, Phone: +46 46 286 8550, E-mail: cristina.glad@bioinvent.se

Dr BERND GLAUNER, Schärfe System GmbH, Krämerstrasse 22, 72764 Reutlingen, GERMANY, Phone: 497121387 860, E-mail: mail@casy-technology.com

Dr CHRIS GODDARD, Gropep Limited, P.O. Box 10065, SA 5000 Adelaide, AUSTRALIA, Phone: 6188354 7705, E-mail: chris.goddard@gropep.com.au

Prof FRANCESC GODIA, Universitat Autonona De Barcelona, Dellaterra 08193 (Barcelona), SPAIN, Phone: +34 93581 2692, E-mail: francesc.godia@uab.es

Ms FIONA GODSMAN, Q-One Biotech Ltd, West of Scotland Science Park, Glasgow G20 G20 0XA, UNITED KINGDOM, Phone: 441419469 999, E-mail: fgodsman@qone.co.uk

Dr JEAN LOUIS GOERGEN, LSGC - CNRS, 2 Avenue de la Foret De Haye, 54500 Vandoeuvre, FRANCE, Phone: +33 3835958 44, E-mail: goergen@ensaia.inpl-nancy.fr

Mr ALEXANDER GOETC, Greiner Bio-One GmbH, Maybachstrasse 2, 72636 Frickenhausen, GERMANY, Phone: 4970229 480, E-mail: Info@greiner-lab.de

Dr RANDAL A GOFFE, Genespan Corp., 19310 N Creek PKWY Suite 100, WA 98011 - 9331 Bothell, USA, Phone: 14254823 003, E-mail: exec@genespan.com

Mr MERLIN GOLDMAN, Seriologicals, Fleming Road, LIVINGSTON EH54 7BN, UNITED KINGDOM, Phone: 441316614 287, E-mail: mhgoldman@binternet.com

Dr VIKTOR GOLOVACHENKO, Zao Alkor-Bio, 70/4 Leningradskaya Str, 189650 Saint-Petersburg, RUSSIA, Phone: 78124375 154, E-mail: alkorbio@ peterlink.ru

Dr SIGRID GONSKI, Aventis Pharma Deutschland GmbH, Building H 825, 65926 Frankfurt am Main, GERMANY, Phone: +49 69305 2761, E-mail: sigrid.gonski@aventis.com

Mr HAROLD GONZALEZ, BioMarin Pharmaceutical, 46 C Alli Dr, 94949 Novato, USA, Phone: 14158846 750, E-mail: ltnesqaol.com

Dr MARGARET GOODALL, The Medical School, Vincent Drive, B15 2TT Birmingham, UNITED KINGDOM, Phone: 441214146839

Mr ROEL GORDIJN, Bio Whittaker Europe, Parc Industriel de Petit Rech., B-4800 Vervuis, BELGIUM, Phone: +32 87321 611, E-mail: roel.gordyn@cambrex.com 
Mr GÉRARD GOURDON, Applikon, FRANCE, Phone: +33 1349299 99, E-mail: applikon@applikon.fr

Dr BRENDAN GRABAU, AUSTRALIA, Phone: +61 39482 0522, E-mail: bjg@bigpond.net.au

Prof ROLAND GRAFSTRÖM, Karolinska Institutet, P.O. Box 210, 17177 Stockholm, SWEDEN, Phone: 4683012 03, E-mail: roland.grafstrom@imm.ki.se

Dr JENS GRAM, CMC Biotech A/S, Nybrovej 136, DK2800 Kgs Lyngby, DENMARK, Phone: +45 29488 407, E-mail: jg@cmcbiotech.com

Dr STEPHANOS GRAMMATIKOS, Boehringer Ingelheim Pharma KG, Birkendorfer Strasse 65, 88397 Biberach, GERMANY, Phone: 4917351544 022, E-mail: stefanos.grammatikos@bc.boehringer-ingelheim.com

Mr DOUG GRAY, JRH Biosciences, 13804 West 107 th Street, 66215 Lenexa, Kansas, USA, Phone: 19134695 580, E-mail: cwempe@jrhbio.com

$\mathrm{Mr}$ ANDRE GREBE, B. Braun Biotech International GmbH, Schwarzenberger Weg 73-79, 34212 Melsungen, GERMANY, Phone: +49 566171 3400, E-mail: andre.grebe@bioscipro.com

Dr BRYAN GRIFFITHS, Esact Secreteriat, Salisbury, UNITED KINGDOM, Phone: 441 980610 405, E-mail: jbgriffiths@ compuserve.com

Ms PHILIPPE GRIMM, Q-One Biotech Ltd, West of ScotlanScience Park, Glasgow G20 0XA, UNITED KINGDOM, Phone: 441419469 999, E-mail: pgrimm@q-one.co.uk

Mr RENE GROENEWOUD, THE NETHERLANDS, E-mail:

groenewor@amsterdam.corning.com

Mr LARS A GRORUD, BioExchange, 758 Clementina, San Francisco, CA 94103, USA, Phone: 18883207090 ext 407, E-mail: lars@ bioexchange.com

Mr FREDERIC GROSJEAN, Ecole Polytechnique Fédérale, CH-1015 Lausanne, SWITZERLAND, Phone: +41 2169355 42, E-mail: frederic.grosjean@epfl.ch

Mr TIM GRYSEELS, Pfizer Inc., Eastern Point Road, Groton 06339, USA, Phone: 18604 411 945, E-mail: timothy_d_gryseels@groton.pfizer.com

Dr HUGH GUAN, School of Clinical Dentistry, Claremont Crescent, Sheffield S10 2TA, UNITED KINGDOM, Phone: 441142717 974, E-mail: y.h.guan@sheffield.ac.uk

Dr FRANK GUDERMANN, Innovatis GmbH, Meissenstrasse 96, 33607 Bielefeld, GERMANY, Phone: 495212997 287, E-mail: info@innovatis.com

Dr FRÉDÉRIQUE GUETTE, Sanofi Synthélabo Recherche, Labége Innopole BP 137, F-31676 Labege Cedex, FRANCE, Phone: +33 5610040 30, E-mail:

frederique.guette@sanofi.com

Dr SUNIL GUPTA, GlaxoSmithKline, 709 Swedeland Road MCCD UE, 3836, King of Prussia PA 19406, USA, Phone: 16102707 111, E-mail: sunil-2-gupta@gsk.com 
MARGIT HAAHR HANSEN, Pd.d., Symphogen A/S, Elektrovej, bldg 375, 2, DK-2800 Lyngby, DENMARK, Phone: +45 452650 57, E-mail: margit@symphogen.com

Dr ULI HACKSELL, Acadia Pharmaceuticals Inc., 3911 Sorrento Valley Boulevard, 921 21 San Diego, USA, Phone: 18585582 871, E-mail: uhacksell

Dr ANDERS HAEGERSTRAND, Neuronova AB, Fiskartorpsvägen 15A, 11433 Stockholm, SWEDEN, Phone: +46 878609 01, E-mail: ander.haegerstrand@nerunova.com

Mr PAUL HAFFENDEN, Terracell International SA, P.O. Box 250, Nobleton LOG INO Ontario, CANADA, Phone: 19058594 991, E-mail: pcansera@inform.net

Prof Dr MATHIAS HAFNER, Mannheim University of Applied Sciences, Windeckstrasse 110, D-68163 Mannheim, GERMANY, Phone: 496212926 538, E-mail: m.hafner@fhmannheim.de

Mr JOHAN HÄGGBLAD, Neuronova AB, Fiskartorpsvägen 15A, 11433 Stockholm, SWEDEN, Phone: 070-668 06 44, E-mail: johan.haggblad@neuronova.com

Prof LENA HÄGGSTRÖM, Royal Institute of Technology, 10044 Stockholm, SWEDEN, Phone: +46879091 65, E-mail: lenah@ biotech.kth.se

Mr ROMAN HÁK, Patent Attorney, Pristavni 24, 17000 Prague 7, CZECH REPUBLIC, Phone: +42 0266710 172, E-mail: hak@thk.cz

CHRISTOPHER HALL, Pall, Europa House, Havant Street, P01 3PD Portsmouth, UNITED KINGDOM, Phone: 4402392303303

Mr ERIK HAMANN, Intervet International BV, P.O. Box 31, 5830 AA Boxmeer, THE NETHERLANDS, Phone: 31485587 182, E-mail: erik.hamann@intervet.com

Ms LING HAN, Royal Institute of Technology, 10044 Stockholm, SWEDEN, E-mail: ling@biotech.kth.mm

Mr JULIAN HANAK, Cobra Therapeutics Limited, The Science Park, ST5 5SP Staffordshire, UNITED KINGDOM, Phone: 441782714 181, E-mail: julian.hanak @ cobrat.com

Dr LOUANE HANN, Genetic Institute, 1 Burtt Road, Andover MA 01810, USA, Phone: 19782472 376, E-mail: lhann@genetics.com

Ms KARIN HANSEN, DENMARK, Phone: +45 461554 40, E-mail:

maltec@mail.danbbs.dk

Mr BRIAN HART, JRH Biosciences, 13804 West 107 th Street, 66215 Lenexa, Kansas, USA, Phone: 19134695 580, E-mail: cwempe@jrhbio.com

Mr RICHARD HART, Covance, 33 Springhill Road, RG8 OBY Goring, UNITED KINGDOM, Phone: 441491875 826, E-mail: richard.hart@ covance.com

Dr TAYMAR HARTMAN, Protein Design Labs, 34801 Campus Drive, 94555 Fremont, USA, Phone: 15105741 400, E-mail: thartman@pdl.com

Dr MARIS HARTMANIS, Gyros AB, Dag Hammarskiölds väg 52, 75183 Uppsala, SWEDEN, Phone: +46 18566 300, E-mail: maris.hartmanis@gyrosmicro.com 
Mr CHRIS HARTOFELIS, Corning Life Sciences, Gordon Road, High Wycombe HP13 6EQ Blick, UNITED KINGDOM

Mr JEFF HARVEY, Guava Technologies Inc, 863 Mitten Road, Burlingame 94010-1303 CA, USA, Phone: 16505520 700, E-mail: jharvey@guavatechnologies.com

Ms LORNA HARVEY, Inveresk Research, Tranent, E Lothian EH33 2NE, UNITED KINGDOM, Phone: 441875618 478, E-mail: lorna.harvey@ inveresk.com

Dr WILLIAM HASELTINE, Human Genome Sciences, 9410 Key West Avenue, Rockville Maryland, USA, Phone: 13013098504

Dr DIANE HATTON, Cambridge Antibody Technology, The Science Park, SG8 6JJ Melbourn, South Cambs, UNITED KINGDOM, Phone: 441763269378 E-mail: emma.dixon@cambridgeantibody.com

Dr JACQUES HATZFELD, CNRS, 7 rue Guy Môquet, F-94801 Villejuif, FRANCE, Phone: +33 1495833 16, E-mail: hatsfeld@infolrogen.fr

Ms KIRSTEN HAUGSETH, Alpharma AS, P.O. Box 158, SKoyen N-0212 Oslo, NORWAY, Phone: +4722529091

Mr HANSJORG HAUSER, GBF, Mascherode weg 1, 38124 Braunschweig, GERMANY, Phone: 495316181 250, E-mail: hha@gbf.de

Prof GABRIELLE HAWKSWORTH, Polwarth Building Forester Hill, Aberdeen AB25 2ZD, UNITED KINGDOM, Phone: 441224552 487, E-mail: g.m.hawksworth@abdn.ac.uk

Mr STEVEN HAWRYLIK, Pfizer Inc., Eastern Point Road, Groton 06339, USA, Phone: 18604415103 E-mail: steven_j_hawrylik@groton.pfizer.com

Mr ANDREW HAYWARD, Biotech-IgG A/S, Østerbrogade 95, DK-2100 Copenhagen, DENMARK

Dr CAROLE HEATH, Immunex Corp., 51 Univeristy Street, Seattle WA 98101, USA, Phone: 12065870 430, E-mail: heathe@immunex.com

Dr RÜDIGER HEIDEMANN, Bayer Corporation, 800 Dwight Way, 94710 Berkeley, USA, Phone: 15107055617

Dr HOLGER HEINE, Serono SA, SPRI, Chemin des Aulx 14, 1228 Plan-les-Ouates, SWITZERLAND, Phone: +41 2270696 66, E-mail: holger.heine@ serono.com

Dr ROBIN HELLER-HARRISON, Genetic Institute, 1 Burtt Road, Andover MA 01810, USA, Phone: 19782471 406, E-mail: rhharrison@genetics.com

Mr HORST HELLWIG, Sigma-Aldrich Sweden AB, Solkraftsvägen 14C 13570 Stockholm, SWEDEN, E-mail: hhellwig@eurnotes.sial.com

Dr HELNA HERMANS, ACTIP Secretariet, P.O. Box 9143, 3007 AC Rotterdam, THE NETHERLANDS

Ms ANNAKAISA HERRALA, University of Oulu, P.O. Box 5000, FIN-90220 Oulu, 
FINLAND, Phone: +358 8 3155636, E-mail: aherrala@ whoccr.oulu.fi

Dr ANDREAS HERRMANN, Cardion AG, Max Plank Strasse 15A, 40699 Erkrath, GERMANY, Phone: 49211205 650, E-mail: herrmann@ casrdion.de

Dr FRIEDEMANN HESSE, German Research Centre for Biotechnology, Mascheroder Weg 1, D-38124 Braunschweig, GERMANY, Phone: 495316181 742, E-mail: fhe@gbf.de

PHILIP HEWITT, Merck GKaA, Frankfurterstrasse 250, 64271 Darmstadt, GERMANY, E-mail: philip.hewitt@merck.de

Ms ULRIKE HILBERT, Institute of Biotechnology 2 Cell Cultur, 52425 Jülich, GERMANY, Phone: +49 246161 2254, E-mail: u.hiubert@fz-juelich.de

\section{Mr FRANK HILBRIG, SWITZERLAND}

Dr WILLIAM HILLEGAS, Solohill Engineering Inc., 4220 Varsity Drive, Ann Arbor Michigan 48108, USA, Phone: 17349732 956, E-mail: solohill@ic.net

Dr ANNA HILLS, Covance, 3301 Kinsman Blvd, P.O. Box 7545, Madison, WI 53704, USA, Phone: 16082422 645, E-mail: tamara.brown@convance.com

Dr NORMA HILTI, Cytos Biotechnol. AG, Wagistrasse 21, CH-8952 Zürich-Schlieren, SWITZERLAND, Phone: +41 173340 35, E-mail: hennecke@cytos.com

MARGARET HIRCOCK, Oxford Glycosciences, Abingdon Science Park, OX11 0BL Oxon, UNITED KINGDOM, Phone: 441235543 200, E-mail:

margaret.hircock@ogs.co.uk

Mr GEOFFREY HODGE, Millennium Pharmaceuticals, 640 Memorial Drive, 02139 Cambridge, Massachusetts, USA, Phone: 16175513 989, E-mail: ghodge@ mpi.com

Mr ANDERS HØIBY, Kendro Laboratory Products GmbH, Heraustrasse 12-14, 63450 Hanau, GERMANY, Phone: +496181 35 3834, E-mail: ykonf@kendro.de

Dr OLLE HOLMQVIST, KHI - Ellco Foods, Box 100, 22651 Kävlinge, SWEDEN, Phone: +46 467228 00, E-mail: olleholmqvist@ hotmail.com

Dr MARGIT HOLZER, Boehringer Ingelheim Pharma KG, Birkendorfer Strasse 65, 88397 Biberach, GERMANY, Phone: 49173515497 916, E-mail: margit.holzer@bc.boehringer-ingelheim.com

Dr MICHAEL HOWALDT, Boehringer Ingelheim Pharma KG, Birkendorfer Strasse 65, 88397 Biberach, GERMANY, Phone: 4973511548 795, E-mail: michael.howaldt@boerhringer.ingelheim.com

Dr ANDREA HOWERKAMP, Innovatis GmbH, Meissenstrasse 96, 33607 Bielefeld, GERMANY, Phone: 495212997 287, E-mail: info@innovatis.com

Dr CYNTHIA HOY, Genentech, Inc., 1 DNA Way, 94080 South San Francisco, CA, USA, Phone: 16502257 412, E-mail: hoyc@gene.com

Dr SYLVIA HU, Amgen Inc., Amgen Center Drive, Thousands Oaks CA 91320, USA, 
Phone: 180564473 322,E-mail: amoore@amgen.com

Dr DIETER F. HÜLSER, Universität Stuttgart, Biophysik, Pfaffenwaldring 57, D-705 50 Stuttgart, GERMANY, Phone: 497116855 002, E-mail: huelser@po.uni-stuttgart.de

Mr STEFAN HULTGREN, Bergman \& Beving Instruments, Box 732, 19427 Upplands Väsby, SWEDEN, Phone: +46 8590988 13, E-mail: stefan.hultgren@bbi.pld.se

HANNELORE HUMMEL, Immeble Paris Sene, 3 aller de la Sene, F-94854 Ivry-SurSene, FRANCE, Phone: 0933149592000

Ms LISA HUNT, Ecole Polytechnique Fédérale, CH-1015 Lausanne, SWITZERLAND, Phone: +41 2169361 52, E-mail: lisa.hunt@epfl.ch

Mr ALISTAIR HURST, Biotech-IgG A/S, Østerbrogade 95, DK-2100 Copenhagen, DENMARK, Phone: 4535380 500, E-mail: ajh @biotech-igg.dk

Ms STEFANIE HUSSMANN, Cardion AG, Max Plank Strasse 15A, 40699 Erkrath, GERMANY, Phone: 49211205 650, E-mail: hussmann@cardion.de

Mr HANS HUTTINGA, Quest International, P.O. Box 21400 CA Bussum, THE NETHERLANDS, Phone: +31 35699 2778, E-mail: hans.huttinga@questintl.com

Dr CHRISTOPHER HWANG, Genzyme, P O Box 9322, Framingham MA 01701-9322 USA, Phone: 15082713 692, E-mail: chris.hwang@genezyme.com

Dr SHIAW-MIN HWANG, TAIWAN, Phone: 886352231 91, E-mail: hsm@ firdi.org.tw Dr NEYSI IBARRA ROQUE, Centro de Ingeneria Genetica y Biotecn., P O Box 6162, Cuidad de la Havana 10600, CUBA

AKIRA ICHIKAWA, JAPAN, Phone: 8133700 9264,E-mail: a_ichika@nihs.go.jp

Mr LAERTIS IKONOMOU, Universite Catholique de Louvain, Place Croix du Sud 2/19, Louvain-la-Neuve B-1348, BELGIUM, Phone: +32 10 473039, E-mail: ikonomon@gebi.ucl.xc.be

Prof KOJI IKURA, Kyoto Institute of Technology, Kyoto 606-8585, JAPAN, Phone: +81 75724 7535, E-mail: ikura@ipc.kit.ac.jp

Dr BEVERLY INGRAM, GlaxoSmithKline, Sout Eden Park, Beckenham BR 3 3BS, UNITED KINGDOM, Phone: 4402086396 607, E-mail: bi66873@ glaxowellcome.co.uk

Dr YUICHI INOUE, Kagoshima University, 1-21-24 Korimoto, 890-0065 Kagoshima, JAPAN, Phone: +81 99285 8651, E-mail: inoue@ chem.agri.kagoshima-u.ac.jp

Dr NOUSHIN IRANI, Boehringer Ingelheim Pharma KG, Birkendorfer Strasse 65, 88397 Biberach, GERMANY, Phone: +497351 544801

Mr TOM IRISH, Amsterdam Molecular Therapeutics, Meibergdreef 61, 1105BA Amsterdam, THE NETHERLANDS, Phone: +31 20566 7394, E-mail: info@amtbv.com

Dr ATSUSHI ISOAI, Asahi Glass Co. Ltd, 1150 Hazawa, Kanagawa, 221-8755 Yokohama, JAPAN, Phone: +81 45374 8722, E-mail: aisoai@agc.co.jp 
Mr MALTE JACOBSEN, DENMARK, Phone: +45 461554 40, E-mail:

maltec@mail.danbbs.dk

\section{LOTTA JACOBSSON, SWEDEN}

Dr VOLKER JÄGER, GBF, Mascherode weg 1, 38124 Braunschweig, GERMANY, Phone: 495316181 102, E-mail: vja@gbf.de

Ms IRMA JANSSON, AstraZeneca, Bgn 841, 15185 Södertälje, SWEDEN, Phone: +46 855251677 , E-mail: irma.jansson@astrazeneca.com

OLOF JANTZE, Invitro Sweden AB, SWEDEN

Dr DAVID JAYME, Life Technologies, 3175 Staley Road, Grand Island, NY 14072, USA, Phone: 17167746 771, E-mail: djayme@lifetech.com

Ms LISE MALENE JENSEN, Medi-Cult A/S, Moellehaven 12, 4040 Jyllinge, DENMARK, Phone: +45 467902 00, E-mail: lmj@medi-cult.dk

Mr YEANTAE JEONG, Kaist, 373-1 Kusong-Dong Yusong-gu, 305-701 Taejon, KOREA, Phone: +82 42869 2654, E-mail: ytjeong@kaist.ac.kr

KIM JINSAN, KOREA, Phone: +82 2772 1745, E-mail: jsOkim@ @amsung.co.kr

Dr EUI-CHEOL JO, Research Center for Biologics, KOREA, E-mail:

ejco@www.kgcc.co.kr

\section{ANNELIE JOHANSSON, SWEDEN}

Dr HELENA JOHANSSON, BioInvent Production, 22370 Lund, SWEDEN, Phone: +46 4628685 50, E-mail: hje@bioinvent.com

Mr MARCUS JOHANSSON, Amersham Pharmacia Biotech AB, Björkgatan 30, 75184 UPPSALA, SWEDEN

Mr PETER JOHANSSON, BioInvent Prod. AB, 22370 Lund, SWEDEN, Phone: + 4646 28686 50, E-mail: pje.bioinvent.com

Mrs ANITA JOHNSSON, KUNGSBACKA, Phone: 0300316 36, E-mail: info@ccoatechlab.se

Dr DAVID JONES, Crucell BV, P.O. Box 2048, 2301 CA Leiden, THE NETHERLANDS, Phone: 31815248 701, E-mail: d.jones@crucell.com

Ms ROSE-MARIE JÖNSSON, Pharmacia Diagnostics AB, Rapsgatan 7, 75182 Uppsala, SWEDEN, Phone: +46181636 30, E-mail: rose-marie.jonsson@eu.pnu.com

Dr MARTIN JORDAN, Ecole Polytechnique Fédérale, CH-1015 Lausanne, SWITZERLAND, Phone: 412169361 52, E-mail: martin.jordan@epfl.ch

Ms ANNETTE JØRGENSEN, Novo Nordisk A/S, Hagedornsvej 1, DK-2820 Gentofte, DENMARK, Phone: +45 444302 38, E-mail: annj@novonordisk.com

Miss PAULA JUDGE, GlaxoSmithKline R\&D, Gunnels Wood Road, Stevenage, Herts SG1 2NY, UNITED KINGDOM, Phone: 441438763 767, E-mail: pmj33147@gsk.com 
CHRISTIAN JULIEN, NBS Co. Inc., P.O. Box 4005, Edison NJ 08818-4005, USA, Phone: +1 7322871200 x2117, E-mail: cjulien@nbsc.com

Dr MARTINA KAHL, Greiner Bio-One GmbH, Maybachstrasse 2, 72636 Frickenhausen, GERMANY, Phone: 497022948 500, E-mail: info@greiner-lab.de

Dr DIRK KAISER, CytoTools GmbH, Petersenstrasse 22, 64287 Darmstadt, GERMANY, Phone: 496151162 175, E-mail: cyto@pop.tu-darmstadt.de

Mr ERIK KAKES, Applikon B.V., P.O. Box 149, 3100 AC Schiedam, THE NETHERLANDS, Phone: +31 102983 576, E-mail: eza@applikon.com

Dr HÉLA KALLEL, Institut Pasteur, 13, Place Pasteur, BP 74, 1002 Tunis, TUNISIA, Phone: 2161848 903, E-mail: hela.kallel@pasteur.rns.tn

Dr ROBERT KALLMEIER, Lonza Biologics, 224 Bath Road, SLI 4DY Slough, UNITED KINGDOM, Phone: 441753716 518, E-mail: rkallmeier@lonza.co.uk

Ms ULLA KÄLLSTRÖM, Pharmacia AB Division Biovitrum, Strandbergsgatan 49, 112 87 Stockholm, SWEDEN, Phone: +46 869727 16, E-mail: ulla.kallstrom @ biovitrum.com

Dr YURO KAMEI, Saga University, 152-1 Shonan-cho, Karatsu, 847-0021 Saga, JAPAN, Phone: +81 95577 4484, E-mail: kameiy@cc.saga-u.ac.jp

Dr GUSTAV KAMPERMAN, Pharmacia, Strandbergsgatan 47, 11287 Stockholm, SWEDEN, E-mail: gustav.kamperman@eu.pnu.com

Mr ARI KANTTINEN, Astra Zeneca, 15185 Södertälje, SWEDEN, Phone: +46 8552 512 08, E-mail: ari.kanttinen@ astrazeneca.com

Dr HERWIG KAPELLER, Biochemie GmbH, Biochemiestrasse 10, A-6250 Kundl, AUSTRIA, Phone: 4353382002 617, E-mail: herwig.kapeller@gx.novartis.com

\section{PELLE KARLSSON}

ANDERS KARLSTRÖM, Astra Zeneca, Building 841, 15185 Södertälje, SWEDEN, Phone: +46 8552557 30, E-mail: anders.karlstrom@astrazeneca.com

Dr CORNELIA KASPER, Institut für Technische Chemie, Callinstrasse 3, 30167 Hannover, GERMANY, Phone: 495117622 967, E-mail: kasper@iftc.uni-hannover.de

Mr JOHN KASTRUP, Bie \& Berntsen AS, Sandbaekvej 7, DK-2610 Rödovre, DENMARK, Phone: +45 449488 22, E-mail: jk@bie-berntsen-as.dk

Prof HERMANN KATINGER, Institute of Applied Microbiology, Muthgasse 18, A-1190 Vienna, AUSTRIA, Phone: +43 136006 6202, E-mail: office@iam.boku.ac.at

Dr HIROHARU KAWAHARA, Kitakyushu Nat. College of Technology, 5-20-1 Shii Kokuraminami-ku, Kitakyushu 802-0985, JAPAN, Phone: +81 93964 7249, E-mail: hk128@kct.ac.jp

Mr TAKAESHI KAWAHARA, Kyushu University, 6-10-1 Hakozaki Higashi-ku, 8128581 Fukuoka, JAPAN, Phone: 926423 050, E-mail: kawahara@grt.kyushu-u.ac.jp 
Mr TIMO KEIJZER, AppliSens, P.O. Box 149, 3100 AC Schiedam THE NETHERLANDS, Phone: +31 1029835 55, E-mail: tke@applikon.com

Dr WOLFGANG KEMMERLING, Life Technologies, Inchinnan Business Park, Paisle, Paisley PA4 9RF, UNITED KINGDOM, Phone: 441418146129

Dr RICHARD KEMP, Inst. of Biological Sciences, Aberystwylt, S423 3 DA WALES, UNITED KINGDOM, Phone: 441970622 333, E-mail: rbk@aber.ac.uk

Ms JULIE KERBY, Merck Sharp \& Dohme, Eastwick Road, Harlow CM20 2QR, UNITED KINGDOM, Phone: 44279440 547, E-mail: j_kerby@ merck.com

Ms INA KERKLOH, Dasgip mbH, Rudolf-Schulten-Strasse 5, 52428 Juelich, GERMANY, Phone: 492461690 650, E-mail: i.kerkloh@dasgip.de

Ms NICOLE KESSLER, Bio Whittaker Europe, Parc Industriel de Petit Rech., B-4800 Vervuis, BELGIUM, Phone: +32 8732 1611, E-mail: kessler@ rockefeller.univ-lyonl.fr

Mr THOMAS KESSLER, Serologicals Proteins Inc, 195 West Birch Street, Kanakaee IL 60901, USA, Phone: 4418159378270

Mr KEN KETLEY, JRH Biosciences, 13804 West 107 th Street, 66215 Lenexa, Kansas, USA, Phone: 19134695 580, E-mail: cwempe@jrhbio.com

ALEXANDER N. KHOKHLOV, Moscow State University, P.O. Box 24, Moscow 117465, RUSSIA, E-mail: khokhlov@gerontol.bio.msu.su

Mr IK-HWAN KIM, Grad. School Biotechnol, 5-1 Anam, Sungbuk, 136-701 Seoul, KOREA, Phone: 008223290 3447, E-mail: ihkkim@mail.korea.ac.kr

Prof LINDA KING, School of BMS Oxford Brookes University, Gipsy Lane Campus, OX3 0BP Oxford, UNITED KINGDOM, Phone: 441865483 288, E-mail:

laking@brookes.ac.uk

Mr ROBERT KING, Perbio Science AB, 862 Milestone Drive, 84335 Smithfield, Utah, USA, Phone: +1 43575749 27, E-mail: robert.king@perbio.com

Mr FRANCOIS KISLIG, Serono, Zone Industrielle, CH 1267 Coinsins, SWITZERLAND, Phone: +41 21923 2274, E-mail: marie-louise.damiens@serono.com

Dr TATIANA KISLYAKOVA, Institute of Cytology, 4 Tikhoretsky av, 194064 SaintPetersburg, RUSSIA, Phone: 78122473 793, E-mail: tkis@chromo.lgu.spb.su

Mr TOMAS KJELSSON, Applikon B.V., P.O. Box 149, 3100 AC Schiedam, THE NETHERLANDS, Phone: 31102983 576, E-mail: eza@applikon.com

GERHARD KLEMENT, Director, Laboratories Serono SA, Zone Industrielle B, 1809 Fenil-Corsier, CH-1809 Fenil-Corsier, SWITZERLAND, Phone: +41 2923 22 22, E-mail: gerhard.klement@serono.com

Ms PETRA KLINGBERG-PERSSON, BioInvent Production, 22370 Lund, SWEDEN, Phone: 046-286 85 61, E-mail: pkp@bioinvent.se

Dr CLAUDIA KLOTH, Medarex, Inc, 1545 Rt 22 East, NJ 08801 Annandale, USA, 
Phone: 9087136000 ,E-mail: claudia.kloth@gmx.net

MIOMIR KNEZEVIC, Educell d.o.o., Teslova 30, SI-1111 Ljubljana, SLOVENIA, Phone: 3866117767 16, E-mail: mio.knezevic@guest.arnes.si

Dr HEIKE KNOESS, Maingen Biotechnologie GmbH, Weismüllerstrasse 45, 60314 Frankfurt am Main, GERMANY, Phone: +49 694001 1245, E-mail: heike.knoess@maingen.de

Ms ISABELLE KNOTT, GlaxoSmithKline Biologicals s.a., rue de l'Institut 89, 1330 Rixensart, BELGIUM, Phone: +32 265692 26, E-mail: isabelle.knott@gskbio.com

Dr STEFAN KOCH, Roche Diagnostics GmbH, Nonnewald 2, 82372 Penzberg, GERMANY, Phone: 498856602 164, E-mail: stefan.koch@roche.com

MICHEL KOEHL, Transgene SA, 11 rue de Molsheim, F-67082 Strasbourg-Cedex, FRANCE, Phone: +33 3882791 00, E-mail: koehl@transgene.fr

Mr FLORIAN KOELLE, Molecular Devices, Gutenbergsstrasse 10, G-Ismaning 85737, GERMANY, Phone: 0094383862023 40, E-mail: flroian.koelle@moldev.de

Ms OLGA KOLOKOLTSOVA, Srevb Vector, Koltsovo, Novosibirsk Region 630559 , RUSSIA, E-mail: kolokolt@mail.ru

Dr TAMARA D KOLOKOLTSOVA, State Research Center Vector, Koltsovo, 630559 Novosibirsk Region, RUSSIA, Phone: 009713832366 481, E-mail: vector@ vector.nsk.su

Mr TAKAAKI KOMATSU, Kyushu University, 6-10-1 Hakozaki Higashi-ku, 812-8581 Fukuoka, JAPAN, Phone: +81 92642 3050, E-mail: komatsu @ grt.kyushu-u.ac.jp

DHINAKAR KOMPALA, University of Colorado, 80309-04234 Boulder, USA, Phone: 13034926350 , E-mail: kompala@colorado.edu

Dr LEIF KONGERSLEV, NatImmune A/S, Fruebjergvej 3, Box 3, DK 2100 Copenhagen, DENMARK, Phone: 4539169 431, E-mail: lko@natimmune.dk

Dr KONSTANTIN KONSTANTINOV, Bayer Corporation, 800 Dwight way/P.O. Box 1986, 94710 Berkeley, California, USA, Phone: 15107057 237, E-mail: konstantin.konstantinov.b@bayer.com

Dr CHRISTOF KÖRNER, MediGene AG, Lochhamer Str. 11, D-82152 Martinsried, GERMANY, Phone: +49 89895632 32, E-mail: christof.koerner@medigene.de

Mr KNUT KOTARSKY, Lund University, Tornavägen 10, 22184 Lund, SWEDEN, Phone: +4622 20 585, E-mail: knut.kotarsky@mphy.lu.se

Dr GENEVIEVE KRACK, Baxter R\&D Europe, 7 rue du Progrès, B-1400 Nivelles, BELGIUM, Phone: +32 67882 481, E-mail: krackg@baxter.com

Ms JUDY KRAMER, The Automation Partnership, York Way, SG8 5WY Royston, UNITED KINGDOM, Phone: 441763227216

Ms DANIELLA KRANJAC, Wave Biotech, 2493 Lamington Road, 07921 Bedminster, NJ, USA, Phone: 19087815 757, E-mail: info@wavebiotech.com 
Ms METKA KRASNA, Educell d.o.o., Teslova 30, SI-1111 Ljubljana, SLOVENIA, Phone: 386015438 176, E-mail: m.krasna@educell.com

Dr RICARDO KRATJE, Universidad Nacional del Litoral, Santa Fe 3000, Provincia de Santa Fe, ARGENTINA, Phone: +54 3424575 214, E-mail: rkratje@fbcb.unl.edu.ar

Mr KARL KREIJ, IFM/Teknisk Biologi, 58183 Linköping, SWEDEN, Phone: +46 813 288 934, E-mail: kakre@ifm.liu.se

Dr RAJESH KRISHNAN, Pfizer Inc., Buildning 126/212 A, Eastern Point Road, 06340 Groton, Connecticut, USA, Phone: 18607151 289, E-mail: rajesh_krishnan@groton.pfizer.com

Mr TOM KRISTENSEN, NatImmune A/S, Fruebjergvej 3, Box 3, DK 2100 Copenhagen, DENMARK, Phone: 4539169 435, E-mail: tkr@natimmune.dk

Dr BERND KRUEGER, Sigma-Aldrich Chemie GMBH, Grünwalder Weg 30, D-82041 Deisenhofen, GERMANY

Dr BERND KRÜGER, Sigma-Aldrich Sweden AB, Solkraftsvägen 14C, 13570 Stockholm, SWEDEN, Phone: +46 874242 00, E-mail: bkreuger@eirnotes.siac.com

Dr KURT KRUMMEN, Novartis Pharma AG, WSJ 360 1404, 4002 Basel, SWITZERLAND, Phone: 0094161324 6394, E-mail: kurt.krummen@pharma.novartis.com

Mr MARKUS KÜHNER, Adolg Kühner AG, Dinkelbergs starsse 1, 4127 Birsfelden, SWITZERLAND, Phone: 0094161319 9393, E-mail: mkuhner@kuhner.com

SUNIL KUMAR, Cochin School of Science \& Tech., Fine Art Avenue, Cochin 682 186, INDIA, Phone: 91484381 120, E-mail: sunilses@ hotmail.com

Dr RENATE KUNERT, Polymun Scientific, Nussdorfer laende 11, A 1190 Vienna, AUSTRIA, Phone: +43 136006 6595, E-mail: r.kunert@iam.boku.ac.at

Dr RIITTA KURKELA, University of Oulu, P.O. Box 5000, FIN-90220 Oulu, FINLAND, Phone: +358 8315 5637, E-mail: rkurkela@ whoccr.oulu.fi

Dr SANJAY LAKHOTIA, Aviron, 297 No Bernardo Avenue, Mountain View 94043, USA, Phone: 16509191 276, E-mail: slakhotia@aviron.com

Ms RENATE LAMBERTI, Cell Culture Technologies GmbH, Buhnrain 14, CH-8052 Zurich, SWITZERLAND, Phone: +41 1301 2008, E-mail: info@cellculture.com

Dr DAMIEN LAMOTTE, Diaclone S.A., BP 1385, FR-25020 Besancon, FRANCE, Phone: +33 381413838 , E-mail: dlamotte@ diaclone.com

Mr KARLHEINZ LANDAUER, Institute of Applied Microbiology, Muthgasse 18, 1190 Vienna, AUSTRIA, Phone: +43 1360066 557, E-mail: landaeur@edv2.boku.ac.at

Mr MOSHE LANDSBERG, ISRAEL, Phone: +792 8940 2612, E-mail: moselan@internet.zahav.net.il

Dr ROBERT LANGER, Mass. Inst. of Technology, 45 Carleton Street E25-342, 02139 Cambridge, MA, USA, Phone: 16172533 107, E-mail: rlanger@mit.edu 
Dr UWE LANGER, Bayer AG, PS-Bildung Fortbildung LEV, Gebäude 9426, 51368 Leverkusen, GERMANY, Phone: +49 202367531

Mrs ANETTE LARSEN, Bio-Image A/S, Moerkhoej 28, 2860 Soeberg, DENMARK, Phone: +4544437522

Ms MERETHE LARSEN, Medi-Cult A/S, Moellehaven 12, 4040 Jyllinge, DENMARK, Phone: +45 467902 00, E-mail: merethe.larsson@medi-cult.dk

Dr LARS-JOHAN LARSSON, Amersham Pharmacia Biotech, P.O. Box 1327, 088551327 Piscataway, New Jersey, USA, Phone: 17329802 987, E-mail:

lars-johan.larsson@am.apbiotech.com

Dr EVA LAUSSERMAIR, Q-One Biotech Ltd, West of ScotlanScience Park, Glasgow G20 0XA, UNITED KINGDOM, Phone: 441419469 999, E-mail:

elaussermair@q-one.co.uk

Dr ARYE LAZAR, Israel Inst. for Biological Research, P.O. Box 19, 70410 Ness-Ziona, ISRAEL, Phone: +972 89381 1485, E-mail: lazar@ubr.gov.il

Mr JEAN-PIERRE LEDIG, Sanofi Synthelabo, 16, rue d'Ankara, 67080 Strasbourg, FRANCE, Phone: 330388454 155, E-mail: jean-pierre.ledig@ @anofi-synthelabo.com

Dr CHANYOUNG LEE, Merck \& Co. Inc., P.O. Box 2000, Rahway NJ 07090, USA, Phone: 17325941 193, E-mail: chanyoung_lee@merck.com

Dr GENE LEE, Genetic Institute, 1 Burtt Road, Andover MA 01810, USA, Phone: 19782 471 963, E-mail: gwlee@genetics.com

Prof GYUN MIN LEE, Kaist, 373-1 Kusong-Dong Yusong-gu, 305-701 Taejon, KOREA, Phone: +82 42869 2618, E-mail: gmlee@ mail.kaist.ac.kr

Ms JANET LEE, PurdueBiopharma, 215 College Road, 08540 Princeton, USA, Phone: 16099193 451, E-mail: janet.lee@pharma.com

Mrs MOON SUE LEE, Kaist, 373-1 Kusong-Dong Yusong-gu, 305-701 Taejon, KOREA, Phone: +82 42869 5618, E-mail: leems@kaist.ac.kr

Mr MYUNG SEOP LEE, Kaist, 373-1 Kusong-Dong Yusong-gu, 305-701 Taejon, KOREA, Phone: +82 42869 5618, E-mail: ooxygen@korea.com

Prof Dr JUERGEN LEHMAN, Technische Fakultaet/Uni-Bielefeld, P.O. Box 100131, 33501 Bielefeld, GERMANY, Phone: 495211066 319, E-mail: jl@zellkult.techfak.unibielefeld.de

Dr CLAUS-MICHAEL LEHR, University Saarbrücken, P.O. Box 151150, 66041 Saarbrücken, GERMANY, Phone: 496813023 039, E-mail: lehr@rz.uni-sb.de

Dr CHRISTIAN LEIST, Novartis Pharma Ltd., CH-4002 Basel, SWITZERLAND, Phone: +416169646 51, E-mail: christian.leist@ pharma.novartis.com

Dr KAREN LEMKE, Inst for Bioproc and Analytical Measurm, Rosenhof, D-37308 Heilbad Heiligenstadt, GERMANY, Phone: 493606671191 
Dr MARK LEONARD, Genetic Institute, 1 Burtt Road, Andover MA 01810, USA, Phone: 19782472 131, E-mail: mleonard@genetics.com

Dr JAN LESKO, W. Inst. of Virology, SLOVAKIA, Phone: 427544775232

JESSICA LESMANA, Dipl. biol., Tu-Darmstadt, Petersen Strasse 22, 64287 Darmstadt, GERMANY, Phone: +49 61511651 57, E-mail: jessica@pop.tu-darmstadt.de

Ms CHRISTINE LETTENBAUER, Wave Biotech AG, Ringstrasse 24, CH-8317 Tagelswangen, SWITZERLAND, Phone: +41 5235420 55, E-mail: yroell@wavebiotech.ch

Dr PATRICIA LEUNG-TACK, Transgene SA, 11 rue de Molsheim, FR-67082 Strasbourg, FRANCE, Phone: +33 3882791 67, E-mail: leung-tack@transgene.fr

Dr GERHARD LEWANDOVSKI, HistoServe GmbH, Hindenburgplatz 55, D-48143 Münster, GERMANY, Phone: +49 25183217 54, E-mail: lewandov@uni-muenster.de

Dr DAVID LEWIS, ECACC/CAMR, Porton Down, Salisbury Wilts SP4 OJG, UNITED KINGDOM, Phone: 441980612 594, E-mail: tanya.saunders@ camr.org.uk

Prof PETER LILJESTRÖM, Karolinska Institutet, Box 280, 17177 Stockholm, SWEDEN, Phone: 0845725 50, E-mail: peter.liljestrom@mtc.ki.se

\section{THERESE LILLIECREUTZ, SWEDEN}

Mr THOMAS LINDÉN, B. Braun Biotech International GmbH, Schwarzenberger Weg 73-79, 34212 Melsungen, GERMANY, Phone: +49 5661713400

Prof Dr TONI LINDL, Institut für Angewandte Zellkultur GmbH, Balanstr. 6, D-81669 München, GERMANY, Phone: 4989487774

Dr ELISABETH LINDNER-OLSSON, Metcon Medicin AB, Dalenum 17, 18170 Lidingö, SWEDEN, Phone: 08-615 27 41, E-mail: elisabeth.lidner-olsson@swipnet.se

Dr L.-C. LIU, GenVec Inc., 65 West Watkins Mill Road, 20878 Gaithersburg, USA, Phone: 12406325 555, E-mail: 1liu@genvec.com

Dr JAN LJUNGGREN, KaroBio AB, 14157 Huddinge, SWEDEN, Phone: 08-6086160, E-mail: jan.ljunggren@karobio.se

EVA LJUNGQVIST, SKD Konferensservice

Mr RENÉ LOHSER, PRIOR Separations Technology GmbH, VWP, A-6840 Götzis, AUSTRIA, Phone: 435523521 060, E-mail: office@priorsep.com

Dr GENEVIEVE LORENT, UCB Pharma Sa, Chemin Du Foriest, 1420 Braine-1 Alleud, BELGIUM, Phone: +32 2386 2598, E-mail: genevieve.lorent@ucb-group.com

Mr CORNELIUS LORENZ, Pharma Novartis, Building WRO-1241 T.02, CH-4002 Basel, SWITZERLAND, Phone: 00416169786 66, E-mail:

cornelius.lorenz@pharma.novartis.com

Mr CHRISTOPHE LOSBERGER, Serono, 14 ch. des Aulx, 1228 Plan-les-Ouates, SWITZERLAND, Phone: +41 22 7069637, E-mail: christophe.losberger@ serono.com 
Mr HANS-JÜRGEN LOTZ, Kendro Laboratory Products GmbH, Heraustrasse 12-14, 63450 Hanau, GERMANY, Phone: +49 61813538 34, E-mail: yknof@kendro.de

Ms ANN LÖVGREN, BioInvent Therapeutic, 22370 Lund, SWEDEN, Phone: +46 46 28686 51, E-mail: ann.lovgren@bioinvent.se

Dr HOLGER LÜBBEN, Chiron Behring GmbH \& Co, Emil von Behringstrasse 76, 35041 Marburg, GERMANY, Phone: 496421395 807, E-mail: holger_luebben@ chironbehring.com

Dr ANTHONY LUBINIECKI, GlaxoSmithKline, 709 Swedeland Road, UE 4021, King of Prussia, PA 19406, USA, Phone: 16102707 358, E-mail: anthony_lubiniecki@sbphed.com

Dr DIRK LUETKEMEYER, University of Bielefeld, P.O. Box 100131, 33501 Bielefeld, GERMANY, Phone: +49 52110663 24, E-mail: dlu@zellkult.techfak.uni.bielefeld.de

Dr ZIVILE LUKSIENE, Lithuania Oncology Center, Poloeko 2, 2007 Vilnius, LITHUANIA, Phone: +370 26296 31, E-mail: zivile@loc.et

Dr ELKE LÜLLAU, Astra Zeneca, Building 841, 15185 Södertälje, SWEDEN, Phone: +468552 51938, E-mail: elke.lullau@astrazeneca.com

Ms REGINE LÜMEN, Innovatis GmbH, Meissenstrasse 96, 33607 Bielefeld, GERMANY, Phone: 495212997 287, E-mail: info@innovatis.com

Mr BJÖRN LUNDGREN, Amersham Pharmacia Biotech AB, Björkgatan 30, 75184 Uppsala, SWEDEN, Phone: +46 186120505 E-mail: bjorn.lundgren@apbiotech.com

Mr TORGNY LUNDGREN, ESLÖV, Phone: 46413555 527, E-mail:

torgny.lundgren@mbox300.swipnet.se

Dr KENNETH LUNDSTRÖM, F. Hoffmann-La Roche, CNS Department, Bldg 69/440, CH 4070 Basel, SWITZERLAND, Phone: +41 61687 8653, E-mail: kenneth.lundstrom@roche.com

Mr IAN LYALL, Life Technologies, Inchinnan Business Park, Paisle, Paisley PA4 9RF, UNITED KINGDOM, Phone: 441418146 129, E-mail: 1yalli@lifetech.com

BJORN LYDERSEN, USA, Phone: 17607535 242, E-mail: bklydersen@AOL.com

CAROLINE MACDONALD, University of Paisley, Witherspoon Building, Paisley, PA1 2BE Renfrewshire, UNITED KINGDOM, Phone: 451418483 100, E-mail: c.macdonald@paisley.ac.uk

Mr KURT MACK, Cell Culture Technologies GmbH, Buhnrain 14, CH-8052 Zurich, SWITZERLAND, Phone: +41 1301 2008, E-mail: info@cellculture.com

Dr MALCOLM MACNAUGHTON, Inveresk Research, Tranent, E Lothian EH33 2NE, UNITED KINGDOM, Phone: 441875618 874, E-mail:

malcolm.macnaughton@inveresk.com

Prof CARL-FREDRIK MANDENIUS, Linköping University, IFM/Biotechnology, 581 
83 Linköping, SWEDEN, Phone: +46 13288 967, E-mail: cfm@ifm.liu.se

Dr MARIA ASSUNTA MANNIELLO, National Institute for Cancer Research, c/o CBA Largo Rosanna Benzi 10, I-16132 Genova, ITALY, Phone: 39105737 289, E-mail: mam@ist.unige.it

Mr LUIS MARANGA, IBET, Apartado 12, 2781-901 Oeiras, PORTUGAL, Phone: 351 214469 422, E-mail: maranga @itqb.unl.pt

Ms ANNIE MARC, LSGC-CNRS-Nancy, 2 av de la Foret de Haye, 54505 Vandoeuvrelés-Nancy, FRANCE, Phone: 0033383595 785, E-mail: Annie.Marc@ensic.inpl-nancy.fr

Ms PAULA MARQUES ALVES, IBET, Apartado 12, 2781-901 Oeiras, PORTUGAL, Phone: +351 1 4469417, E-mail: marques@itgb.upl.pt

Mr ROLF MARTEIJN, Wageningen University, P.O. Box 81296700 EV Wageningen, THE NETHERLANDS, Phone: 31317483 435, E-mail: rolf.marteijn@algemeen.pk.wau.nl

Dr CARL MARTIN, Covance Laboratories, Harrogate, North Yorkshire HG3 1OY, UNITED KINGDOM, Phone: +44 14238484 02, E-mail: carl.martin@ covance.com

Dr KRISTINA MARTINELLE, Pharmacia \& Upjohn AB, S34:6, 11287 Stockholm, SWEDEN, Phone: 08-695 42 51, E-mail: kristina.martinelle@eu.pnu.com

Dr ALFREDO MARTINEZ MOGARRA, Laboratorios Serono, Tres Cantos, 28760 Madrid, SPAIN, Phone: +34 918064 500, E-mail: alfredo.martinez@ serono.com

Dr RICCARDO MARZOCCHINI, Viale G.B., Morgagni 50, I-50134 Firenze, ITALY, Phone: 39055413 765, E-mail: riccardo.marzocchini@vuifi.it

Dr HUGH MATHESON, TCS Biologicals, Park Leys Botolph Clayton, Buckingham MK18 2LR, UNITED KINGDOM

Dr HIROSHI MATSUOKA, Teikyo University, 2525 Uenohara-machi, 409-0193 Yamanashi-ken, JAPAN, Phone: +81 5546344 11, E-mail: matsuoka@ntu.ac.jp

Mr RON MAYER, NewLab BioQuality AG, Max Planck-strasse 15A, D-406 99 Erkrath, GERMANY, Phone: 492119255 340, E-mail: mayer@newlab.de

Ms MICHAELA MCADAM, The Automation Partnership, York Way, SG8 5WY Royston, UNITED KINGDOM, Phone: 441763227 216, E-mail:

michaela.mcadam@automationpartnership.com

Mr PETER MCGRADY, Biovest International, 22A Roehampton Drive, Merseyside L23 7XD, UNITED KINGDOM, Phone: +44 15192453 51, E-mail: biovesteurope@a.o.l.com

Dr JEFFREY MCGREW, Immunex Corp., 51 Univeristy Street, Seattle WA 98101, USA, Phone: 12065870 430, E-mail: mcgrewj@immunex.com

Prof RICARDO MEDRONHO, Federal University of Rio de Janeiro, Escola De Quimica CT Bl E Ilha Do Funda, 21949900 Rio de Janeiro, BRAZIL, Phone: 55215627635 , E-mail: medronho@eq.ufrj.br 
RICHARD D MEDWID, Ph.D., Eli Lilly \& Co, Drop Code 1731, Indianapolis, IN 46256, USA, Phone: 13174335 221, E-mail: medvid_richard_d@lilly.com

Mr HEIKO MEENTS, Boehringer Ingelheim Pharma KG, Birkendorfer Strasse 65, 88397 Biberach, GERMANY, Phone: +49 735154 8172, E-mail: susi.mueller@bc.boehringeringelheim.com

Mr JORN MEIDAHL PETERSEN, Novo Nordisk A/S, Novo Allé Building 3BM1.03, 2880 Bagsvaerd, DENMARK, Phone: +45 44422 634, E-mail: jump@novo.dk

Dr BERNARD MEIGNIER, Aventis Pasteur, 1541 Av. Marcel Mérieux, 69280 Marcy l'Etoile, FRANCE, Phone: +33 4373734 81, E-mail: bernard.meigner@aventis.com

Ms ADINA-GABRIELA MEILA, ROMANIA, Phone: +40 1682 6400, E-mail: adina_gabriela@yahoo.com

Dr KARIN MELLSTRÖM, KaroBio AB, 14157 Huddinge, SWEDEN, Phone: 0860861 70, E-mail: karin.mellstrom@karobio.se

Dr KLAUS MEMMERT, Novartis Pharma AG, CH-4002 Basel, SWITZERLAND, Phone: +41 61324 6885, E-mail: klaus.memmert@pharma.novartis.com

Mr JIM MERCER, Genetic Institute, 1 Burtt Road, Andover MA 01810, USA, Phone: 19 782472 113, E-mail: jmercer@genetics.com

Dr LEE MERMELSTEIN, Scios Inc., 820 West Maude Ave., Sunnyvale, CA 94086 USA, Phone: 14086168 330, E-mail: mermelstein@ sciosinc.com

Prof OTTO-WILHELM MERTEN, Genethon, 1 Rue de Lt' internat. BP 60, F-91000 Evry, FRANCE, Phone: +33 16947 2590, E-mail: omerten@genethon.fr

Dr FERRUCCIO MESSI, Cell Culture Technologies GmbH, Buhnrain 14, CH-8052 Zurich, SWITZERLAND, Phone: +41 130120 08, E-mail: info@cellculture.com

Mrs FATHIA METHNANI, Microsafe BV, Niels Bohrweg 11-13, 2333CA Leiden, THE NETHERLANDS, Phone: +31 71523 1886, E-mail: info@microsafe.nl

Mr JOCHEN METZGER, Haematology/Oncology, Fritz Berke Strasse 54, 81241 Munich, GERMANY, Phone: 498941406 238, E-mail: jochen.metzger@lrz.tum.de

Mr RON MEYER, NewLab BioQuality AG, Max Planck-strasse 15A, D-406 99 Erkrath, GERMANY, Phone: 492119255 340, E-mail: meyer@newlab.de

Dr MARINA MEZENTSEVA, N.F. Gamaleya, Gamaleya St. 18, RUS-123 098 Moscow, RUSSIA, Phone: +7 95193 5582, E-mail: marianmez@ cityline.ru

Dr JIM MICHAELS, Bayer Corporation, 800 Dwight Way, 94710 Berkeley, USA, Phone: 15107055 468, E-mail: jim.michaels.b@mayer.com

Dr MONIQUE MICHEL-MARTIN, BIO-RAD, 3 Boulevard Raymond Poincarré 92430 Marnes La Coquette, FRANCE, Phone: +33 1479561 28, E-mail: monique_martin@biorad.com

Prof WILLIAM M MILLER, Northwestern University, 2145 Sheridan Rd Tech B 136, 
Evanstone, IL, USA, Phone: 18474914 828, E-mail: wmiller@northwestern.edu

Mr JON MILLS, The Automation Partnership, York Way, SG8 5WY Royston, UNITED KINGDOM, Phone: 441763227216

Mr JEAN MAURICE MIMRAN, JRH Biosciences, 13804 West 107 th Street, 66215 Lenexa, Kansas, USA, Phone: 19134695 580, E-mail: cwempe@jrhbio.com

Mrs VEE MITCHELL, SmithKline Beecham, Harlow Essex, CM19 5AW Harlow, UNITED KINGDOM, Phone: 441279622 645,E-mail: Davina_Mitchell-1@ @sphrd.com

Dr CHRISTINE MITCHELL-LOGEAN, Serono, Zone Industrielle B, Fenil-sur-Corsier 1809, SWITZERLAND, Phone: +41 2192322 28, E-mail: christine.logeanmitchell@serono.com

Mr SHERWIN MIZANI, Pall, Europa House, Havant Street, P01 3PD Portsmouth, UNITED KINGDOM, Phone: 4402392303303

Dr DIETER MÖBEST, GERMANY, Phone: 497612706 367, E-mail: moebest@ch11.ukl.uni-freiburg.de

Ms IDA MOELGAARD KNUDSEN, Novo Nordisk A/S, Novo Allé, DK-2880 Bagsvaerd, DENMARK, Phone: 4544422 917, E-mail: imq@novonordisk.com

Mr MOHAMMED MOHAMMED, Novartis Animal Vaccines, Springwood Ind. Estate, Braintree C09 2BT, UNITED KINGDOM, Phone: 441376551 222, E-mail: karen.hughes@novartis.com

CYRUS MOHAMMEDIAN, Dasgip mbH, Rudolf-Schulten-Strasse 5, 52428 Juelich, GERMANY, Phone: 4924619 800,E-mail: c.mohammedian@dasgip.de

Mr JOHANN MOLS, University of Louvain, 1, Place Louis Pasteur, 1348 Louvain la Neuve, BELGIUM, Phone: +32 104730 39, E-mail: mols@bioc.ucl.ac.be

BRUNO MONTEWIS, Perbio Science, Industrielaan 27, B-9320 AALST, BELGIUM, Phone: +32 538344 04, E-mail: bruno.montewis@perbio.com

Dr GORDON MOORE, Centocor, 244 Great Valley Pkwy, 19355 Malvern, USA, Phone: 916106516871

Dr MAURIZIO MORANDI, Chiron SpA, Via Fiorentina 1, 53100 Siena, ITALY, Phone: 390577243 580, E-mail: maruzio-morandi@chiron.it

Prof ANTONIO MOREIRA, UMBC, 1000 Hilltop Circle, Baltimore MD 21250, USA, Phone: 14104556 576,E-mail: moreira@umbc.edu

Dr JOSE MOREIRA, IBET, Apartado 12, 2781-901 Oeiras, PORTUGAL, Phone: 3511 44694 93, E-mail: moreira@itqb.unl.pt

Dr DIANA MORGAN, BioReliance, Innovation Park Hillfoots Road, Stirling FK9 4NF, UNITED KINGDOM, Phone: 441786451 318, E-mail: atully@bioreliance.com

Dr SANDRO MORI, Molmed S.P.A, Via Olgettina 58, 20132 Milano, ITALY, Phone: +39 02 212771,E-mail: sandro.mori@molmed.it 
Dr ANA MARIA MORO, Instituto Butantan, Av. Vital Brasil 1500, 05503-900 Sao Paulo, BRAZIL, Phone: 551137267 222, E-mail: anammoro@usp.br

Dr ARVIA MORRIS, Immunex Corp., 51 University Street, Seattle WA 98101, USA, Phone: 12065870 430, E-mail: morrisa@immunex.com

Mr NICK MOSGROVE, Dasgip mbH, Rudolf-Schulten-Strasse 5, 52428 Juelich, GERMANY

Mr LARS MOSTRÖM, Tillquist, Box 1505, 17229 Sundbyberg, SWEDEN

Dr JON MOWLES, 17 Northbrook, Mkt. Lavington, SN10 4AN Devizes, UNITED KINGDOM, Phone: 441380812 374, E-mail: jon.mowles@psion.net

Dr PETER MUELLER, GBF, Mascherode weg 1, 38124 Braunschweig, GERMANY, Phone: 495316181 252, E-mail: pmu@gbf.de

Dr TONY MULCAHY, Cobra Therapeutics Limited, The Science Park, ST5 5SP Staffordshire, UNITED KINGDOM, Phone: 441782714 181, E-mail: tony.mulcahy@cobrat.com

Ms BRIGITTE MÜLLER, SSS Rütten Engineering AG, Industriestrasse 9, CH-8712 Stäfa, SWITZERLAND, Phone: 4119282 930, E-mail: brigitte.mueller@swissonline.ch

Dr DETHARDT MÜLLER, Institute of Applied Microbiology, Muthgasse 18, 1190 Vienna, AUSTRIA, Phone: +43 136006 6230, E-mail: office@iam.bokv.ac.at

Ms DOROTHEE MÜLLER, Schärfe System GmbH, Krämerstrasse 22, 72764 Reutlingen, GERMANY, Phone: 497121387 860, E-mail: anie.marc@ensic.inpl-nancy.fr

Dr PETER MÜLLER, GBF, Mascherode weg 1, 38124 Braunschweig, GERMANY

Dr ISABELLE NADEAU, BioReliance, 14920 Broschart Road, 20850-3349 Rockville, MD, USA, Phone: 13016102 795, E-mail: isabelle.nadeau @bioreliance.com

Ms STEPHANIE NAGEL-HEYER, Technische Universität Hamburg-Harburg, Denickestrasse 15, 21071 Hamburg, GERMANY, Phone: +49 4042878 3950, Email: nagel-heyer@tu-harburg.de

Prof ALEXANDER NAROVLYANSKY, N.F. Gamaleya, Gamaleya St. 18, RUS-123 098 Moscow, RUSSIA, Phone: +7 95193 4306, E-mail: narovl@mail.infotel.ru

Mr STEFAN NASCHBERGER, Polymun Scientific, Nussdorfer laende 11, A 1190 Vienna, AUSTRIA, Phone: +43 136006 6202, E-mail: h9230784@edv1.boku.ac.at

Ms ELLEN NATH, Lonza Biologics Plc, 228 Bath Road, SLI 4DY Slough, UNITED KINGDOM, Phone: 441753777 000, E-mail: enath@longza.co.uk

Dr ELENA NECHAEVA, State Research Center Vector, Koltsovo, 630559 Novosibirsk Region, RUSSIA, Phone: 73832366 481, E-mail: nechaeva@ vector.nsk.su

Ms NICOLA NEFF, Dupont Pharmaceutical Co, Rt 141 \& Henry Clay Road Dupont, Ext.Stn, Wilmington De 199880, USA, Phone: 13026953 310, E-mail: nicola.t.neff@dupontpharma.com 
Dr ANDRÉ NEVES, University of Cambridge, 80 Tennis Court Road, CB2 1GA Cambridge, UNITED KINGDOM, Phone: 44122333 676, E-mail: atrmdn2@cam.ac.uk

Dr LARS SØEGAARD NIELSEN, Novo Nordisk A/S, Novo Allé, 2880 Bagsvaerd, DENMARK, Phone: 4544421 784, E-mail: 1sni@novonordisk.com

\section{Mr OLE NIELSEN, DENMARK}

INGE NILSSON, BioInvent Prod. AB, 22370 Lund, SWEDEN, Phone: 46462868552 , E-mail: inge.nilsson@bioinvent.com

Mr JAN ANDERS NILSSON, BioInvent Therapeutic, 22370 Lund, SWEDEN, Phone: +46462868561, E-mail: pkp@ bioionvent.se

Dr KJELL NILSSON, ÅSTORP, Phone: 042-502 82, E-mail: kjell.nilsson@parcell

THOMAS NOLL, Institute of Biotechnology 2, Leo Brand Strasse, 52425 Julich, GERMANY, Phone: 492461613 955, E-mail: th.noll@fz-juelich.de

Dr MARIA LUISA NOLLI, Areta International, via Roberto Lepetit 34, 21040 Gerenzano, ITALY, Phone: 390296489 264, E-mail: mlnolli@aretaint.com

Dr MARTIN NORIN, Biovitrum, Lindhagensgatan 133, 11287 Stockholm, SWEDEN, Phone: +46 869725 28, E-mail: martin.norin@pharmacia.com

Dr HUBERT P.J.M. NOTEBORN, Rikilt-DLO, P O Box 230, NL-6700 AE Wageningen, THE NETHERLANDS, Phone: 31317475 462, E-mail: h.p.j.m.noteborn@ rikilt-dlo.nl

Ms JACKIE O'CONNELL, Organon Laboratories Ldt, Newhouse, Lanarkshire ML1 5SH, UNITED KINGDOM, Phone: 441698736 292, E-mail: k.cochrane@organon.nhe.akzonobel.nl

Prof KIM O’CONNOR, Tulane University, Lindy Boggs Center Room 300, New Orleans LA 70118, USA, Phone: 15048655 740,E-mail: koc@mailhost.tcs.tulane.edu

Ms DONNA O’DRISCOLL, Archport Ltd, Glasnevin, Dublin 9, IRELAND, Phone: +353 1700 5283, E-mail: donnacha.odriscou@dcu.ie

Dr ANETTE OCKLIND, Melacure Therapeutics AB, Ulleråkersvägen 38, 75643 Uppsala, SWEDEN, Phone: +46 18 530082, E-mail: anette.ocklind@melacure.com

Ms MARIE-LOUISE OERBECH, LITTLE, Angio Science, Fruebjergvej 3, DK-2100 Copenhagen, DENMARK, Phone: +45 391 799 34, E-mail: ml@angioscience.com

Mr JEFF OFFICER, Cell Science Therapeutics, 50 Cummings Park, 01801 Woborn, MA, USA, Phone: 18585239 789, E-mail: cellwerker@aol.com

Mr PHILIP OFFIN, The Automation Partnership, York Way, SG8 5WY Royston, UNITED KINGDOM, Phone: 441763227216

Ms AKIKO OGAWA, Fukui University, 3-9-1, Bunkyo, 910-8507 Fukui, JAPAN, Phone: +81 77627 8645, E-mail: akky@acbio2.acbio.fukui-u.ac.jp

Dr SATOSHI OGUCHI, Kirin Brewery Co. Ltd, 2-2 Souja-Machi 1 chome Maebashi-Shi, 
Gunma 371-0853, JAPAN, Phone: 810272548 601, E-mail: ta-suzuki@kirin.co.jp

Mr ERIK OHR, New Brunswick, NORWAY

Mr EDUARDO OJITO, Center of Molecular Immunology, P.O. Box 16040, Hab 11600 Habana, CUBA, Phone: +53 72133 57, E-mail: ojito@ict.cim.sld.cu

Prof CHRISTIAN OKER-BLOM, University of Jyväskyla, P.O. Box 35, 40351 Jyväskyla, FINLAND, Phone: 358-14-260 22 85, E-mail: okerblom@jyu.fi

Mr SPENCER OLIVER, Veterinary Medicines Directorate, Woodham Lane, New Haw, Addlestone Surrey KT15 3LS, UNITED KINGDOM, Phone: 441932338 415, E-mail: s.oliver@vmd.maff.gov.uk

Dr KUNLE ONADIPE, Lonza Biologics Plc, 228 Bath Road, SLI 4DY Slough, UNITED KINGDOM, Phone: 441753777 000, E-mail: konadipe@lonza.co.uk

Dr DIRK-JAN OPSTELTEN, Crucell BV, P.O. Box 2048, 2301 CA Leiden, THE NETHERLANDS, Phone: 31715248 701, E-mail: dj.opstelten@crucell.com

Dr GEORG ORBERGER, Arimedes Biotechnology GmbH, Rubert Roessle Strasse 10, D13125 Berlin, GERMANY, Phone: +49 3094892 110, E-mail: arimedes@mdc-berlin.de

Ms SANDRINE ORLANDO, Aventis Pasteur, 1541 Av. Marcel Mérieux, 69280 Marcy l'Etoile, FRANCE, Phone: +33 4373792 76, E-mail: sandrine.orlando@aventis.com

Mr MATTHEW OSBORNE, Cambridge Antibody Technology, The Science Park, SG8 6JJ Melbourn, South Cambs, UNITED KINGDOM, Phone: 441763269 378, E-mail: emma.dixon@cambridgeantibody.com

MAJA OSMAK, Ruder Boskovic Institute, Bijenicka Cesta 54, CR-10000 Zagreb, CROATIA, E-mail: osmak@rudjer.irb.hr

Dr RALPH OTTO, Boehringer Ingelheim Pharma KG, Birkendorfer Strasse 65, 88397 Biberach, GERMANY, Phone: +49 735154 8172, E-mail: susi.mueller@bc.boehringeringelheim.com

PETER OUDSHOORN, Research Coordinator, Akzo Nobel Pharma, P O Box 20, NL-5340 BH Oss, THE NETHERLANDS, Phone: +31 412666330

Ms LAURIE OVERTON, Glaxo Wellcome, 5 More Drive, 27709 RTP, NC, USA, Phone: 19194836 209, E-mail: iko8763@galxowellcome.com

Dr JEPPE ØVLESEN, Chemometec, Herlev Hovdegade 15, DK-2730 Herlev, DENMARK, Phone: +45 448800 59, E-mail: jo@chemometec.dk

Dr MERAN OWEN, Elsevier Science, 68 Hills Road, CB2 ILA Cambridge, UNITED KINGDOM, Phone: 441223315 961, E-mail: m.owen@elsevier.co.uk

Dr SADETTIN OZTURK, GlaxoSmithKline, 709 Swedeland Road, UE 4021, King of Prussia, PA 19406, USA, Phone: 16102393 912, E-mail: s_ozturk@earthling.net

Dr UTE PAEGELOW, GBF, Mascherode weg 1, 38124 Braunschweig, GERMANY, Phone: 495316181 762, E-mail: UTP@gbf.de 
JOLANTA PALTAUF-DOBURZYNSKA, Oregon Graduate Institute, 20000 NW Walker Rd, 97006 Beaverton, Oregon, USA, jolanta.paltauf@kfunigraz.ac.at

Mr MANFRED PAPASPYROU, Papaspyrou Biotechnologie GmbH, Karl Heinz Beckurts Strasse 13, 52428 Jülich, GERMANY, Phone: +49 24616905 76, E-mail: info@papspyrou.de

Mr NAVIN PATEL, Life Technologies, 3 Fountain Drive, Inchinnan Business Park, UNITED KINGDOM

Mr WOLFGANG PAUL, Institute of Biotechnology 2 Cell Cultur, 52425 Jülich, GERMANY, Phone: +49 24616139 48, E-mail: w.paul@fz-juelich.de

Mr LASSE LINDHAVDT PEDERSEN, Statens Serum Institut, Artillerivej 5, 2300 Copenhagen S, DENMARK, Phone: +45 326837 07, E-mail: 1lp@ssi.dk

Mr LUIS IGNACIO PÉREZ-ORDOYO, García, SPAIN, Phone: 34902235 700, E-mail: ovejero@adenet.es

Dr FRÉDÉRIC PERRAUD, Transgene SA, 11 rue de Molsheim, FR-67082 Strasbourg, FRANCE, E-mail: peraaud@ transgene.fr

Dr BO PERSSON, ZymoGenetics, 1201 Eastlake Ave. East, Seattle, WA 98102, USA, Phone: 12064426 824, E-mail: perssonb@zgi.com

Dr INGE PERSSON, BioInvent Production, 22370 Lund, SWEDEN, Phone: +46 28685 50/61, E-mail: inge.nilsson@bioinvent.se

THOMAS PETRI, Schering AB, Postfach 650311, D-13342 Berlin, GERMANY, Phone: +4930 46859 43, E-mail: thomas.petri@ schering.de

Mr DIDIER PEYRET, Sorebio Sárl, 1 rue Jarques Monod - Site, Montosquieu, 33650 Martillac, FRANCE, Phone: 00335579609 60, E-mail: evelyn.timmers@ serano.com

Dr JOERG PFISTEREV, Sartorius AG, D-37070 Giettingen, GERMANY

Ms INKA PFITZNER, Greiner Bio-One GmbH, Maybachstrasse 2, 72636 Frickenhausen, GERMANY, Phone: 497022948 500, E-mail: info@greiner-lab.de

Prof LENNART PHILIPSON, CMB, Karolinska Institutet, Box 285, 17177 Stockholm, SWEDEN, Phone: +46 872873 33, E-mail: lennart.philipson@cmb.ki.se

Ms LOUISE PHILLIPS, Selborne Biological Services, Goleigh Farm, Selborne, Alton Hants GU34 3SE, UNITED KINGDOM, Phone: 441420511 535, E-mail: sbsuk@cwcom.net

Ms BRITTA PIETSCH, Greiner Bio-One GmbH, Maybachstrasse 2, 72636 Frickenhausen, GERMANY, Phone: 497022948 500, E-mail: info@greine-lab.de

EARL PINEDA, BioMarin Pharmaceutical, 46 C Alli Dr, 94949 Novato, USA, Phone: 14 158846 750, E-mail: epineda@biomarinpharm.com

Dr HERVÉ PINTON, Aventis Pasteur, 1541 Av. Marcel Mérieux, 69280 Marcy l'Etoile, FRANCE, Phone: +33 43737 3134, E-mail: herve.pinton@aventis.com 
SELVAKUMAR PITCHAIVELU, School of Chemical Engineering, Edgbaston, B15 2TT Birmingham, UNITED KINGDOM, Phone: 441214143 885, E-mail: selvakumarp@hotmail.com

Mr ALLAN POINSARD, Corning Life Sciences, Gordon Road, High Wycombe HP13 6EQ Blick, UNITED KINGDOM, Phone: 441494684 703, E-mail:

allenj@london.corning.com

Dr DMITRY POLYNTSEV, Zao Alkor-Bio, 70/4 Leningradskaya Str, 189650 SaintPetersburg, RUSSIA, Phone: 78124375 154, E-mail: alkorbio@peterlink.ru

Ms JOANNE POPOLOSKI, Biogen Inc., 14 Cambridge Center, Cambridge MS 02142, USA, Phone: 16176792 506, E-mail: joanne.popoloski@biogen.com

Dr LOURDES PORQUET GARANTO, Laboratorios Hipra S.A., Avda. L selva 135 17170 Ameiz, SPAIN, Phone: +34 9724306 60, E-mail: lpg@hipra.com

Dr RAY PÖRTNER, TU Hamburg- Harburg, Denichestr. 15, D-21071 Hamburg, GERMANY, Phone: 494042878 2886, E-mail: poertner@tu-harburg.de

Mr CHANDRA PRAFULLA KUMAR, Molecular Biology Research, Laboratory D, Ganeshkind Road, 411007 Pune, INDIA, Phone: 910205658 432, E-mail: pnc@unipune.ernet.in

Dr ANJA PREISSMANN, Boehringer Ingelheim Vetmedica, Inc, 2621 Notrh Belt Highway, 64506 St Joseph, Missouri, USA, Phone: 18163900 432, E-mail: apreissmann@bi-vetmedica.com

Dr ALAN PRESTON, Moregate TCS Ltd, Botolph Clamdon, NK18 2LR Buckingham, UNITED KINGDOM, Phone: 441296714 555, E-mail: catherine@tesgroup.co.uk

Dr A PRIOR, PRIOR Separations Technology GmbH, VWP, A-6840 Götzis, AUSTRIA

Dr KEN PULLEN, GlaxoSmithKline, Sout Eden Park, Beckenham BR 3 3BS, UNITED KINGDOM, Phone: +44 020863964 24, E-mail: kfp45960@glaxowellcome.co.uk

HENRY QI, Bayer Corporation, Building 28, P.O. Box 1986, Berkeley, CA 94701-1986, USA, Phone: 15107055 680, E-mail: henry.qi.b@bayer.com

Mr SEBASTIEN QUESNEY, Aventis Pasteur, 1541 Av. Marcel Mérieux 69280 Marcy l'Etoile, FRANCE, Phone: +33 43737 3881, E-mail: sebastien.quesney@aventis.com

Dr ANDREW RACHER, Lonza Biologics Plc, 228 Bath Road, SLI 4DY Slough, UNITED KINGDOM, Phone: 441753716 560, E-mail: aracher@lonza.co.uk

Dr MARINA RADRIZZANI, Molmed S.P.A, Via Olgettina 58, 20132 Milano, ITALY, Phone: 3902212 771, E-mail: marina.radrizzani@molmed.it

Mrs MARTINE RAES, Bioch Biol. Cell, Rue De Bruxelles 61, BELGIUM, Phone: 3281 724 124, E-mail: martine.raes@fundp.ac.bc

Dr DIVAKAR RAMAKRISHNAN, Eli Lilly \& Co, Drop Code 1731, Indianapolis, IN 46256, USA, Phone: 13174332 547, E-mail: divakar@lily.com 
Prof OCTAVIO T RAMIREZ, Instituto de Biotecnologia/UNAM, Av. Universidad 2001, 62250 Cuernavaca, Morelos, MEXICO, Phone: +52 5 6227617, E-mail: tonatiuh@ibt.unam.mx

Mr LUCIANO RAMOS, SmithKline Beecham Pharmaceuticals, P.O. Box 1539, King of Russia, 19406 PA, USA, Phone: 161027077 963, E-mail: luciano_ramos-1 @ sbphri.com

Dr PRANHITHA REDDY, Immunex Corp., 51 Univeristy Street, Seattle WA 98101, USA, Phone: 12065870 431, E-mail: reddyp@immunex.com

Dr SRIDHAR REDDY, Bayer Corporation, 800 Dwight way/P.O. Box 1986, 94710 Berkeley, California, USA, Phone: 16509193 778, E-mail: sreddy@aviron.com

Dr FRANS REEK, ID-Lelystad B.V., P.O. Box 65, 8200 AB Lelystad, THE NETHERLANDS, Phone: 31320238 275, E-mail: e.vandenbos@id.wag.ur.nl

BERND REHBERGER, MediGene AG, Lochhamer Str. 11, D-82152 Martinsried, GERMANY, Phone: +49 89 89563232, E-mail: bernd.rehberger@medigene.de

Prof Dr-Ing UDO REICHL, Max-Planck-Institute Magdeburg, Leipziger Str. 44, 39120 Magdeburg, GERMANY, Phone: 493916718 401, E-mail: udo.reichl@vst.unimagdeburg.de

Mr JON REID, Perbio Science, Industrielaan 27, B-9320 Aalst, BELGIUM, Phone: 44 411892775 , E-mail: jon.reid@perbio.com

Dr MANFRED REITER, AUSTRIA, Phone: +43 120100 4688, E-mail: reiterm@baxter.com

MARK RENDALL, PhD, Lonza Biologics Plc, 228 Bath Road, SLI 4DY Slough, UNITED KINGDOM, Phone: 441753716 552, E-mail: mrendall@lonza.co.uk

Mr PER REXEN, Novo Nordisk A/S, Hallas Allé, DK-4400 Kalundborg, DENMARK, Phone: +45 444354 12, E-mail: prex@novonordisk.com

Mr MALCOLM RHODES, Serologicals Proteins Inc, 195 West Birch Street, Kanakaee IL 60901, UNITED KINGDOM, Phone: +44 1223574958

Mr SIMON RICE, GlaxoSmithKline Pharmaceuticals, Third Ave, Harlow Essex CM19 5AW, UNITED KINGDOM, E-mail: simon_q_rice@sbphrd.com

Dr ANDREAS RICHTER, NewLab BioQuality AG, Max Planck-strasse 15A, D-406 99 Erkrath, GERMANY, Phone: +49 2119255 340, E-mail: richter@newlab.de

Dr ERWIN RIEKE, GERMANY, Phone: 496151722 114, E-mail: rieke@merck.de

Mr NIGEL RIMMER, Y.S.I., Lynchford Lane, GV14 6LT Farnborough, Hants, UNITED KINGDOM, Phone: 441252514 711, E-mail: narinmer@aol.com

Mr KARL RIX, Dasgip mbH, Karl Heinz Beckurts starsse 13, D-52428 Jülich, GERMANY, Phone: +49 24619800

Ms JOËLLE ROBERT, VIRBAC, 13ḿe Avenue, FR-06511 Carros, FRANCE, Phone: +33492087627 
Mr JOHN ROBERTSON, Selborne Biological Services, Goleigh Farm, Selborne, Alton Hants GU34 3SE, UNITED KINGDOM, Phone: +44 142020511 535, E-mail: sbsuk@cwcom.net

DAVID K. ROBINSON, Director, Merck \& Co. Inc., P O Box 2000, Rahway NJ 07090, USA, Phone: 17325945 828, E-mail: david.robinson@merck.com

Dr MARIA PILAR RODRIGUEZ MOTTÓ, Centro de Ingeneria Genetica y Biotecn., P O Box 6162, Cuidad de la Havana 10600, CUBA, E-mail: pilar.rodriguez@cigb.edu.cu

Mr ELIAS NELSON RODRIQUEZ, Cent. for Genetic Engineering and Biotec, Av. 31 b/158 and 190, 10600 Havana, CUBA, E-mail: elias.nelson@ cigb.edu.cu

Mr MARCEL ROELL, Wave Biotech AG, Ringstrasse 24, CH-8317 Tagelswangen, SWITZERLAND, Phone: +41 52354 2055, E-mail: info@wavebiotech.ch

Mrs MARIETTE ROESINK, Amsterdam Molecular Therapeutics, Meibergdreef 61, 1105BA Amsterdam, THE NETHERLANDS, Phone: +31 20566 7394, E-mail: info@amtbv.com

Dr GEORG ROESSLING, Schering AG, Müllerstrasse 170, DE-13342 Berlin, GERMANY, Phone: 00949304681 4442, E-mail: georg.roessling @ pschering.de

Prof VERA ROGIERS, Vrije Universitet Brussel, Laar Beeklaan 103, B.1090 Bruxelles, BELGIUM, Phone: 32247745 16, E-mail: vera@fafy.vub.ac.be

Mr MARKUS ROHDE, GERMANY, Phone: 4956815 107, E-mail: markus.rohde@tonline.de

Dr DOMINIQUE ROLLAND, Biomerieux, Chemin De L'Orme, 69280 Marcy L'Etoile, FRANCE, Phone: 33478872 099, E-mail: dominique_rolland@eu.biomerieux.com

Prof JEAN-LOUIS ROMETTE, AFMB-DISP/ ESIL, Parc Scientifique de Luming, 13288 Marseille, FRANCE, Phone: 33491828 622, E-mail: zomette@esil.univ-mrs.fr

PNINA ROTEM, Interpharm Lab. Ltd, Nessa Zionna, ISRAEL, Phone: +972 89382619

Dr SARBARI ROY, BioInvent Production, 22370 Lund, SWEDEN, Phone: +46 46286 85 60, E-mail: sre@ bioinvent.com

Dr MAORONG RUAN, ArctiCon Biopharm Production AB, Industrivägen 24, 97254 Luleå, SWEDEN, Phone: 46920211 887, E-mail: j-ruan@mailandnews.com

Mrs KURT RUETTEN, Ruetten Engineering, Industriestrasse 3, CH-8712 Staefa, SWITZERLAND, Phone: 009411328 2930, E-mail: kurt.ruettn@

Mr KURT RUSS, Rentschler Biotechnologie, Erwin Rentschler strasse 21, 88471 Laupheim, GERMANY, Phone: 9497342704 518, E-mail: kurt.russ@ rentschler.de

Ms ANNETTE RUSSELL, Bayer Plc, Stoke Poges, Slough SL2 4LY Buckinghamshire, UNITED KINGDOM, Phone: 4401753645 151, E-mail: annette.russell.ar@bayer.co.uk

Dr KURT RÜTTEN, SSS Rütten Engineering AG, Industriestrasse 9, CH-8712 Stäfa, SWITZERLAND, Phone: 4119282 930, E-mail: kurt.ruetten@swissonline.ch 
Ms NICOLINE RUIJS, Perbio Science, Industrielaan 27, B-9320 Aalst, BELGIUM, Phone: +3253834404

Dr THOMAS RYLL, Abgenix, 7601 Dumbarton Circle, Freemont CA 94555, USA, Phone: 15106084 653,E-mail: ryll_t@abgenix.com

Dr JOONSOO RYU, ISU Chemical Co, 112-4 Banpo-Dong Seocho-Gu, 137-044 Seoul, KOREA, Phone: +82 2590 6617, E-mail: joonsooryu@ hotmail.com

Mr PETER SÄBOM, Colly Filtreringsteknik, Box 81, 16494 Kista, SWEDEN, Phone: +4687030100, E-mail: peter.sabom@colly.se

Ms JENNIE SANDBERG, Pharmacia, Lindhagensgatan 133, 11287 Stockholm, SWEDEN, Phone: +46 869598 78, E-mail: jennie.sandberg@eu.pnu.com

Mr PETER SANDBERG, GTF, Södra Långbergsgatan 30, 42132 Västra Frölunda, SWEDEN, Phone: 031-680490, E-mail: gtf@gtf.se

Mr PETER SANDBERG, GTF (Göteborgs Termometerfabrik), Södra Långebergsgatan 30, 42132 Göteborg, SWEDEN, Phone: +46 316894 00, E-mail: gtf@gtf.se

Dr PAUL SAUER, Protein Design Labs, 34801 Campus Drive, 94555 Fremont, USA, Phone: 15105741 400, E-mail: psauer@pdl.com

JENNY SÄVENHED, Royal Institute of Technology, 10044 Stockholm, SWEDEN, E-mail: jenny.savenhed@karobio.se

Mrs MELINDA SCANLEN, Onderstepoort Veterinary Division, Private Bag Xs Onderspoorts, 110 PRETORIA, SOUTH AFRICA, Phone: 0092712529 9227, E-mail: melinda@moon.ovi.ac.za

Mr STEFAN SCHAEFER, Infors AG, Rittergasse 27, 4103 Bottmingen, SWITZERLAND, Phone: 416142257 723, E-mail: st.schaefer@infors.ch

BARBARA SCHAERRINGER, Biogen Inc., 14 Cambridge Center, Cambridge MS 02142, USA, E-mail: barbara_schaerringer@biogen.com

Dr JÜRGEN SCHÄRFE, Schärfe System GmbH, Krämerstrasse 22, 72764 Reutlingen, GERMANY, Phone: 497121387 860,E-mail: mail@casy-tehcnology.com

Dr KLAUS SCHARFENBERG, Aventis Pharma Deutschland GmbH, Emil von Behringstrasse 76, 35041 Marburg, GERMANY, Phone: +49 612139 3613, E-mail: klaus.scharfenberg@aventis.com

Prof Dr ROLAND SCHAUER, Christian-Albrechts-Universität, Medizinische Fakultät, Olshausenstrassse 40, D-24098 Kiel, GERMANY, Phone: 4318802 210, E-mail: schauer@biochem.uni-kiel.de

Dr NATASCHA SCHILL, Biogen Inc., 14 Cambridge Center, Cambridge MS 02142, USA, Phone: 16176793 262, E-mail: natascha schill@biogen.com

Dr ERNST-JÜRGEN SCHLAEGER, F. Hoffman la Roche Ltd, PRBT 661108 Grenzacherstr., CH-4070 Basel, SWITZERLAND, Phone: 004161688 5465, E- 
mail: ernst.j.schlaeger@roche.com

Dr PETER SCHLENKE, Rentschler Biotechnologie, Erwin Rentschler strasse 21, 88471 Laupheim, GERMANY, Phone: 497392701 537, E-mail: peter.schlenke@ rentschler.de

Dr UWE SCHLOKAT, Baxter AG, Uferstr. 15, 2304 Orth, AUSTRIA, Phone: +43 1 2010040 44, E-mail: uwe.schlokat@baxter.com

Dr GEORG SCHMID, F. Hoffman - La Roche, Building 66/112A, 4070 Basel, SWITZERLAND, Phone: +41 61688 2886, E-mail: georg.schmid@roche.com

Dr JÜRGEN SCHMITZ, Papaspyrou Biotechnologie GmbH, Karl Heinz Beckurts Strasse 13, 52428 Jülich, GERMANY, Phone: 492461690576

Ms EVELYN SCHMUCKER, Boehringer Ingelheim Pharma KG, Birkendorfer Strasse 65, 88397 Biberach, GERMANY, Phone: +49 735154 4801, E-mail: evelyn.schmucker@bc.boehringer-ingelheim.com

Dr MARKUS SCHNEIDER, Laboratoires Serono S.A, Zone Industrielle B CH 1809 Fenil-Sur-Corsier, SWITZERLAND, Phone: +41 2192323 69, E-mail: markus.schneider@serono.com

Prof YVES-JACQUES SCHNEIDER, University of Louvain, 1, Place Louis Pasteur, 1348 Louvain la Neuve, BELGIUM, Phone: +32 104748 95, E-mail: yjs@bioc.ucl.ac.be

RICHARD A. SCHOENFELD, Sr. Vice President, Genzyme, P.O.Box 9322, Framingham MA 01701-9322, USA, E-mail: rschoenfeld@gensyme.com

Mr PETER SCHORN, Boehringer Ingelheim Pharma KG, Birkendorfer Strasse 65, 88397 Biberach, GERMANY, Phone: +497351 544801

Dr BERND SCHRÖDER, Maingen Biotechnologie GmbH, Weismüllerstrasse 45, 60314 Frankfurt am Main, GERMANY, Phone: +49 694001 1216, E-mail: bernd.schroeder@mainben.de

Mr EDWIN SCHWANDER, Nunc A/S, Kamstrupvej 90, DK-4000 Roskilde, DENMARK, Phone: +45 463120 00, E-mail: infociety@nunc.dk

Dr ZIVIA SCHWARZBARD, SWITZERLAND, Phone: +41 21800 5617, E-mail: zivia.schwarzbard@ hotmail.com

Dr JÖRG SCHWINDE, Dasgip mbH, Rudolf-Schulten-Strasse 5, 52428 Juelich, GERMANY, Phone: 4924619800

THOMAS SEEWOESTER, BASF Bioresearch Corporation, 100 Research Drive, Worcester MA 01605, USA, Phone: 15088492 836, E-mail: seewoet@basf.com

Ms HEIDI SEIDENFADEN, NatImmune A/S, Fruebjergvej 3, Box 3, DK 2100 Copenhagen, DENMARK, Phone: +45 391694 36, E-mail: hs@natimunne.dk

Mr MARTIN SELANDER, Astra Zeneca, Building 841, 15185 Södertälje, SWEDEN, Phone: +46 8552803 27, E-mail: martin.selander@astrazeneca.com

Dr CECILIA SENDRESEN, Q-One Biotech Ltd, West of ScotlanScience Park, Glasgow 
G20 0XA, UNITED KINGDOM, Phone: 441419469 999, E-mail: csendresen@qone.co.uk

Mr JEROME SERRURIER, Serono, Zone Industrielle B, Fenil-sur-Corsier 1809, SWITZERLAND, Phone: +41 21923 2000, E-mail: jerome.serruier@ serono.com

Dr RAY SEXTON, BioReliance, Innovation Park Hillfoots Road, Stirling FK9 4NF, UNITED KINGDOM, Phone: 441786451 318, E-mail: atully@bioreliance.com

Dr GIRISH SHAH, Glaxo Wellcome R+D, Gunnels Wood Road, SG1 2NY Stevenage, UNITED KINGDOM, Phone: 44143876 3542, E-mail: GS1666@Glaxowellcome.com

ELI SHANNON, USA, E-mail: maestrow23@yahoo.com

Mrs ILANA SHAPIRO, Kenes Ltd., P O Box 50006, IL-61500 TEL AVIV, ISRAEL, Phone: +972 351400 29, E-mail: rkinris@kenes.com

Dr ROSEMARY SHARPIN, Immuno-Chemical Products Ltd, 31 Morningside Drive, 1004 Auckland, NEW ZEALAND, Phone: 64098150 624, E-mail: jenny @icp.co.nz

Prof SANETAKA SHIRAHATA, Kyushu University, 6-10-1 Hakozaki, Higashi-ku 8128581 Fukuoka, JAPAN, Phone: +81 92642 3045, E-mail: sirahata@ grt.kyushu-u.ac.jp

Ms JOSEPHINE SIDDALL, Novartis Animal Vaccines, Springwood Ind. Estate, Braintree C09 2BT, UNITED KINGDOM, Phone: 441376551 222, E-mail: karen.hughes@novartis.com

Mr WILHELM SIEBERTZ, Greiner Bio-One GmbH, Maybachstrasse 2, 72636 Frickenhausen, GERMANY, Phone: 4970229 480, E-mail: info@greiner-lab.de

Mr ANDRÉ SIEMENSMA, Quest International, P.O. Box 2, 1400 CA Bussum, THE NETHERLANDS, Phone: +31 35699 2778, E-mail: ingrid.de-nooy@questintl.com

Mr NICHOLAS SIMPSON, Wageningen University, P.O. Box 8129, 6700 EV Wageningen, THE NETHERLANDS, Phone: 31317483 435, E-mail: nicholas.simpson@algemeen.pk.wag-ur.nl

Dr MARTIN SINACORE, Wyeth/Genetics Institute, One Burtt Road, 01810 Andover, MA, USA, Phone: 19782472 028, E-mail: msinacore@genetics.com

Dr VIJAY SINGH, Wave Biotech, 2493 Lamington Road, 07921 Bedminster, NJ, USA, Phone: 19087815 757, E-mail: info@wavebiotech.com

Dr ALEXANDER SIROTKIN, Research Institute of Animal Production, Hlohovka 2, 949 92 Nitra, SLOVAKIA, Phone: 42187546 335, E-mail: sirotkin@vuzv.sk

Dr CAMILLA SKAGERMARK, Astra Zeneca, Building 841, 15185 Södertälje, SWEDEN, Phone: +46 8552533 94, E-mail: christine.dartsch@astrazeneca.com

Ms RANDI SKOVGAARD, Novo Nordisk A/S, Novo Allé, 2880 Bagsvaerd, DENMARK, Phone: 4544421 180, E-mail: rns@novo.dk

Dr OLE SKYGGJEBERG, Chemometec, Herlev Hovdegade 15, DK-2730 Herlev, DENMARK, Phone: +45 448800 59, E-mail: os@ chemometec.dk 
Mr DICK SMIT, ID-Lelystad B.V., P.O. Box 65, 8200 AB Lelystad, THE NETHERLANDS, Phone: 31320238 667, E-mail: d.i.smit@id.way-ur.nl

LORRAINE SMITH, Edinburgh Research \& Innovation, 15 South College Street, EH7 4FR Edinburgh, UNITED KINGDOM, Phone: 441316509 044, E-mail: lorraine.smith@ed.ac.uk

Dr RODNEY SMITH, Xenova Group Plc, 310 Cambridge Science Park, CB4 0WG, UNITED KINGDOM, Phone: 441223 423 413, E-mail: rodney_smith@xenova.co.uk

Mrs SANDRA SMITH, Selborne Biological Services, Goleigh Farm, Selborne, Alton Hants GU34 3SE, UNITED KINGDOM, Phone: 441420511535

MOSHE SMOLARSKY, Interpharm Lab. Ltd, Nessa Zionna, ISRAEL, Phone: +972 8 938 2651, E-mail: moshe.smolarsky@serono.com

Ms HEIDI SØRENSEN, Novo Nordisk A/S, Hallas Allé, DK-4400 Kalundborg, DENMARK, Phone: 4544448 888, E-mail: hsqr@novo.dk

Mr GLEN SPAULDING, USA, Phone: 16177340 498, E-mail: glsdvm@earthlink.net

Dr ROBERT SPOKANE, Y.S.I., Lynchford Lane, GV14 6LT Farnborough, Hants, UNITED KINGDOM, Phone: 441252514 711, E-mail: narimmer@aol.com

TONY STAPLETON, UNITED KINGDOM, E-mail: as4678@glaxowellcome.co.uk

Dr DANIEL STARK, Swiss Serum \& Vaccine Inst. Berne, P.O. Box, 3001 Berne, SWITZERLAND, Phone: +41 31980 6394, E-mail: daniel.stark@berna.org

Dr ANDREAS STÄRK, Aventis Pharma Deutschland GmbH, Emil von Behringstrasse 76, 35041 Marburg, GERMANY, Phone: +49 642139 5131, E-mail: ulrich.valley@aventis.com

Mr JAN STEELS, Cellon SA, 2021 Ronie Argon, L8010 Strassen, LUXEMBURG, Phone: 352312 313, E-mail: cellon@gms.lu

Dr THOMAS STEENSTRUP, Novo Nordisk A/S, Novo Alle 6B2.107.1, DK-2880 Bagsvaerd, DENMARK, Phone: 4544424 167, E-mail: stee@novo.dk

Dr WOLFRAM STEINHILBER, Byk Guiden Pharmaceuticals, Byk-Guiden Strasse 2, 78467 Konstanz, GERMANY, Phone: +49 75318433 74, E-mail: wolfram.steinhilber@byk.de

Mr JOHN STERLING, Genetic Engineering News, 2 Madison Avenue, 10538 Larchmont NY, USA, Phone: 19148343 880, E-mail: editor@genengnews.com

Mrs HELENA STERNER, Biovitrum, Strandbergsgatan 49, 11287 Stockholm, SWEDEN, Phone: +46 869727 25, E-mail: helena.sterner@biovitrum.com

Mr THIBAUD STOLL, Huningue Biotech Production, BP349, 68333 Huningue Cedex, FRANCE

Mr CLAUDIO STREBEL, University of Applied Sciences HSW, P.O. Box 335, 8820 Wädenswil, SWITZERLAND, Phone: +41 17899 738, E-mail: c.strebel@ mail.hswzfh.ch 
Mr MARC STRIJBOS, Perbio Science, Industrielaan 27, B-9320 Aalst, BELGIUM, Phone: +3253834404

Dr G SUBRAMANIAN, UNITED KINGDOM, Phone: 441227720 819, E-mail: gsub@globalnet.co.uk

TAKUYA SUGAHARA, JAPAN, Phone: +81 89946 9863, E-mail: mars95@agr.ehimeu.ac.jp

Mr RICK SULLIVAN, Perbio/Hyclone, 1725 South Hyclone Road, 84321 Logan Utah, USA, Phone: 14357920 164, E-mail: rick.sullivan@perbio.com

Dr ZOLTAN SÜMEGHY, Novartis Pharma Ltd, TRD BDP Prod Building WSJ 316 4, 08, CH-4020 Basel, SWITZERLAND, Phone: +41 6132460 39, E-mail: zoltan.suemeghy@pharma.novartis.com

Ms YUN HEE SUNG, Kaist, 373-1 Kusong-Dong Yusong-gu, 305-701 Taejon, KOREA, Phone: +82 42869 5618, E-mail: sungyh@bioneer.kaist.ac.kr

Dr NOELLE SUNSTROM, University of N.S.W., 2052 Sydney, AUSTRALIA, Phone: +61 29385 3693, E-mail: n.sunstrom@unsw.edu.au

Mrs BRENDA SUURLAND, Amsterdam Molecular Therapeutics, Meibergdreef 61, 1105BA Amsterdam, THE NETHERLANDS, Phone: +31 20566 9272, E-mail: f.vander.steen@amtbv.com

Mr IVAN SVENDSEN, Novo Nordisk A/S, Novo Alle 6B3.99.1, DK 2880 Bagsvaerd, DENMARK, Phone: +45 44421 987, E-mail: jcw@novonordisk.coom

Dr HIROFUMI TACHIBANA, Kyushyu University, Higashu-Ku, 8128581 Fukuoka, JAPAN, Phone: +81 92642 3008, E-mail: tatibana@agr.kyushu-u.ac.jp

Mr ANDREW TAIT, University College London, 20 Wellington Buildings, Wellington Way Bow, London E3 4NA, UNITED KINGDOM, Phone: 447879640 043, E-mail: ucbeast@ucl.ac.uk

Mrs CHRISTINE TANS, SmithKline Beecham, B-1330 Rixensart, BELGIUM, Phone: +3226569880

Mr ALEXANDER TAPPE, Institut für Technische Chemie, Callinstrasse 3, 30167 Hannover, GERMANY, Phone: 495117622 966, E-mail: tappe@iftc.uni-hannover.de

Dr RON TATICEK, Genentech, Inc., 1 DNA Way, 94080 South San Francisco, CA, USA, Phone: 16502253 569, E-mail: rtaticek@gene.com

Mr IAN TAYLOR, Astra Zeneca, Room 13S28 Mereside, SK10 4TG Macclesfield, UNITED KINGDOM, Phone: 441625512 700, E-mail: ian.w.taylor@astrazeneca.com

Mrs MARIANNÉ TAYLOR, Pfizer Central Research, Ramsgate Road, Sandwich CT13 9NJ, UNITED KINGDOM, Phone: 441304646 151, E-mail:

marianne_taylor@sandwich.pfizer.com

Dr HERMANN TEBBE, Roche Diagnostics GmbH, Nonnewald 2, 82372 Penzberg, 
GERMANY, Phone: 498856603 776,E-mail: hermann.tebbe@roche.com

Mr ANDY TEE, Pfizer, Sandwich, Kent CT13 9NJ, UNITED KINGDOM, Phone: +44 13046484 83, E-mail: andy.tee@pfizer.com

SATOSHI TERADA, PhD, Fukui University, 3-9-1 Bunkyo, 910-8507 Fukui, JAPAN, Phone: 8177627 8645, E-mail: terada@acbio.fukui-u.ac.jp

Dr KIICHIRO TERUYA, Kyushu University, 6-10-1 Hakozaki Higashi-ku, 812-8581 Fukuoka, JAPAN, Phone: +81 92642 3047, E-mail: kteruya@grt.kyushu-u.ac.jp

Dr VANESSA TETT, Pfizer Central Research, Ramsgate Road, Sandwich CT13 9NJ, UNITED KINGDOM, Phone: 441304643 114, E-mail: tettv@pfizer.com

BENGTI TEY, School of Chemical Engineering, Edgbaston, B15 2TT Birmingham, UNITED KINGDOM, Phone: 441214145 264, E-mail: b.t.tey@bham.ac.uk

Mr LAURENS G THEUNIS, Galapagos Genomics NV, P.O. Box 2048, 2301 CA Leiden, THE NETHERLANDS, Phone: +31 715248 735, E-mail: laurens@galapagos.nl

Dr JAMES THOMAS, Immunex Corp., 51 University Street, Seattle WA 98052, USA, Phone: 912063894 034, E-mail: thomasj@immunex.com

Dr JAMES THOMAS, Immunex Corp., 51 University Street, Seattle WA 98052, USA, Phone: 12063894 034, E-mail: thomasj@immunex.com

Dr JÖRG THÖMMES, Universität Düsseldorf, 52426 Jülich, GERMANY, Phone: 492 461614 173, E-mail: J.thoemmes2fz-juelich.de

Dr ERIK THORSELL, Läkemedelsverket, Box 26, 75103 Uppsala, SWEDEN, E-mail: erik.thorsell@mpa.se

Mr JOHN THRIFT, Bayer Corporation, 800 Dwight way/P.O. Box 1986, 94710 Berkeley, California, USA, Phone: 15107055 426, E-mail: john.thrift.b@bayer.com

Dr JERRY TONG, Lonza Biologics Plc, 228 Bath Road, SLI 4DY Slough, UNITED KINGDOM, Phone: 441753716 565, E-mail: jtong@lonza.co.uk

Dr HELMUT TRAUTMANN, Biospectra AG, Zuercherstrasse 137, CH-8952 ZuerichSchlieren, SWITZERLAND, Phone: +41 173021 20, E-mail: trautmann@ biospectra.ch

Dr BEATRICE TRENKTROG, Novartis Pharma AG, CH-4002 Basel, SWITZERLAND, Phone: +41 6169670 13, E-mail: beatrice.trenktrog@pharma.novartis.com

Mrs GUNN IRENE TROSETH, Alpharma AS, P.O. Box 158, SKoyen, N-0212 Oslo, NORWAY, Phone: +47 225290 91, E-mail: gunn-irene.troseth@alpharma.no

Dr GALINA TROSHKOVA, State Research Center, Vector, RUS-633159 Koltsovo, RUSSIA, Phone: 73832366 215, E-mail: troshkova@online.nsk.su

Mr CHI KWAN TSANG, Saga University, 152-1 Shonan-cho, Karatsu, 847-0021 Saga, JAPAN, Phone: +81 95577 4484, E-mail: calvintsang@hotmail.com

Dr FRITZ TSCHOPP, Sensorix, Technoparkstr. 1, CH-8005 Zurich, SWITZERLAND, 
Phone: +41 144512 46, E-mail: fritz.tschopp@ sensorix.com

Dr HARUHIKO TSUMURA, Kirin Brewery Co Ltd, 1-2-2 Soujja, Maebashi Gunma 371-0853, JAPAN, Phone: +81 27254 8606, E-mail: htsumura@kirin.co.jp

Dr IOANNIS TUBULEKAS, Biovitrum, Lindhagensgatan 133, 11287 Stockholm, SWEDEN, Phone: +46 8695 4377, E-mail: yoannis.tubulekas@eu.pnu.com

Mrs ANNE TULLY, UNITED KINGDOM, Phone: 4401786451 318, E-mail: atully@bioreliance.com

Ms HILARY TURNBULL, Genetic Engineering News, 2 Madison Avenue, 10538 Larchmont NY, USA

Ms CAROLYN UNGER, Amersham Pharmacia Biotech AB, Björkgatan 30, 75184 Uppsala, SWEDEN, E-mail: carolyn.unger@eu.apbiotech.com

Dr FLORIAN UNTERLUGGAUER, Polymun Scientific, Nüssdorfer Laende 11, A 1190 Vienna, AUSTRIA, Phone: +43 136006 6202, E-mail: unterlug@edv2.boku.ac.at

Mr JAIME M. URIBE, Centro de Investigación en Biotecnologia Av Universidad No 1001, 62210 Cuernavaca, MEXICO, Phone: 5254195 223, E-mail: uribejm@ hotmail.com

Dr JANA VAN DE GOOR, Genetech Inc, 1 DNA way, Bldg. 3D323, CA 94080 South San Francisco, USA, Phone: 16502252 018, E-mail: goor@gene.com

Mr PATRICK VAN DE VELDE, Sigma-Aldrich Sweden AB, Solkraftsvägen 14C, 13570 Stockholm, SWEDEN, Phone: +46 87424200

Mr HANS VAN DEN BERG, AppliSens, P.O. Box 149, 3100 AC Schiedam, THE NETHERLANDS, Phone: +31 102983 576, E-mail: eza@ applikon.com

Dr RENE VAN DEN GRIEND, Biocult, Niels Bohrweg 11-13, CA 2333 Leiden, THE NETHERLANDS, Phone: +31 71 5215443, E-mail: biocult@sandtcourses.nl

Mrs DIANA VAN DER LINDE, Diosynth, P.O. Box 20, 5340 BH Oss, THE NETHERLANDS, Phone: 31412663 157, E-mail: d.linde@ diosynth.oss.akzonobel.nl

Dr LEO VAN DER POL, DSM Biologics, P.O. Box 454, NL-9700 AL Groningen, THE NETHERLANDS, Phone: +31 505222 231, E-mail: leo.pol-van-der@dsm-group.com

Mr JOHN VAN DER VEEKEN, JM Separations BV, Valkenierstraat 12, Ridderkerk, THE NETHERLANDS, Phone: +31 1804814 14, E-mail: jms@wxs.nl

Mr PIETER VAN GELDER, Intervet International BV, P.O. Box 31, 5830 AA, Boxmeer, THE NETHERLANDS, Phone: 31485587357

Mr MIRANDA VAN IERSEL, Quest International, P.O. Box 2, 1400 CA Bussum, THE NETHERLANDS, Phone: +31 356992778

Dr WOLFGANG VAN WEGEN PRIOR Separations Technology GmbH, VWP, A-6840 Götzis, AUSTRIA, Phone: 435523521 060, E-mail: egineering@ priorsep.com

Dr DAVID VENABLES, Covance Laboratories, Harrogate, North Yorkshire HG3 1OY, 
UNITED KINGDOM, Phone: 441423848 017, E-mail: david.venables@convance.com

Dr FRANCIS VERMOEYE, University of Louvain, 1, Place Louis Pasteur, 1348 Louvain la Neuve, BELGIUM, Phone: +32 104730 39, E-mail: vermoeye@bioc.ucl.ac.be

Mr HENRIK VERWOHLT, Nunc A/S, Kamstrupvej 90, DK-4000 Roskilde, DENMARK, Phone: +45 463121 83, E-mail: hbv@nunc.dk

THOMAS VIERTEL, bioS AG, Büelgasse 1a, CH-8855 WANGEN, SWITZERLAND, Phone: +41 5545060 00, E-mail: info@bio-s.com

Dr VICTOR VINCI, Eli Lilli \& Company, Lilly Corporate Centre, Indiannapolis IN 46285, USA, Phone: 1312277 589, E-mail: vinci_victor_a@lilly.com

Mr JOAQUIM VIVES-ARMENGOL, Univ. Autonoma De Barcelona, Edifici C Dept. Eng. Quirnica, 08193 BellaCerra, SPAIN, Phone: +34 9368118 08, E-mail: joaquim.vives@uab.es

Dr JENS VOGEL, Bayer Corporation, P.O. Box 1986, Berkeley, CA 94701-1986, USA, Phone: 15107104 751, E-mail: jens.vogel@bayer.com

Ms REGINA VOGLAUER, Institute of Applied Microbiology, Muthgasse 18, 1190 Vienna, AUSTRIA, Phone: +43 136006 6231, E-mail: r.voglauer@iam.boku.ac.at

Dr MICHAEL VON PEIN, Bio Whittaker Europe, Parc Industriel de Petit Rech., B-4800 Vervuis, BELGIUM, Phone: +32 87 1633, E-mail: michael.vonpein@ cambrex.com

Dr BÉNÉDICTE VONACH, Novartis Pharma Ltd, CH-4002 Basel, SWITZERLAND, Phone: +4161696 6427, E-mail: hanspeter.knopf@pharma.novartis.com

Dr JUERGEN VORLOP, Chiron Behring GmbH \& Co, Emil von Behringstrasse 76, 35041 Marburg, GERMANY, Phone: 0094964213949 19, E-mail: juergen.vorlop@chironbehring.com

Mr NICK VOSPER, New Brunswick Scientific, Kerkenbos 1101, 6546 BC Nijmegen, THE NETHERLANDS, Phone: +31 243717608

Dr NIENKE VRIEZEN, Centocor B.V., P.O. Box 251, NL-2300 AG Leiden, THE NETHERLANDS, Phone: 00931715242 492, E-mail: vriezenn@ centocor.com

Ms BARBARA WACHTLER, Baxter Vaccines AB, Uferstrasse 15, 2304 Orth/Donau, AUSTRIA, Phone: +43 120100 4635, E-mail: wachtlb@baxter.com

\section{PIA WADENBORG, SWEDEN}

Dr ROLAND WAGNER, GBF, Mascherode weg 1, 38124 Braunschweig, GERMANY, Phone: 9495316181 104, E-mail: wagner.roland@gbfo.de

Dr CLAUS WALLERIUS, Roche Diagnostics GmbH, Nonnewald 2, 82372 Penzberg, GERMANY, Phone: +49 88566036 49, E-mail: claus.wallerius@ roche.com

Mr DIRK WALRAVENS, Life Technologies, Inchinnan Business Park, Paisle, Paisley PA4 9RF, UNITED KINGDOM, Phone: 441418146129 
Dr FREINZ WALZ, Boehringer Ingelheim Pharma KG, Birkendorfer Strasse 65, 88397 Biberach, GERMANY, Phone: +497351 544801

ING-KAE WANG, Pfizer Central Research, MS 4092, Eastern Point Road, 06340-8003 Groton, USA, Phone: 18604417 334, E-mail: wangi@pfizer.com

Ms JIN WANG, Schering-Plough Research Inst., 1011 Morris Avenue, Union, NJ 07083, USA, Phone: 19088204 931, E-mail: jin.wang@spcorp.com

Dr THOMAS WARREN, Pharmacia Corporation, $800 \mathrm{~N}$ Lindbergh Blvd, St Louis MO 63167, USA, Phone: 13146944 877, E-mail: thomas.g.warren@pharmacia.com

Dr SHIKIKO WATANABE, University of Birmingham, B15 2TT Birmingham, UNITED KINGDOM, Phone: 1214145 310,E-mail: s.watanabe@bham.ac.uk

JEZ WAYTE, Lonza Biologics Plc, 228 Bath Road, SLI 4DY Slough, UNITED KINGDOM

Mr ARNO WEGKAMP, Wageningen University, Bomenweg 2, 6703 HD Wageningen, THE NETHERLANDS, Phone: +31 $318 \quad 854$ 47, E-mail: arno.wegkamp@algemeen.pk.wau.nl

Dr HENRY WEICHERT, CTL Cell Technolgie GmbH, Südstrasse 55, D-04430 Leipzig, GERMANY, Phone: 4934144 19047,E-mail: henrywei@t-online.de

Dr DAVID WEINER, University of Pennsylvania, 422 Curie Blvd., 09104 Philadelphia, USA, Phone: 12153458 365, E-mail: dbweiner@mail.med.upenn.edv

STEFAN WEISS, Perbio Science, +32 5383 4404, Industrielaan 27 B-9320 Aalst, BELGIUM, Phone: +3253837638

SARA WELLBO, SWEDEN

Ms SUSAN WELSH, Abbott, 100 Research Drive, 01605 Worcester, USA, Phone: 15088 492 965, E-mail: welsh@basf.com

CINDY WEMPE, USA, Phone: 19134695 580, E-mail: cwempe@jrhbio.com

Prof JOHN WÉRENNE, ULB, 50, Av F.D. Roosevelt, 1050 Brussels, BELGIUM, Phone: +32 265032 29, E-mail: biocelan@ulb.ac.be

Dr ROLF WERNER, Boehringer Ingelheim Pharma KG, Birkendorfer Strasse 65, 88397 Biberach, GERMANY, Phone: 00949735154 4800, E-mail: rolf.werner@bc.boehringeringelheim.coi

BENGT WESTERMARK, PhD, Dept. of Genetics and Pathology, University Hospital, 75185 Uppsala, SWEDEN, Phone: +46 1861138 21, E-mail: bengt.westermark@genpat.uu.se

Dr MARUN WESTSTRATE, THE NETHERLANDS

Dr CHRISTOPHER WIBURN, CAMR, Porton Down, Salisbury Wilts SP4 0JG, UNITED KINGDOM 
Ms HANNA WILLEMER, GERMANY, Phone: 49221732 150, E-mail:

willemer.lyophilization@online.de

GILES WILSON, Novo Nordisk A/S, Hagedornsvej 1, DK-2280 Gentofte Kopenhamn, DENMARK, Phone: 4544438 299, E-mail: gew@novo.dk

Dr BIRGITTA WINKLER, Sigma-Aldrich Chemie GMBH, Grünwalder Weg 30, D-82041

Deisenhofen, GERMANY, Phone: +49 896513 1551, E-mail:

bwinkler@euronotes.sial.com

Dr MANFRED WIRTH, GBF, Mascherode weg 1, 38124 Braunschweig, GERMANY, Phone: +495316181262, E-mail: mwi@gbf.de

Dr MARTIN WISHER, BioReliance, Innovation Park Hillfoots Road, Stirling FK9 4NF, UNITED KINGDOM, Phone: 9441786451 318, E-mail: mwisher@bioreliance.com

PD Dr ANNA M. WOBUS, Inst. für Pflanzengenetik und, D-06466 Gatersleben, GERMANY, Phone: 4939482 5256, E-mail: wobusam@ipk-gatersleben.de

Prof Dr WILFRIED WOEHRER, Baxter AG, Uferstr. 15, 2304 Orth, AUSTRIA, Phone: 43120100 4649, E-mail: woehrew@baxter.com

Ms JULIE WONG, Pharmacia, Lindhagensgatan 133, 11287 Stockholm, SWEDEN, Phone: +4686959878, E-mail: julie-ann.wong@eu.pnu.com

Ms WEERAH WONGKHAM, Chang Mai University, Faculty of Science, Chang Mai 50200, THAILAND, Phone: +66 53 943346, E-mail: weerah@ @cience.cmu.ac.th

Ms SHARON WONG-MADDEN, Immunex, 51 University Street, SEATTLE, WA 98101, USA, Phone: 12065870 430, E-mail: wongmads@immunex.com

Dr JENS CHRISTIAN WORTMANN, Novo Nordisk A/S, Novo Alle 6B3.99.1, DK 2880 Bagsvaerd, DENMARK, Phone: +45 44421 987, E-mail: jcw@ novonordisk.com

Ms DIANE WOTTA, R\&D Systems, Inc, 614 McKinley Place N E, 55413 Minneapolis, USA, Phone: 16123792 956, E-mail: dianew@rndsystems.com

Mr GARY WRIGHT, Biovest International, 22A Roehampton Drive, Merseyside L23 7XD, THE UNITED KINGDOM, Phone: +44 1519245351

Mr JASON WRIGHT, Ecole Polytechnique Fédérale, CH-1015 Lausanne, SWITZERLAND, Phone: 412169355 62, E-mail: jason.wright@epfl.ch

Prof DAVID WU, University of Rochester, Gavett Hall, Rochester NY 14627, USA, Phone: 17164426 686, E-mail: davidwu@che.rochester.edu

Dr JIANYONG WU, Hong Kong Polytechnic University, Kowloon, Hong Kong, CHINA, Phone: 85227666 687, E-mail: bcjywu@polyu.edu.hk

Mr THOMAS WULF, Papaspyrou Biotechnologie GmbH, Karl Heinz Beckurts Strasse 13, 52428 Jülich, GERMANY, Phone: 492461690576

Mr WUNSCHEL, Quest International, P.O. Box 2, 1400 CA Bussum, THE NETHERLANDS 
Prof FLORIAN WURM, EPFL, CH-1015 Lausanne, SWITZERLAND, Phone: 00941 (21) 693 6141, E-mail: florian.wurm@epfl.ch

Prof CHENGZU XIAO, Institute of Biotechnology, Fengtai, 100071 Beijing, CHINA, Phone: 86163841 526,E-mail: xiaozc@nic.bmi.ac.cn

Mr ERKAN YALCIN, University of Leipzig, Delitzscher Stasse 135, 04129 Leipzig, GERMANY, Phone: 493419719758

Mr CHRISTOPHER YALLOP, Novo Nordisk A/S, Novo Alle 6B3.99.1, DK 2880 Bagsvaerd, DENMARK, Phone: +45 44421 987, E-mail: jcw @ novonordisk.com

Ms MAIKIKO YAMASHITA, Kyushu University, 6-10-1 Hakozaki Higashi-ku, 812-8581 Fukuoka, JAPAN, Phone: +81 92642 3046, E-mail: makiko@grt.kyushu-u.ac.jp

Mrs. SHIGERU YASUTAKE, Ashai Chemical Ind. Co Ltd, 9-1 Kanada Mitoshirocho Chiyoda-ku, Tokyo 101-8481, JAPAN, Phone: 00981332595723

Mr SUNG KWAN YOON, LG Chemical Investment Ltd, 104-1 Moonji-dong Yuseong-gu, Daejeon, KOREA, Phone: +82 42866 2166, E-mail: skyoonb@lgci.co.kr

Mr ED ZAPPEIJ, Applikon B.V., P.O. Box 149, 3100 AC Schiedam, THE NETHERLANDS, Phone: +31 102983 576, E-mail: eza@applikon.com

Prof PETER ZAVODSZKY, Hungerian Academy of Sciences, H- 1518 Pf 7 Budapest, HUNGARY, Phone: 36120935 35, E-mail: zxp@enzim.hu

Dr GADEK ZBIGNIEW, Centre for Holistic Medicine \& Naturapathy, Talweg 14, 57392 Schmallenberg-Nordenau, GERMANY, Phone: 4929759622 190, E-mail: zgngmbh@tonline.de

Mrs TRACEY ZECCHINI, Xenova Group Plc, 310 Cambridge Science Park, CB4 0WG, UNITED KINGDOM, Phone: 441223423 413, E-mail: tracey_zecchini@xenova.co.uk

ARNO ZEISER, CANADA, Phone: 15144962 543, E-mail: arno.zeiser@nrc.ca

Dr AN-PING ZENG, GBF, Mascheroder Weg 1, D-38 124 Braunschweig, GERMANY, Phone: 495316181 188, E-mail: aze@gbf.de 


\section{Introduction: From Target to Market}

This book is the lasting product, a resource of up-to-date information in the scientific literature for the field of animal cell technology, as it was presented during a pleasant and stimulating meeting that was held in Tylösand, Sweden in June 2001. The title of the meeting, From Target to Market, indicates the usefulness of animal cell technology during all steps in the pharmaceutical development process.

It costs around 600 million USD to bring a new Molecular Entity to the market including a 440 million USD cost for New Molecular Entities failing in the R\&D process. In order to reduce the attrition cost, many companies have put in place portfolio management systems with particular emphasis on project selection prior to entry in the development phase. This has triggered a shift in expenditure from discovery to non-clinical research by the leading companies, reflecting the portfolio management using more extensive preclinical data before a development decision is taken. Animal cells have become a very important tool in the drug discovery process. A new session was held on this topic.

Looking specifically on biotech products, historically the anti-infectives, growth hormone and cardiovascular areas have been strongest. In the development pipeline though anti-cancer represents the largest proportion, $27 \%$, of the total number of biotech projects in development followed by immunologicals, $15 \%$, and anti-infectives $14 \%$.

The majority of projects reaching from preclinical to market are still recombinant proteins with monoclonal antibodies representing the largest proportion, recombinant vaccines and growth factors being other major subclasses. Following the biotech products reaching the market shows an upward trend in the contribution of biotech products to total NME output in the 1990s, which continued until 1996 when biotech represented $25 \%$ of the annual output. In 1997, 5 products were launched representing only $11 \%$. Looking at approvals 1998-2000, there is no change in this trend.

A perceived hurdle from a market perspective is that a protein is per definition biodegradable and thus requires intravenous, or for some drugs, subcutaneous administration. Intravenous administration is connected to hospital care and subcutaneous administration can be used for self-medication. New promising administration technologies such as pulmonary delivery were highlighted on this meeting.

The next generation of products will evolve from applications such as gene therapy, novel vaccines, cell therapy and gene regulation.

Animal Cell Technology has a major role to play in the post-sequence era.

The conference in Tylösand attracted the largest number of participants in the history of ESACT.

This is probably a reflection of the incorporation of new fields that had not previously been considered to have animal cell applications. 
This book captures, in the form of concise papers of limited length, the essence of the latest development in those fields of animal cell technology. We hope that it will become a useful resource of the most up to date information in Animal Cell Technology, at least until the next meeting in May 2003 in Spain.

Elisabeth Lindner-Olsson

Nathalie Chatzissavidou

Elke Lüllau 


\section{Acknowledgements}

This meeting would not have been possible without the help of a large number of people, some of whom you will find mentioned below.

In addition to the Organizing Committee and the Scientific Committee, Mrs Eva Ljungkvist and Mrs Ewa Engström of SKD Konferensservice have been most important to us. They have had to bear with us, scientists with specific demands for everything.

Mrs Ewa Engström has also, together with Dr Björn Lundgren, organized the trade fare and the fund raising.

Mr Henrik Levin at SKD has coordinated the distribution of all confirmation letters for oral presentations and posters as well as the coordination of the manuscripts for the proceedings.

We would also like to thank Micael Worbin at Tylösand for local coordination.

We have just had a stimulating, pleasant and enriching ESACT 2001 meeting. Your participation was a success and we feel privileged and honored that you decided to come to Tylösand.

Elisabeth Lindner-Olsson

Chair ESACT 2001 